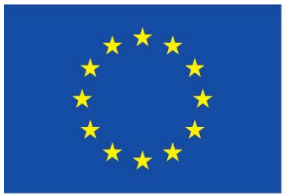

Directorate-General for

EUROPEAN COMMISSION

Health \& Consumers

Scientific Committee on Emerging and Newly Identified Health Risks

\author{
SCENIHR
}

Assessment of the Antibiotic Resistance Effects of Biocides

\title{
Scientific Committees
}

- on consumer products

- on emerging and newly identified health risks

- on health and environmental risks

The SCENIHR adopted this opinion at the 28th plenary on 19 January 2009 after public consultation. 


\section{About the Scientific Committees}

Three independent non-food Scientific Committees provide the Commission with the scientific advice it needs when preparing policy and proposals relating to consumer safety, public health and the environment. The Committees also draw the Commission's attention to the new or emerging problems which may pose an actual or potential threat.

They are: the Scientific Committee on Consumer Products (SCCP), the Scientific Committee on Health and Environmental Risks (SCHER) and the Scientific Committee on Emerging and Newly Identified Health Risks (SCENIHR), and are made up of external experts.

In addition, the Commission relies upon the work of the European Food Safety Authority (EFSA), the European Medicines Evaluation Agency (EMEA), the European Centre for Disease prevention and Control (ECDC) and the European Chemicals Agency (ECHA).

\section{SCENIHR}

Questions concerning emerging or newly-identified risks and on broad, complex or multidisciplinary issues requiring a comprehensive assessment of risks to consumer safety or public health and related issues not covered by other Community risk-assessment bodies.

In particular, the Committee addresses questions related to potential risks associated with interaction of risk factors, synergic effects, cumulative effects, antimicrobial resistance, new technologies such as nanotechnologies, medical devices, tissue engineering, blood products, fertility reduction, cancer of endocrine organs, physical hazards such as noise and electromagnetic fields and methodologies for assessing new risks.

Scientific Committee members

Anders Ahlbom, James Bridges, Wim De Jong, Philippe Hartemann, Thomas Jung, Mats-

Olof Mattsson, Jean-Marie Pagès, Konrad Rydzynski, Dorothea Stahl, Mogens Thomsen

\section{Contact:}

\section{European Commission}

Health \& Consumer Protection DG

Directorate C: Public Health and Risk Assessment

Unit C7 - Risk Assessment

Office: B232 B-1049 Brussels

\section{Sanco-Sc1-Secretariat@ec.europa.eu}

(C) European Commission 2009

The opinions of the Scientific Committees present the views of the independent scientists who are members of the committees. They do not necessarily reflect the views of the European Commission. The opinions are published by the European Commission in their original language only. 


\section{ACKNOWLEDGMENTS}

Members of the working group are acknowledged for their valuable contribution to this opinion. The members of the working group are:

\section{SCENIHR members:}

Dr. Jean-Marie Pagès (Chair), Université de Marseille

Prof. Jim Bridges, University of Surrey

Prof. Philippe Hartemann, Université de Nancy

\section{External experts:}

Prof. P. Cocconcelli ${ }^{1}$, Università Cattolica del Sacro Cuore, Piacenza

Prof. D. Dietrich², Universität Konstanz

Prof. J. Fink-Gremmels, Universiteit Utrecht

Dr. J-Y. Maillard ${ }^{2}$, Cardiff University

Prof. C. Pasquarella, Università degli Studi di Parma

Prof. S. Rastogi, National Environmental Research Institute, Roskilde

\footnotetext{
${ }^{1}$ Declared Interest (see minutes of the $22^{\text {nd }}$ SCENIHR plenary meeting of 6 February 2008): http://ec.europa.eu/health/ph risk/committees/04 scenihr/docs/scenihr mi 022.pdf

2 Declared Interest (see minutes of the $21^{\text {st }}$ SCENIHR plenary meeting of 29 November 2007): http://ec.europa.eu/health/ph risk/committees/04 scenihr/docs/scenihr mi 021.pdf
} 


\section{ABSTRACT}

Serious concerns about the resistance of nosocomial, community-acquired and foodborne pathogens to antibiotics have been growing for a number of years at both national and international levels. Resistance of bacterial pathogens to antibiotics has increased worldwide, leading to treatment failures in human and animal infectious diseases. Bacteria have the capacity to adapt rapidly to new environmental conditions and can survive exposure to antimicrobials by using a battery of resistance mechanisms. The frequency of antimicrobial resistance in bacteria has increased in concert with increasing usage of antimicrobial compounds. Bacterial resistance against different types of biocides has been reported and characterised only relatively recently when compared to our understanding of antibiotic resistance.

Some resistance mechanisms are common to both biocides and antibiotics. Scientific evidence from bacteriological, biochemical and genetic data does indicate that the use of active molecules in biocidal products may contribute to the increased occurrence of antibiotic resistant bacteria. The selective stress exerted by biocides may favour bacteria expressing resistance mechanisms and their dissemination. Some biocides have the capacity to maintain the presence of mobile genetic elements that carry genes involved in cross-resistance between biocides and antibiotics. The dissemination of these mobile elements, their genetic organisation and the formation of biofilms, provide conditions that could create a potential risk of development of cross-resistance between antibiotics and biocides.

To date, the lack of precise data, in particular on quantities of biocides used, makes it impossible to determine which biocides create the highest risk of generating antibiotic resistance. However, horizontal gene transfer and overlapping genetic cascades of regulation that can be stimulated by external chemical compounds such asbiocides are likely triggers of bacterial resistance.

In view of the large and increasing use of biocides and the continuous increase of bacterial resistance to antibiotics, data and methodologies are urgently needed to clearly characterise the risk, especially:

a) Quantitative data on exposure to biocides: "in use" and residual concentrations, environmental conditions (e.g. water, soiling, exposure time, temperature, $\mathrm{pH}$, etc.), change in microbial population, dissemination of resistant determinants (horizontal transfer) and potential synergies or interactions with other molecules.

b) Standards and methods to evaluate the ability of a biocide to induce/select for resistance against biocides and antibiotics. Surveillance programmes using these standardised methods must be developed to monitor the level of resistance and cross resistance in all areas of biocide usage.

c) Environmental studies focussing on the identification and characterisation of resistance and cross-resistance to antibiotics following use and misuse of biocides.

Keywords:

Biocides, resistance to antibiotics, bacteria, SCENIHR

Opinion to be cited as:

SCENIHR (Scientific Committee on Emerging and Newly Identified Health Risks), Assessment of the Antibiotic Resistance Effects of Biocides, 19 January 2009 
TABLE OF CONTENTS

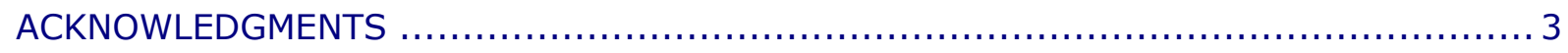

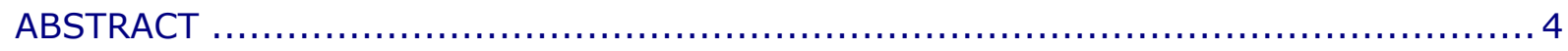

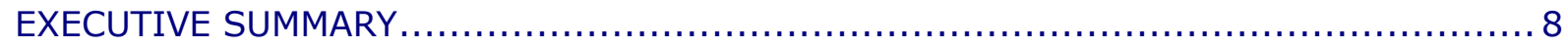

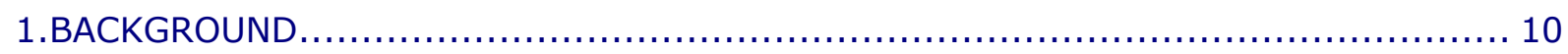

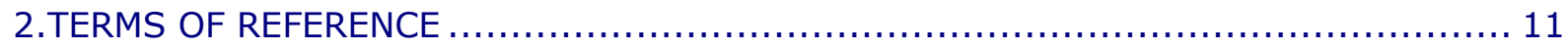

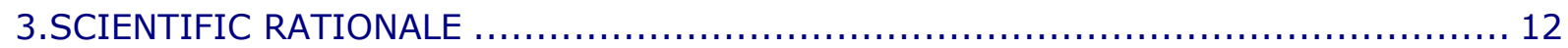

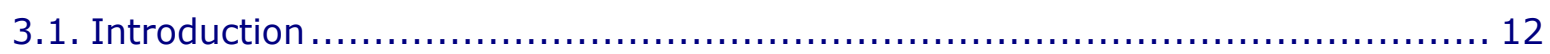

3.2. Scope of opinion, definition of active substances considered..................... 12

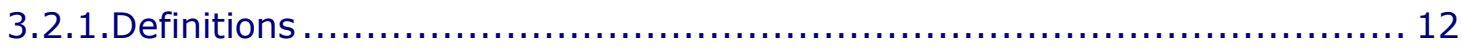

3.2.1.1. Official definitions ............................................. 12

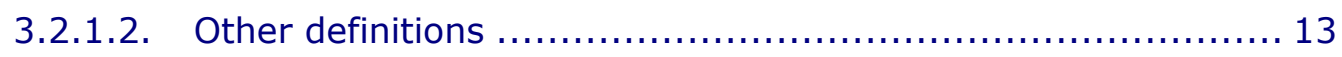

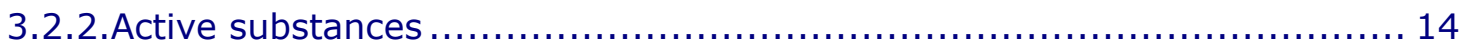

3.3. Production, use and fate of biocides.......................................... 19

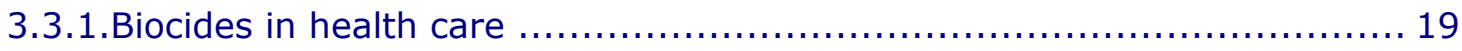

3.3.1.1. Biocides (disinfectants) on medical devices and surfaces....... 19

3.3.1.2. Biocides (disinfectants and antiseptics) used on skin and mucosa 21

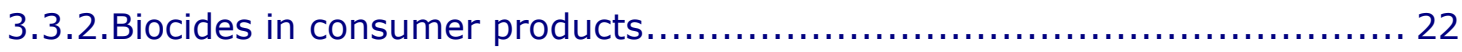

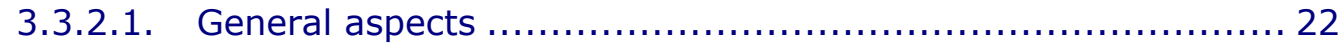

3.3.2.2. Cosmetics and personal care products ........................ 22

3.3.2.3. Household products ............................................ 23

3.3.2.4. Triclosan in consumer products and textiles ................... 23

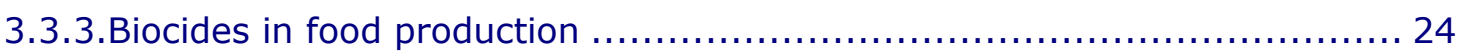

3.3.3.1. Biocides as disinfectants...................................... 24

3.3.3.2. Biocides as food preservatives............................. 24

3.3.4. Biocides in animal husbandry ............................................... 24

3.3.4.1. Biocides as feed preservatives............................... 26

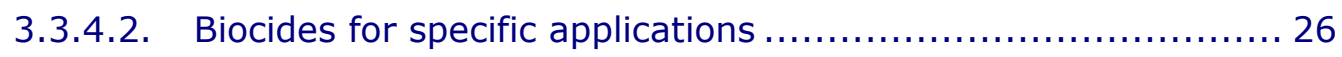

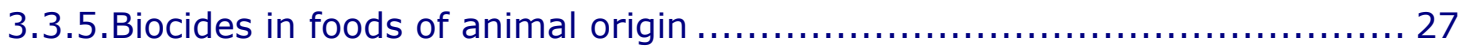

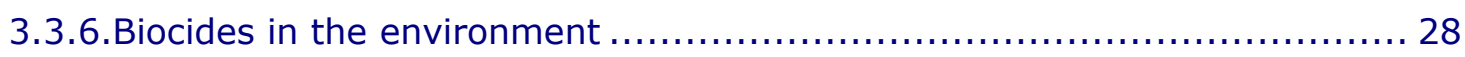

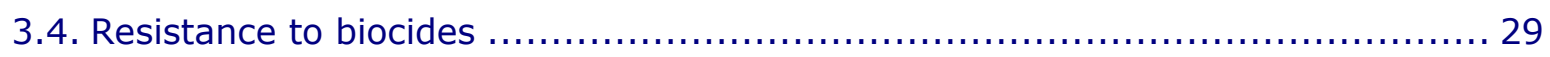

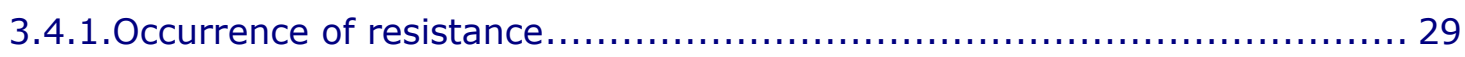

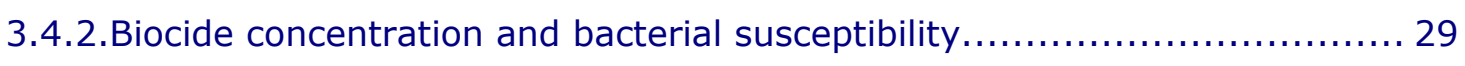

3.4.3. Mechanisms of resistance to biocides....................................... 30

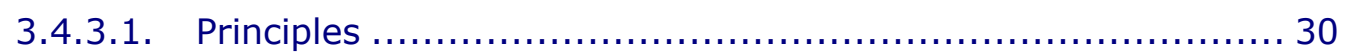

3.4.3.2. Mechanisms of intrinsic bacterial resistance to biocides ......... 31

3.4.3.3. Mechanisms of acquired bacterial resistance to biocides ........ 32

3.4.3.4. Expression of genes conferring resistance ..................... 33

3.4.4. Resistance to biocides in specific applications........................... 34 
3.4.4.1. Resistance to biocides used in health care ...................... 34

3.4.4.2. Resistance to biocides used in consumer products ............... 35

3.4.4.3. Resistance to biocides used in food production.................. 36

3.4.4.4. Resistance to biocides used in animal husbandry............... 37

3.4.4.5. Resistance to biocides used in foods of animal origin ............ 38

3.4.4.6. Resistance to biocides that occur in the environment ........... 38

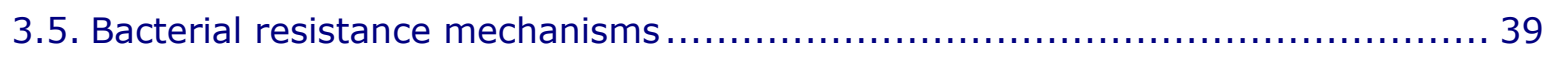

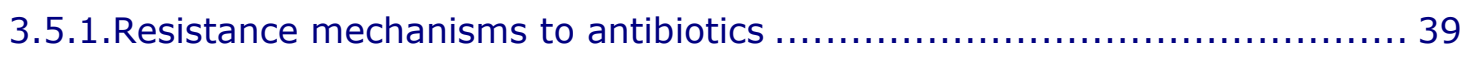

3.5.1.1. Antibiotics, targets and activities .......................... 39

3.5.1.2. Main bacterial mechanisms of antibiotic resistance ............. 40

3.5.1.3. Multi-drug resistant bacteria ................................. 41

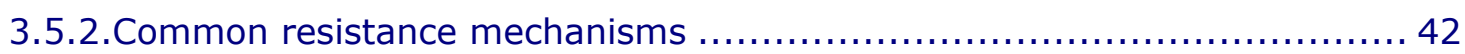

3.5.2.1. Biocides and antibiotics share common resistance mechanisms 42

3.5.2.2. Bacterial biofilms and resistance .............................. 43

3.5.2.3. Induction of antibiotic resistance by biocide molecules ......... 43

3.5.2.4. Regulation pathway and overlap between biocides and

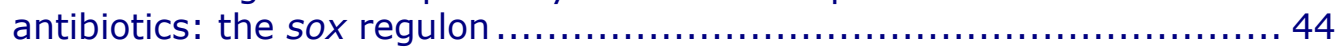

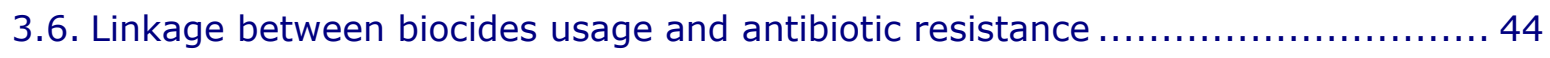

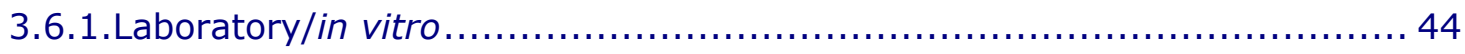

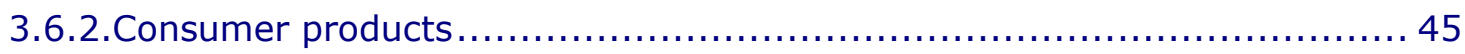

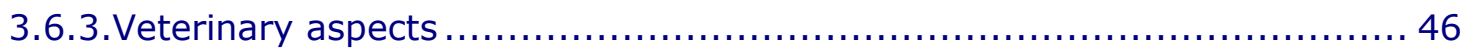

3.7. Relationship between biocide bioavailability to bacteria and resistance selection 46

3.7.1. Measurement of the effects of biocides on the susceptibility to antibiotics . 46

3.7.2. Possible confounding factors in dose-effect relationships $\ldots \ldots \ldots \ldots \ldots \ldots \ldots 47$

3.7.3. Changes in microbiota following exposure to biocides $\ldots \ldots \ldots \ldots \ldots \ldots \ldots \ldots \ldots 4$

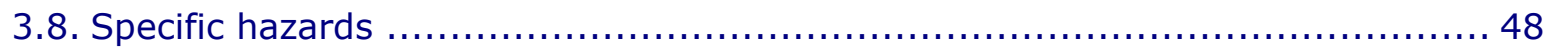

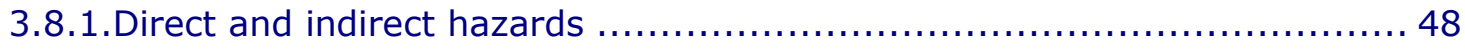

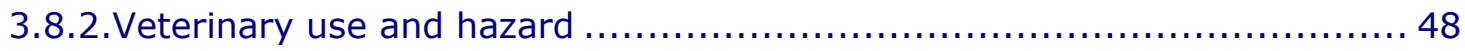

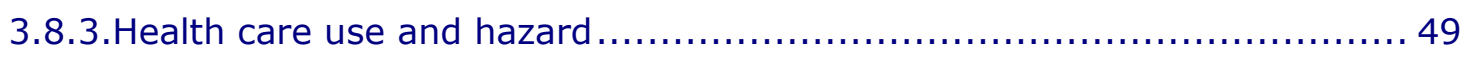

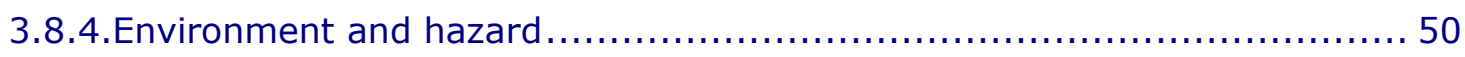

3.8.5. Relationship between biocide resistance and antibiotic resistance ........... 51

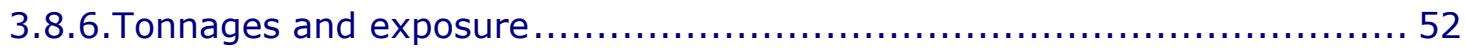

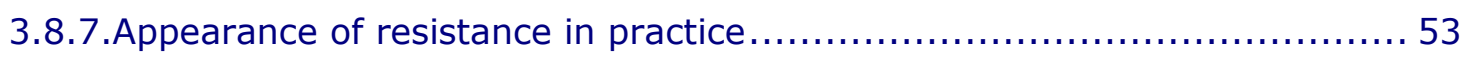

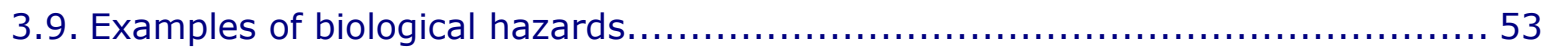

3.9.1.Genetic dissemination of resistance genes............................... 53

3.9.2.Biofilms 54

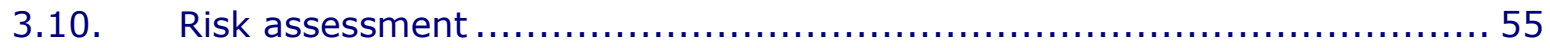

3.10.1. Categorisation of potential factors involved in the biological risk ........... 56 3.10.1.1. Predisposition of bacterial species to acquire resistance ........ 56

3.10.1.2. Induction of antibiotic resistance gene via genetic cascade .... 56 3.10.1.3. Type of antimicrobial (intrinsic potential for generating

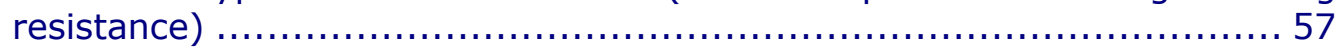

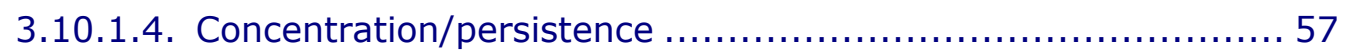




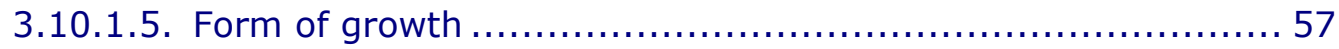

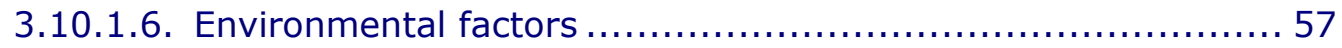

3.10.1.7. Prevalence of bacterial species ............................ 58

3.10.2. Risk factors for resistance to antimicrobials .............................. 58

3.10.3. Requirement for new methodologies for risk assessment of the effect of

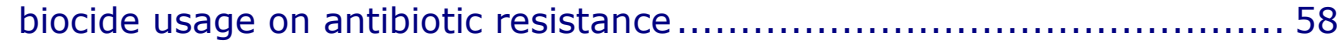

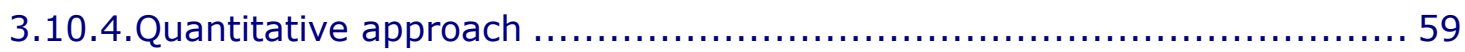

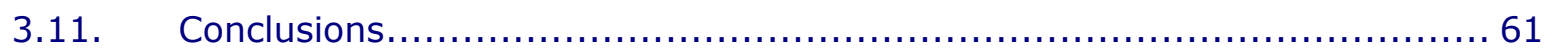

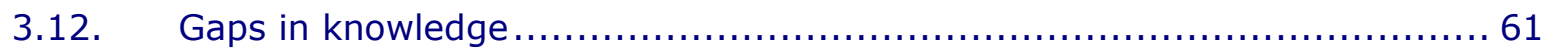

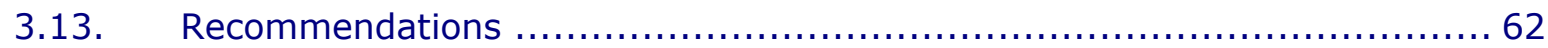

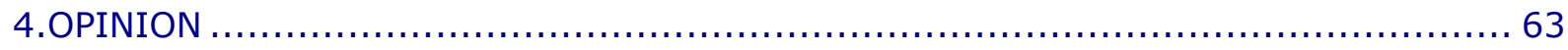

5.COMMENTS RECEIVED DURING THE PUBLIC CONSULTATION $\ldots \ldots \ldots \ldots \ldots \ldots \ldots \ldots \ldots \ldots$

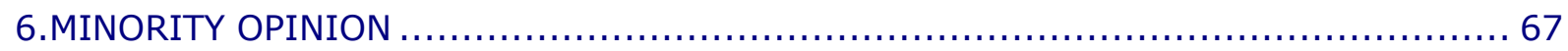

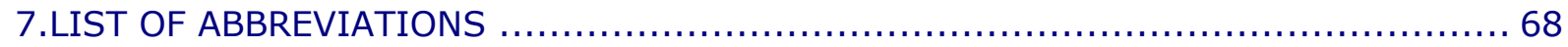

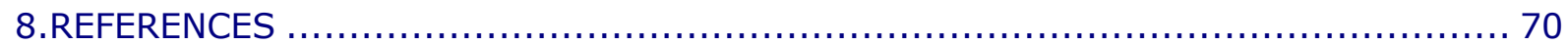

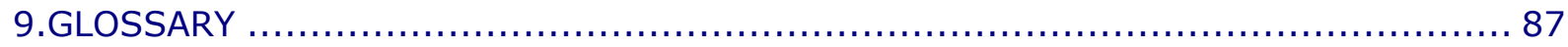




\section{EXECUTIVE SUMMARY}

Antibiotic resistance has increased worldwide in bacterial pathogens leading to treatment failures in human and animal infectious diseases. Resistance against antibiotics by pathogenic bacteria is a major concern in the anti-infective therapy of both humans and animals. Bacteria are able to adapt rapidly to new environmental conditions such as the presence of antimicrobial molecules and, as a consequence, resistance may increase with increasing exposure to antimicrobials. Serious concerns about bacterial antibiotic resistance from nosocomial, community-acquired and food-borne pathogens have been growing for a number of years, and have been raised at both national and international levels.

Emerging bacterial resistance against different types of biocides (including disinfectants, antiseptics, preservatives and sterilants) has been studied and characterised only recently. Only limited scientific evidence is available to correctly weigh the risks of antibiotic resistance induced by resistance to biocides and some controversies remain. Furthermore, research indicates that biocides and antibiotics may have some similar and common interactions and target sites with bacteria, which might express shared resistance mechanisms to both antimicrobials.

Therefore the Commission requested the SCENIHR to answer the following questions:

1. Does current scientific evidence indicate that the use of certain active substances in biocidal products in various settings as mentioned above can contribute to the occurrence of antibiotic resistant bacteria, both in humans and in the environment? If so, how does this effect compare to resistance due to application of medicinal products or veterinary medicinal products and other relevant applications?

2. If yes, which types of active substances, modes of action or areas of application create the highest risks for increasing antibiotic resistance?

3. If yes, what are the extent of the resulting antibiotic resistance and the relative contribution of the different applications to the risk of increasing antibiotic resistance?

4. How can the development of antibiotic resistance due to the use of active substances in biocidal products be examined? Could the Committee advise on the methodologies?

5. Please identify relevant gaps in scientific knowledge and suggest major research needs.

Biocides are invaluable compounds that provide society with numerous benefits. They play an important role in the control of bacteria in a variety of applications and are thus a precious resource that must be managed so as to be protected from loss of activity over time. Therefore, in order to preserve the role of biocides in infection control and hygiene, it is paramount to prevent the emergence of bacterial resistance and cross-resistance through their appropriate and prudent use.

Current scientific evidence (including bacteriological, biochemical and genetic data) does indicate that the use of certain active substances in biocidal products in various settings may contribute to the increased occurrence of antibiotic resistant bacteria. Some mechanisms of resistance are common to both biocides and antibiotics (e.g. efflux pumps, permeability changes and biofilms). The selective pressure exerted by biocides may favour the expression and dissemination of these mechanisms of resistance. The most studied biocides; triclosan and quaternary ammonium compounds, are likely to contribute to maintaining selective pressure allowing the presence of mobile genetic elements harbouring specific genes involved in the resistance to biocides and antibiotics. However, the lack of data on the other biocidal compounds prevents reaching a definitive answer as to their role in selecting for or maintaining bacterial antibiotic resistance. The existence of horizontal gene transfer, particularly associated with mobile genetic 
elements, is the most likely mechanism for selecting and increasing antibiotic resistance. The dissemination of these mobile genetic elements, their genetic capacity to contain several resistance genes, and the presence of overlapping genetic cascades of regulation responding to selective pressures from chemicals on bacteria represent the highest risk factors. The formation of biofilms could also be considered a potential risk factor for the development of cross-resistance between antibiotics and biocides.

In the face of the large increase of biocide use in various fields (human, animals, foods etc.) and the continuous increase in bacterial antibiotic resistance, there is a serious lack of data and methodologies to clearly identify the risks arising from the indiscriminate use of biocides:

1. Quantitative data on biocide exposure including concentrations, environmental conditions affecting activity (e.g. temperature, organic load, exposure time etc.), dissemination of resistance genes, change in bacterial population following exposure, and potential synergies with other molecules are required to formulate an appropriate risk assessment.

2. There are no accepted standard protocols for the evaluation of antimicrobial resistance induced or selected by a biocide. Such standards must be developed to provide informative data for biocidal product development and usage, and for regulatory bodies. In addition, surveillance programmes must be introduced to monitor the level of bacterial resistance and cross-resistance in all areas of biocide usage.

3. Environmental studies focussing on the identification and characterisation of resistance and cross-resistance to antibiotics following use and misuse of biocides.

All suggestions and questions raised at the occasion of the public consultation on this opinion were taken into account and adequate responses were formulated in the final version. 


\section{BACKGROUND}

Directive $98 / 8 / \mathrm{EC}^{3}$ of the European Parliament and of the Council on the placing on the market of biocidal products was adopted in 1998. According to the Directive, Member States had to transpose the rules before 14 May 2000 into national law. It has a transitional period of ten years, during which all existing active substances have to be reviewed with regard to the safety of their use for human health and the environment.

The Directive aims to harmonise the European market for biocidal products and their active substances. At the same time it aims to provide a high level of protection for humans, animals and the environment. Active substances (both chemical and biological) are assessed at Community level, and if the outcome of the evaluation is positive, they are included in Annex I to the Directive. Member States then authorise biocidal products containing these active substances in accordance with harmonised criteria. While authorisation of products takes place at the national level, a biocidal product authorised in one Member State shall be authorised upon application also in other Member State unless there are specific grounds to derogate from this principle of mutual recognition.

The scope of the Directive is very wide, covering 23 different product types. These include disinfectants used in different areas, preservatives of products and materials, substances for pest control in non-agricultural applications, and others such as antifouling products used on hulls of vessels. However, the Directive does not apply to certain product types already covered by other Community legislation, such as plant protection products, medicines, food contact materials and cosmetics. Moreover, the Directive does not apply to articles (e.g. textiles and clothes, wood and plastic objects) treated with biocides imported from the third countries.

The Scientific Steering Committee recommended in its opinion on Antimicrobial Resistance $^{4}$ (adopted on 28 May 1999), inter alia, "prudent use of antimicrobials", "reduction of the overall use of antimicrobials in a balanced way in all areas" and "the identification of major contributors to resistance." Furthermore, it recommended in its opinion on triclosan ${ }^{5}$ (adopted on $27 / 28$ June 2002) "that the potential for biocides, in general, to induce antimicrobial resistance of importance to clinical medicine, or management of the wider environment be kept under continuous review. If new scientific evidence were to indicate a significant risk of biocides causing anti-microbial resistance to antibiotics used in human medicines, then appropriate action to manage these risks might be needed."

Recent scientific evidence suggests that during the last decade, antibiotic resistance by various mechanisms has increased worldwide in bacterial pathogens leading to treatment failures in human and animal infections. However, the resistance against different types of biocides (including disinfectants, antiseptics, preservatives and sterilants) has been studied and characterised only recently. Only limited sound scientific evidence to correctly weigh the risks of antibiotic resistance induced by resistance to biocides is available and some controversies remain. Furthermore, research indicates that biocides and antibiotics may share some common behaviour and properties in their respective activity and in the resistance mechanisms developed by bacteria.

One of the problems within Directive 98/8/EC and directives dealing with similar kinds of substances is that cumulative risks and impacts resulting from the use of the active substance outside the scope of the Directive (e.g. in plant protection products, cosmetics, medicines, food contact materials, food hygiene, industrial chemicals, textiles and clothes, wood and plastic objects) are not addressed in the evaluation process. This is especially problematic in view of such cross-cutting issues as antimicrobial resistance.

\footnotetext{
${ }^{3}$ http://eur-lex.europa.eu/LexUriServ/site/en/oj/1998/I 123/I 12319980424en00010063.pdf

${ }^{4}$ http://ec.europa.eu/food/fs/sc/ssc/out50 en.pdf

${ }^{5}$ http://ec.europa.eu/food/fs/sc/ssc/out269 en.pdf
} 
Therefore, it is considered relevant that the scientific assessment addresses the products regulated under the biocides Directive 98/8/EC but also takes into account the potential contribution to antibiotic resistance of active substances in biocidal products covered by other legislation or in other applications (not regulated). This would include for example, cosmetics, surface biocides in food-contact materials, feed additives, and antimicrobial treatment of textiles or clothes. These different applications will be called "active substances in biocidal products" for the purpose of this mandate. These active substances may have the capability ${ }^{6}$ to induce the activation/selection of an antibiotic resistance mechanism in potential/recognised bacterial pathogens. In relation to active substances in food and feed applications, SCENIHR should co-ordinate with EFSA.

A report on the implementation of the Directive is foreseen in 2007, which could lead to the review of certain of its provisions. In light of the recent scientific evidence, clarification is sought as to whether cross resistance to antibiotics should be an additional criterion to consider in the common principles for the evaluation of dossiers for biocidal products as laid out in Annex VI of the Directive or whether the issue should be addressed by other means. Therefore, clarification of the questions listed in the Terms of Reference is sought. In parallel, a request for an opinion concerning (1) the environmental impact and (2) the effect on antimicrobial resistance of four substances used for the removal of microbial surface contamination of poultry carcases, will be submitted for evaluation by SCHER (1) and SCENIHR (2) in close collaboration with EFSA. SCENIHR is invited to ensure the appropriate co-ordination with the relevant activities as appropriate.

\section{TERMS OF REFERENCE}

1) Does current scientific evidence indicate that the use of certain active substances in biocidal products in various settings as mentioned above can contribute to the occurrence of antibiotic resistant bacteria, both in humans and in the environment? If so, how does this effect compare to resistance due to application of medicinal products or veterinary medicinal products and other relevant applications? ${ }^{7}$

2) If yes, which types of active substances, modes of action or areas of application create the highest risks for increasing antibiotic resistance?

3) If yes, what are the extent of the resulting antibiotic resistance and the relative contribution of the different applications to the risk of increasing antibiotic resistance?

4) How can the development of antibiotic resistance due to the use of active substances in biocidal products be examined? Could the Committee advise on the methodologies?

5) Please identify relevant gaps in scientific knowledge and suggest major research needs.

\footnotetext{
${ }^{6}$ This capability is exercised through alteration of the pre-existing level of antibiotic susceptibility in "reference strains" or in potential bacterial pathogens (for humans and animals).

${ }^{7}$ The SCENIHR is in particular asked to consider the possible risk that exposure to biocides or active substances in biocidal products may favour the emergence or selection of cross resistance mechanisms (in bacterial species) that may decrease the efficacy of antibiotic molecules during therapy.
} 


\section{SCIENTIFIC RATIONALE}

\subsection{Introduction}

During the last decade, antibiotic resistance by various mechanisms has increased worldwide in bacterial pathogens leading to treatment failures in human and animal infectious diseases (EARSS 2005, Harbarth and Samore 2005, WHO 2007). Resistance against antibiotics by pathogenic bacteria is a major concern in the anti-infective therapy of both humans and animals. Bacteria are able to adapt rapidly to new environmental conditions such as the presence of antimicrobial molecules and, as a consequence, resistance increases with the antimicrobial use (Falagas and Bliziotis 2007, Jansen et al. 2006). Serious concerns about bacterial drug resistance from nosocomial, communityacquired and food-borne pathogens have been growing for a number of years and have been raised at both national and international levels (see Reports from EARSS 2005 EASAC 2005, EFSA 2007 and WHO 2007, Jansen et al 2006).

Antimicrobial molecules include antibiotics and biocides having a bactericidal/bacteriostatic effect on bacteria (see the definition in section 3.2.1.1). The various antibiotic resistance strategies are well-described in the scientific literature. By comparison, resistance against other biocides has only been studied and characterised recently. Biocides and antibiotics may share some common behaviour and properties in their respective activity and in the resistance mechanisms developed by bacteria (Russell 2003, Sheldon 2005). Today, it is important to weigh the risks of selecting antibiotic resistant bacteria by biocide use correctly and to have a clear view of the corresponding emerging health risk. Moreover, understanding the selection and dissemination of biocide resistant pathogens is very important for combating the dissemination of health care associated diseases and foodborne pathogens.

In 2006, the market for biocides amounted to $€ 10-11$ billion with a growth of $4-5 \%$ per annum for the previous 15 years. Market expansion is predicted to continue (for further details, see http://www.pan-europe.info/Biocides.htm). As a result, the hazard/risk of biocide use leading to the selection of antibiotic resistant bacteria followed by selection and dissemination of resistant pathogens is of increasing concern. Therefore, the aim of the present opinion is to assess the risk relating to the possible interactions between the use of biocides and the emergence of antibiotic resistance in pathogenic bacteria.

The objective of this opinion is to review evidence on the emergence of biocide resistance and cross-resistance between biocides and antibiotics in bacteria, and to determine if the increasing use of biocides may be associated with an increase in antibiotic resistance in bacterial pathogens. Areas where information is scarce or not available and subsequent additional research will be highlighted.

\subsection{Scope of opinion, definition of active substances considered}

Within the scope of the mandate our proposition is to limit the definition of "antimicrobials" to substances that are primarily active against bacteria, and does exclude for example antifungal and antiprotozoal agents.

\subsubsection{Definitions}

\subsubsection{Official definitions}

According to the Directive 98/8/EC of the European Parliament and Council of the 16 February 1998, biocidal products are defined as active substances and preparations containing one or more active substances, put up in the form in which they are supplied 
to the user, intended to destroy, render harmless, prevent the action of, or otherwise exert a controlling effect on any harmful organism by chemical or biological means. In the Annex $V$ of the Directive is presented a list of 23 product types with an indicative set of descriptions.

The active substances are without concern (Annex IA of the directive) or with concern about their inherent capacity to cause an adverse effect on humans, animals or the environment.

Within the scope of the mandates our proposition is to limit this definition to chemical means only and to apply the following definitions:

- Biocide: an active chemical molecule to control the growth of or kill bacteria in a biocidal product.

- Antibiotic: an active substance of synthetic or natural origin which is used to eradicate bacterial infections in humans or animals.

- Antimicrobial activity ${ }^{8}$ : an inhibitory or lethal effect of a biocidal product or an antibiotic.

\subsubsection{Other definitions}

The mandate to the Committee did not require the clarification of the terminology used to define resistance to biocides. The definitions used in this opinion are based on the experts' assessment of the currently used definitions in the peer-reviewed literature.

There are several definitions of resistance to antimicrobials biocides or/and antibiotics and several terms used to describe similar phenomena in the literature. A literal definition of resistance is the capacity of bacteria to withstand the effects of a harmful chemical agent.

The terms employed in the context of this mandate are defined below in order to avoid confusion in the definitions used to describe the level and type of resistance reported.

The following definitions are based partly on those put forward by Chapman and colleagues (Chapman 1998, Chapman et al. 1998), Russell and colleagues (Hammond et al. 1987, Russell 2003) and Cloete (2003).

The practical meaning of antibiotic resistance is to describe situations where (i) a strain is not killed or inhibited by a concentration attained in vivo, (ii) a strain is not killed or inhibited by a concentration to which the majority of strains of that organism are susceptible or (iii) bacterial cells that are not killed or inhibited by a concentration acting upon the majority of cells in that culture.

In the context of this mandate, when non-antibiotic antimicrobial agents (i.e. biocides) are considered, the word "resistance" is used in a similar way where a strain is not killed or inhibited by a concentration attained in practice (the in-use concentration) and in situations (ii) and (iii) described above.

These definitions reflect those given by EFSA whereby "antimicrobial susceptibility or resistance is generally defined on the basis of in vitro parameters. The terms reflect the capacity of bacteria to survive exposure to a defined concentration of an antimicrobial agent, but different definitions are used depending on whether the objective of the investigation is clinical diagnostics or epidemiological surveillance" (EFSA 2008a, EFSA 2008b)

\footnotetext{
8 Article 2(2)(c) of Directive 2003/99/EC on the monitoring on zoonoses and zoonotic agents (OJ L 325, 12.12.2003, p. 31): "(c) 'antimicrobial resistance' means the ability of micro-organisms of certain species to survive or even to grow in the presence of a given concentration of an antimicrobial agent, that is usually sufficient to inhibit or kill micro-organisms of the same species."
} 
The term 'Multi-Drug Resistant' (MDR) applies to a bacterium that is simultaneously resistant to a number of antibiotics belonging to different chemical classes by using various mechanisms (Depardieu et al. 2007). The EFSA uses the term multiple resistance (MR) or multi-resistance when a bacterial strain is resistant to several different antimicrobials or antimicrobial classes (EFSA 2008a, EFSA 2008b).

The term "cross-resistant" is used to denote a strain possessing a resistance mechanism that enables it to survive the effects of several antimicrobial molecules with mechanism(s) of action that are related or overlap.

Other terms such as "insusceptibility", "tolerance" and "co-resistance" have been used in the published literature. Insusceptibility refers to an intrinsic (innate) property of a micro-organism, such as cell layer impermeability in mycobacteria and Gram-negative bacteria. Tolerance denotes a reduced susceptibility to an antimicrobial molecule characterised by a raised minimum inhibitory concentration (MIC), or a situation in which a preservative system no longer prevents microbial growth. Co-resistance specifically refers to genetic determinants (such as integrons, transposons or plasmids) encoding for unrelated resistance mechanisms, that are transferred in a single event and expressed jointly in a new bacterial host.

\subsubsection{Active substances}

The number of biocides in use is large. In the context of this mandate, biocides used for their surfactant properties, and for which the primary purpose is not their antimicrobial activity, as well as antimicrobial peptides (for instance, bacteriocins), will not be considered.

For the purpose of this document, only the most commonly used biocides for which information about bacterial resistance is available in the public domain, will be discussed. The list of such active substances classified on the basis of their chemical groups or their mode of action is presented in Table 1 and Table 2, respectively. Components of the formulation might have an effect on the antimicrobial activity of the biocide $(\mathrm{pH}$, surfactants, antioxidants, chelating agents, aroma chemicals and alcohols, botanical and herbals, antimicrobial amphiphillic peptides [defensins, Cationic Antimicrobial Peptides (CAMP)], enzymatic antimicrobial systems), or several biocides might be used in the same formulation to increase the overall antimicrobial activity. The effects of combining two or more biocides can be defined as (i) additive when the combined action is no greater than the sum of the activities of the individual actives, (ii) synergistic when the combined action is greater than the sum of the activities of any actives on their own and (iii) antagonistic where the combined effect results in a lower activity than the sum of the activities of the individual actives. For a biocidal formulation containing more than two different active molecules, synergy is the goal.

Some of the components that are commonly found in household products are surface active agents (surfactants) and "membrane permeabilisers". Surfactants have an intrinsic antibacterial activity (anionic, non-ionic, organic acids [active against Gram-positive bacteria] and compounds with alkyl chains [active against both Gram positive and negative bacteria]) (Birnie et al. 2000) and may increase the overall bactericidal activity of the associated products when used in combination. They are not usually described or labelled as active molecules of the products. Membrane permeabilisers and chaotropic agents (e.g. EDTA, detergents) increase the bactericidal efficacy of a product mainly against Gram-negative bacteria when used in combination with a biocide. Their mechanism of action has been well-described (Alakomi et al. 2006, Ayres et al. 1999, Denyer and Maillard 2002, Maillard 2005). 
Table 1 List of active molecules in biocidal products classified on the basis of chemical groups.

\begin{tabular}{|c|c|c|c|c|}
\hline \multirow{2}{*}{$\begin{array}{l}\text { Chemical } \\
\text { Groups } \\
\text { Phenols }\end{array}$} & \multicolumn{2}{|c|}{$\begin{array}{l}\text { Active molecules } \\
\end{array}$} & \multirow{2}{*}{$\begin{array}{c}\text { CAS } \\
\text { Registry } \\
\text { Number }\end{array}$} & \multirow[t]{2}{*}{$\begin{array}{c}\text { Possible } \\
\text { concentration } \\
\text { range (\%) } \\
\end{array}$} \\
\hline & \multirow[t]{2}{*}{ Cresol } & m-cresol ${ }^{9}$ & & \\
\hline & & Isomeric mixtures & $1319-77-3$ & \\
\hline & \multirow{3}{*}{$\begin{array}{l}\text { Non-coal tar } \\
\text { phenols }\end{array}$} & 4-Tertiary octylphenol ${ }^{10}$ & $140-66-9$ & \\
\hline & & 2-Phenylphenol(2-phenylphenoxide) & $90-43-7$ & \\
\hline & & 4-Hexylresorcinol & $136-77-6$ & \\
\hline & \multirow{9}{*}{$\begin{array}{l}\text { Halo- and } \\
\text { nitrophenols }\end{array}$} & 2,4,6-Trichlorophenol & $88-06-2$ & \\
\hline & & $\begin{array}{l}\text { Pentachlorophenol (2-phenylphenoxide) [2 } \\
\text { different substances, CAS No refers to first] }\end{array}$ & $87-86-5$ & \multirow[t]{8}{*}{ Forbidden in EU } \\
\hline & & 4-Chloro-3-methylphenol (chlorocresol) & $59-50-7$ & \\
\hline & & $\begin{array}{l}\text { 4-Chloro-3,5-dimethylphenol } \\
\text { (chloroxylenol; para-chloro-meta-xylenol; } \\
\text { PCMX) }\end{array}$ & $88-04-0$ & \\
\hline & & $\begin{array}{l}\text { 2,4-Dichloro-3,5-dimethylphenol } \\
\text { (dichloroxylenol; dichloro-meta-xylenol; } \\
\text { DCMX) }\end{array}$ & $133-53-9$ & \\
\hline & & 4-chloro-2-phenylphenol & $607-12-5$ & \\
\hline & & $\begin{array}{l}\text { 2-Benzyl-4-chlorophenol (chlorphen; ortho- } \\
\text { benzyl-para-chlorophenol; OBPCP) }\end{array}$ & $8013-49-8$ & \\
\hline & & Nitrophenols & & \\
\hline & & Phenol & $108-95-2$ & \\
\hline & \multirow[t]{4}{*}{ Bis-phenols } & Derivatives of dihydroxydiphenylmethane & & \multirow[t]{4}{*}{0.5} \\
\hline & & Derivatives of hydroxydiphenylether & & \\
\hline & & Derivatives of diphenylsulphide & & \\
\hline & & $\begin{array}{l}\operatorname{Triclosan}^{11}(2,4,4 \text { '-trichloro-2'- } \\
\text { hydroxydiphenyl ether) }\end{array}$ & $3380-34-5$ & \\
\hline \multirow{13}{*}{$\begin{array}{l}\text { Organic and } \\
\text { inorganic } \\
\text { acids: esters } \\
\text { and salts }\end{array}$} & \multicolumn{2}{|l|}{ Formic acid } & $64-18-6$ & \\
\hline & \multicolumn{2}{|c|}{ Acetic acid (ethanoic acid) } & $64-19-7$ & $0.4-52$ \\
\hline & \multicolumn{2}{|l|}{ Propionic acid } & $79-09-4$ & \\
\hline & \multicolumn{2}{|c|}{ Undecanoic acid (undecylenic acid) } & $112-37-8$ & \\
\hline & \multicolumn{2}{|c|}{ 2,4-Hexadienoic acid (sorbic acid) } & $110-44-1$ & \\
\hline & \multicolumn{2}{|l|}{ Lactic acid } & $598-82-3$ & \\
\hline & \multicolumn{2}{|l|}{ Benzoic acid } & $65-85-0$ & \\
\hline & \multicolumn{2}{|l|}{ Salicylic acid } & $69-72-7$ & \\
\hline & \multicolumn{2}{|c|}{$\begin{array}{l}\text { Dehydroacetic acid (DHA, 3-acetyl-6-methylpyran-2,4[3H]- } \\
\text { dione) }\end{array}$} & $520-45-6$ & \\
\hline & \multicolumn{2}{|c|}{ Sulphur dioxide, sulphites, bisulphites } & & \\
\hline & \multicolumn{2}{|c|}{ Esters of p-hydroxybenzoic acid (parabens): } & & \\
\hline & \multicolumn{2}{|c|}{ Methyl paraben } & $99-76-3$ & \\
\hline & \multicolumn{2}{|l|}{ Ethyl paraben } & $120-47-8$ & \\
\hline
\end{tabular}

\footnotetext{
${ }^{9}$ Estimated production in EU for $\mathrm{m}$-cresol is greater than 1,000 t per year (Dye et al. 2007).

${ }^{10}$ USA: > 500 t (Calafat et al. 2008).

${ }^{11}$ Estimated production in EU for triclosan is $10-1,000$ tonnes per year (Dye et al. 2007).
} 


\begin{tabular}{|c|c|c|c|}
\hline \multirow[t]{4}{*}{$\begin{array}{l}\text { Chemical } \\
\text { Groups }\end{array}$} & Active molecules & \multirow{2}{*}{$\begin{array}{c}\text { CAS } \\
\text { Registry } \\
\text { Number }\end{array}$} & \multirow[t]{2}{*}{$\begin{array}{c}\text { Possible } \\
\text { concentration } \\
\text { range }(\%) \\
\end{array}$} \\
\hline & Propyl paraben & & \\
\hline & Butyl paraben & $94-26-8$ & \\
\hline & Vanillic acid esters & & \\
\hline \multirow{2}{*}{$\begin{array}{l}\text { Aromatic } \\
\text { diamidines }\end{array}$} & Propamidine & $104-32-5$ & \\
\hline & Dibromopropamidine & $496-00-4$ & \\
\hline \multirow[t]{3}{*}{ Biguanides } & Chlorhexidine & $55-56-1$ & \\
\hline & Alexidine & $48110-46-8$ & \\
\hline & Polymeric biguanides & & 0.43 \\
\hline \multirow{4}{*}{$\begin{array}{l}\text { Surface- } \\
\text { active } \\
\text { agents }^{12}\end{array}$} & Cationic agents (QACs) & & $0.03-50$ \\
\hline & Anionic agents & & \\
\hline & Nonionic agents & & \\
\hline & Amphoteric (ampholytic) agents & & \\
\hline \multirow[t]{4}{*}{ Aldehydes } & Glutaraldehyde (pentanedial) & $111-30-8$ & 2 \\
\hline & Formaldehyde (methanal) & $50-00-0$ & $0.03-15.7$ \\
\hline & Ortho-phthalaldehyde & $643-79-8$ & \\
\hline & Other aldehydes & & 0.5 \\
\hline \multirow{3}{*}{$\begin{array}{l}\text { Antimicrobial } \\
\text { dyes }\end{array}$} & Acridines & & \\
\hline & Triphenylmethane dyes & & \\
\hline & Quinones & & \\
\hline \multirow[t]{3}{*}{ Halogens } & Iodine compounds & & \\
\hline & Iodophors & & \\
\hline & Iodoform & $75-47-8$ & \\
\hline \multirow{2}{*}{$\begin{array}{l}\text { Chlorine } \\
\text { compounds }\end{array}$} & Chlorine-releasing compounds & & $0.02-22.4$ \\
\hline & Chloroform & $67-66-3$ & $\begin{array}{l}\text { Forbidden in EU by } \\
\text { Directive } 98 / 8 / E C\end{array}$ \\
\hline \multirow[t]{2}{*}{ Bromine } & $\mathrm{NH}_{4} \mathrm{Br}$ & $12124-97-9$ & \\
\hline & Alkaline bromine derivative & & $10-25$ \\
\hline \multirow{3}{*}{$\begin{array}{l}\text { Quinoline and } \\
\text { isoquinoline } \\
\text { derivatives }\end{array}$} & 8-Hydroxyquinoline derivatives & & \\
\hline & 4-Aminoquinaldinium derivatives & & \\
\hline & Isoquinoline derivatives & & \\
\hline \multirow[t]{9}{*}{ Alcohols } & Ethyl alcohol (ethanol) & $64-17-5$ & $0.1-99.9$ \\
\hline & Methyl alcohol (methanol) & $67-56-1$ & $0.03-15$ \\
\hline & Isopropyl alcohol (isopropanol) & $67-63-0$ & $0.1-77.22$ \\
\hline & Benzyl alcohol & $100-51-6$ & \\
\hline & Phenylethanol (phenylethyl alcohol) & $60-12-8$ & \\
\hline & Bronopol $^{13}$ (2-bromo-2-nitro-1,3-diol) & $52-51-7$ & \\
\hline & Phenoxyethanol (phenoxetol) & $122-99-6$ & \\
\hline & Chlorbutanol (chlorbutol) & $57-15-8$ & \\
\hline & 2,4-Dichlorobenzyl alcohol & $1777-82-8$ & \\
\hline
\end{tabular}

${ }^{12}$ Surface active agents may not necessarily be used as active in a formulation, but as a surfactant.

${ }^{13}$ Bronopol tonnage is estimated from 10 to 1,000 tonnes per year in the EU (Dye et al. 2007). 
Antibiotic Resistance Effects of Biocides

\begin{tabular}{|c|c|c|c|c|}
\hline $\begin{array}{l}\text { Chemical } \\
\text { Groups }\end{array}$ & \multicolumn{2}{|c|}{ Active molecules } & $\begin{array}{c}\text { CAS } \\
\text { Registry } \\
\text { Number }\end{array}$ & $\begin{array}{c}\text { Possible } \\
\text { concentration } \\
\text { range }(\%)\end{array}$ \\
\hline \multirow[t]{2}{*}{ Peroxygens } & \multicolumn{2}{|l|}{ Hydrogen peroxide } & $7722-84-1$ & $0.5-29$ \\
\hline & \multicolumn{2}{|l|}{ Peracetic acid } & $79-21-0$ & $0.008-0.23$ \\
\hline \multirow{9}{*}{$\begin{array}{l}\text { Heavy-metal } \\
\text { derivatives }\end{array}$} & \multicolumn{4}{|l|}{ Copper compounds } \\
\hline & \multicolumn{4}{|l|}{ Silver compounds } \\
\hline & \multirow[t]{5}{*}{ Mercury compounds } & $\begin{array}{l}\text { Mercurochrome (disodium- } \\
\text { 2,7-dibromo-4- } \\
\text { hydroxymercurifluorescein) }\end{array}$ & $129-16-8$ & \\
\hline & & $\begin{array}{l}\text { Nitromersol (anhydro-2- } \\
\text { hydroxymercuri-6-methyl- } \\
\text { 3-nitrophenol) }\end{array}$ & & \\
\hline & & $\begin{array}{l}\text { Thiomersal (merthiolate; } \\
\text { sodium-o- } \\
\text { (ethylmercurithio)- } \\
\text { benzoate) }\end{array}$ & $54-64-8$ & \\
\hline & & Phenylmercuric nitrate (PMN) & $55-68-5$ & \\
\hline & & Phenylmercuric acetate (PMA) & $62-38-4$ & \\
\hline & \multicolumn{4}{|c|}{ Tin and its compounds (organotins) } \\
\hline & \multicolumn{4}{|l|}{ Titanium } \\
\hline \multirow[t]{2}{*}{ Anilides } & Salicylanilide & & $87-17-2$ & \\
\hline & \multicolumn{4}{|c|}{ Diphenylureas (carbanilides) } \\
\hline \multirow[t]{2}{*}{$\begin{array}{l}\text { Derivatives of } \\
1,3 \text {-dioxane }\end{array}$} & \multicolumn{2}{|c|}{$\begin{array}{l}\text { 2,6-dimethyl-1,3-dioxan-4-ol acetate (isomeric } \\
\text { mixture)(dimethoxane) }\end{array}$} & $828-00-2$ & \\
\hline & \multicolumn{2}{|c|}{ 5-Bromo-5-nitro-1,3-dioxane (Bronidox) } & $30007-47-7$ & \\
\hline \multirow[t]{3}{*}{$\begin{array}{l}\text { Derivatives of } \\
\text { imidazole }\end{array}$} & \multicolumn{2}{|c|}{$\begin{array}{l}\text { 1,3-Di(hydroxymethyl)-5,5-dimethyl-2,4-dioxoimidazole; } \\
\text { 1,3-Di-hydroxymethyl)-5,5-dimethylhydantoin (Dantoin) }\end{array}$} & $6440-58-0$ & $96-100$ \\
\hline & \multicolumn{2}{|c|}{$\begin{array}{l}\mathrm{N}, \mathrm{N}^{\prime \prime} \text {-methylene bis [5'[1-bydroxymethyl]-2,5-dioxo-4- } \\
\text { imidazolidinyl urea] (Germall } 115\end{array}$} & $39236-46-9$ & \\
\hline & \multicolumn{2}{|l|}{ Diazolidinyl Urea } & $78491-02-8$ & \\
\hline \multirow[t]{4}{*}{ Isothiazolones } & \multicolumn{2}{|c|}{$\begin{array}{l}\text { 5-Chloro-2-methyl-4-isothiazolin-3-one (CMIT) and 2-Methyl- } \\
\text { 4-isothiazolin-3-one (MIT) (mixture) }\end{array}$} & $26172-55-4$ & $\begin{array}{l}0.00007- \\
0.000141\end{array}$ \\
\hline & \multicolumn{2}{|c|}{ 2-Methyl-4-isothiazolin-3-one (MIT) } & $2682-20-4$ & \\
\hline & \multicolumn{2}{|c|}{ 2-n-Octyl-4-isothiazolin-3-one } & $26530-20-1$ & \\
\hline & \multicolumn{2}{|c|}{ 1,2-Benzisothiazolin-3-one (BIT) } & $2634-33-5$ & \\
\hline \multirow{6}{*}{$\begin{array}{l}\text { Derivatives of } \\
\text { hexamine }\end{array}$} & \multicolumn{4}{|l|}{ Triazines } \\
\hline & \multicolumn{4}{|l|}{ Oxazolo-oxazoles } \\
\hline & \multicolumn{2}{|c|}{ Sodium hydroxymethylglycinate } & $70161-44-3$ & \\
\hline & \multicolumn{2}{|c|}{ Methylene bisthiocyanate } & $6317-18-6$ & \\
\hline & Captan & & $133-06-2$ & \\
\hline & 1,2-dibromo-2,4-dicy & ne (Tektamer 38) & $35691-65-7$ & \\
\hline Terpenes & Limonene (isomeric & & & \\
\hline Vapour-phase & Ethylene oxide & & $75-21-8$ & \\
\hline & Formaldehyde-releas & & & \\
\hline & Propylene oxide & & $75-56-9$ & \\
\hline & Methyl bromide & & $74-83-9$ & \\
\hline & Ozone & & & \\
\hline
\end{tabular}


Table 2 List of active substances in biocidal products and their mode of action

\begin{tabular}{|c|c|c|}
\hline Biocide & Usage/areas of applications & General mode of action \\
\hline $\begin{array}{l}\text { Quaternary } \\
\text { ammonium } \\
\text { compounds }\end{array}$ & $\begin{array}{l}\text { Health care, household products, } \\
\text { surface preservation (various } \\
\text { application), food industry, } \\
\text { pharmaceutical/cosmetic } \\
\text { (preservation) }\end{array}$ & $\begin{array}{l}\text { Membrane destabiliser, at a high concentration - } \\
\text { produce cytoplasmic protein aggregation (loss of } \\
\text { tertiary structure) }\end{array}$ \\
\hline Biguanides & Health care, household products & $\begin{array}{l}\text { Chlorhexidine specifically inhibits membrane-bound } \\
\text { ATPase }\end{array}$ \\
\hline Phenols/cresols & $\begin{array}{l}\text { Health care, home care products, } \\
\text { surface preservation (various } \\
\text { applications) }\end{array}$ & $\begin{array}{l}\text { Triclosan: enoyl acyl reductase at a low } \\
\text { concentration } \\
\text { Dinitrophenol collapses membrane energy (ATP } \\
\text { synthesis) } \\
\text { A low concentration of fentichlor and triclosan } \\
\text { inhibits energy-dependent uptake of amino acids } \\
\text { A low concentration of triclosan discharges } \\
\text { membrane potential in } E \text {. faecalis }\end{array}$ \\
\hline Alcohols & $\begin{array}{l}\text { Health care, pharmaceutical/cosmetic } \\
\text { (preservation) }\end{array}$ & $\begin{array}{l}\text { Inhibition of DNA and RNA synthesis, cell wall } \\
\text { synthesis (secondary effect) } \\
\text { Low concentration of phenoxyethanol induce proton } \\
\text { translocation in E. coli }\end{array}$ \\
\hline Aldehydes & $\begin{array}{l}\text { Health care, pharmaceutical/cosmetic } \\
\text { (preservation), industry (paper) }\end{array}$ & Alkylating agents \\
\hline Ethylene oxide & $\begin{array}{l}\text { Health care, single-used medical } \\
\text { devices (e.g. catheter sterilisation) }\end{array}$ & Alkylating agent \\
\hline Anionic agents & $\begin{array}{l}\text { Household products, } \\
\text { Pharmaceutical/cosmetic } \\
\text { (preservation) }\end{array}$ & $\begin{array}{l}\text { As part of a formulation (i.e. usually not the main } \\
\text { active) }\end{array}$ \\
\hline Organic acids & $\begin{array}{l}\text { Pharmaceutical/cosmetic } \\
\text { (preservation), food preservation }\end{array}$ & $\begin{array}{l}\text { Dissipation of proton motive force; Inhibition of } \\
\text { uptake of amino acids }\end{array}$ \\
\hline Metallic salts & $\begin{array}{l}\text { Health care, pharmaceutical } \\
\text { preservation }\end{array}$ & Interactions with thiol-group (mercury, silver) \\
\hline Isothiazolinones & $\begin{array}{l}\text { Personal care products, Household } \\
\text { products and Industrial products }\end{array}$ & $\begin{array}{l}\text { BIT (benzisothiazolnone) affects active transport and } \\
\text { oxidation of glucose in S. aureus, activity of thiol- } \\
\text { containing enzymes, ATPAses, glyceraldehyde-3- } \\
\text { phosphate dehydrogenase }\end{array}$ \\
\hline Peroxides & $\begin{array}{l}\text { Health care, personal care products } \\
\text { and Industrial products }\end{array}$ & Oxidising agents \\
\hline $\begin{array}{l}\text { Chlorine } \\
\text { compounds and } \\
\text { halogens }\end{array}$ & $\begin{array}{l}\text { Health care, Household products, } \\
\text { Industrial products, water treatment } \\
\text { (private and industrial use) }\end{array}$ & Oxidising agents \\
\hline Amphoteric agents & Health care, household products & Unknown membrane interaction \\
\hline Non-ionic agents & Health care, household products & Unknown membrane interaction \\
\hline Limonene & Household and industrial products & Unknown membrane interaction \\
\hline Antimicrobial dyes & Health care & DNA-intercalating agents \\
\hline Iodophors & Health care products & Covalent binding to thiol groups \\
\hline $\begin{array}{l}\text { Pentamidine, } \\
\text { isethinate of } \\
\text { pentamidine, } \\
\text { propamidine } \\
\text { (dibromo } \\
\text { derivatives) } \\
\end{array}$ & Medical devices (e.g. catheters) & Inhibition of DNA synthesis \\
\hline
\end{tabular}




\subsection{Production, use and fate of biocides}

In contrast to the surveillance on the use of antibiotics used in human and animal health care, the use of biocides is not regularly monitored, and the amounts of products applied or used remains largely unknown (see Tables 1 and 2). Only general figures, such as the estimated EU-market value of $€ 10-11$ billion in 2006, with a continuing increase, are available (http://www.pan-europe.info/Biocides.htm).

While most biocides are known to be high volume products, the Committee could not obtain any valid tonnage information despite several efforts. However, production volumes of many of these compounds are considered to be several orders of magnitude higher than those of antibiotics. It is conceivable that the huge amount of biocides disseminated in the environment may, per se, induce a biological hazard via the selective pressure ${ }^{14}$ applied to bacterial populations.

In general, Directive 98/8/EC on the placing of biocidal products on the market ${ }^{15}$ governs the use of active substances in biocidal products. In this Directive the prerequisites for placing of biocidal products on the market are defined, including detailed requirements of the pre-marketing approval process. Requirements are among others, the demonstration of efficacy, safety, analytical methods for detection and identification, toxicity, the control of residues including metabolites and degradation products (Art 2a-g) and ecotoxicological studies.

\subsubsection{Biocides in health care}

The proper use of biocides is a cornerstone of any effective programme of prevention and control of health care-associated infections (HAIs) (Maillard 2005). According to CEN/TC 216 (CEN/TC 216 Chemical disinfectants and antiseptics) the term disinfection designates an operation aimed at preventing an infection, the term antisepsis should be used to indicate the treatment of an infection. Disinfectants are used in the decontamination process of patient-care devices, environmental surfaces and intact skin. Antiseptics are applied to non intact skin and mucosa.

\subsubsection{Biocides (disinfectants) on medical devices and surfaces}

Biocides used to control the growth of pathogenic microorganisms or to eliminate them from inanimate objects, surfaces or intact skin, are classified on the basis of the level of inactivation reached. Low-level disinfectants inactivate most vegetative bacteria, some fungi and some viruses (enveloped viruses); intermediate-level disinfectants inactivate vegetative bacteria, mycobacteria, most viruses and most fungi, but do not necessarily kill bacterial spores; high-level disinfectants inactivate all micro-organisms (vegetative bacteria, mycobacteria, fungi, enveloped and non-enveloped viruses) except large numbers of bacterial spores. High-level disinfectants can inactivate spores when applied with prolonged exposure times and are called chemical sterilants.

Table 3 shows the disinfectants that have been approved for use in health care settings by the US Food and Drug Administration (US-FDA) or registered by the US Environmental Protection Agency (US-EPA) (Rutala 1996, Rutala and Weber 2007, Weber and Rutala 2006).

\footnotetext{
${ }^{14}$ Selective pressure: chemical, physical, or biological factors or constraints which select well-adapted bacteria or induce the expression of specific biological mechanisms involved in the bacterial response to external stresses.

${ }^{15}$ Directive 98/8/EC of the European Parliament and of the Council of 16 February 1998 concerning the placing of biocidal products on the market.
} 
Table 3 Biocides approved by US-FDA for health care settings, or registered by the US-EPA

\begin{tabular}{|c|c|}
\hline Disinfection level & Biocides \\
\hline \multirow{5}{*}{ Low-level } & Ethyl or isopropyl alcohol (70-90\%) \\
\hline & Iodophor solution (follow product label for use-dilution) \\
\hline & Phenolic (follow product label for use-dilution) \\
\hline & $\begin{array}{l}\text { Quaternary ammonium detergent solution (follow product label for } \\
\text { use-dilution) }\end{array}$ \\
\hline & $\begin{array}{l}\text { Sodium hypochlorite }(5.25 \%-6.15 \% \text { household bleach diluted } \\
1: 500, \approx 100 \mathrm{ppm} \text { available chlorine) }\end{array}$ \\
\hline \multirow[t]{3}{*}{ Intermediate-level } & Ethyl or isopropyl alcohol (70-90\%) \\
\hline & Phenolic (follow product label for use-dilution) \\
\hline & $\begin{array}{l}\text { Sodium hypochlorite }(5.25 \%-6.15 \% \text { household bleach diluted } \\
1: 100, \approx 500 \mathrm{ppm} \text { available chlorine) }\end{array}$ \\
\hline \multirow{8}{*}{ High-level } & Glutaraldehyde $\geq 2 \%$ \\
\hline & Glutaraldehyde (1.12\%) and phenol/phenate (1.93\%) \\
\hline & Hydrogen peroxide $(7.5 \%)$ \\
\hline & Hydrogen peroxide $(7.35 \%)$ and peracetic acid $(0.23 \%)$ \\
\hline & Hydrogen peroxide $(1 \%)$ and peracetic acid $(0.08 \%)$ \\
\hline & $\begin{array}{l}\text { Hypochlorite (single-use chlorine generated by electrolyzing saline } \\
\text { containing }>650-675 \mathrm{ppm} \text { of active free chlorine) }\end{array}$ \\
\hline & Ortho-phthalaldehyde $(0.55 \%)$ \\
\hline & Peracetic acid $(0.2 \%)$ \\
\hline
\end{tabular}

In 1968, Spaulding devised a rational approach to disinfection and sterilisation of patientcare devices, which were divided into three categories taking into account the degree of infection risk involved in the use of each one: critical devices, semicritical devices, non critical devices (Spaulding 1968).

Critical devices penetrate sterile tissues, including sterile cavities and the vascular system (e.g. surgical instruments, needles, syringes, implantable devices, intravascular devices, cardiac and urinary catheters, arthroscopes and laparoscopes) and must be sterile at the time of use because any microbial contamination could result in pathogen transmission. The most efficient and reliable method of sterilisation is steam under pressure; however, if heat sensitive, the device must be treated with ethylene oxide (ETO) or hydrogen peroxide plasma, or by chemical sterilants. Due to the inherent limitations of using liquid chemical sterilants in a non-automated reprocessor, their use must be restricted to critical devices that are heat sensitive and incompatible with other sterilisation methods.

Semi-critical devices are those that come into contact with mucous membranes or non intact skin. Examples of semicritical devices are: respiratory therapy and anesthesia equipment, flexible endoscopes, laryngeal blades, esophageal manometry probes, vaginal and rectal probes, anorectal manometry catheters and nasal specula. Sterilisation is the preferred method in order to provide the widest margin of safety, even though a high level disinfection would provide a patient-safe device.

Non-critical devices are those that come into contact with intact skin or those items that do not make contact with the patient. Examples of non-critical devices are stethoscopes, 
bedpans, blood pressure cuffs, ECG cables and electrodes. There is generally little risk of transmitting infectious agents to patients by means of non-critical devices. Therefore, low-level disinfectants may be used to process them. Environmental surfaces are also included in this category. Biocides are commonly used to disinfect environmental surfaces and near-patient surfaces (e.g. floors, walls, tables, bedrails, screens etc.); however, the routine use of biocides to disinfect environmental surfaces is controversial (Allerberger et al. 2002, Boyce 2007, Dettenkoffer et al. 2004, Dharan et al. 1999, Rutala and Weber 2001, Rutala and Weber 2004.).

The role of environmental surfaces in spreading of HAIs has not been clearly established. Even though they do not come into contact with the patients, there is evidence that they may contribute to epidemic or endemic spread of epidemiologically important bacteria, such as methicillin-resistant Staphylococcus aureus (MRSA), vancomycin-resistant enterococci (VRE) and Clostridium difficile by acting as a reservoir from which health care workers contaminate their hands (Hota 2004, Talon 1999). Targeted disinfection of certain environmental surfaces is recommended in some instances to prevent the spread of pathogenic bacteria; for example surfaces contaminated with blood, stool, urine, or other potentially contaminated material, or frequently touched surfaces in high risk wards (for example intensive care units).

Given the complex and multifactorial nature of HAIs, it is advisable to implement welldesigned studies that systematically investigate the role of environmental surface disinfection in preventing HAIs, and to define bacteriological standards with which to assess surface hygiene in health care settings (Dancer 2004, Dettenkoffer et al. 2004, Griffith et al. 2000).

A number of manufacturers have now developed a range of surfaces containing biocides that have started to appear in health care settings. Such products include, for example, plastics, shower rails, curtains or trolleys. These surfaces are often based on the use of metallic ions such as silver ions. A number of recent studies have also been performed on the re-introduction of metallic surfaces, e.g. copper for door handles and objects that are frequently manipulated (Mehtar et al. 2008, Noyce et al. 2006, Santo et al. 2008, Weaver et al. 2008). While some studies showed an antimicrobial activity of copper surfaces, their actual impact is difficult to ascertain (Airey and Verran 2007) when compared to other currently used surfaces (mainly stainless steel).

Antimicrobial wipes are being used with an increasing frequency in the health care environment. The active ingredients providing antimicrobial efficacy vary largely depending on the content of detergents, natural products and biocides within commercially available wipes. While these wipes might be part of the disinfection regime in place, a recent study highlighted the problems associated with them, in particular with inappropriate usage, such as repeated use on several surfaces (Williams et al. 2008).

\subsubsection{Biocides (disinfectants and antiseptics) used on skin and mucosa}

Some biocides are used to reduce total micro-organism counts or to eliminate pathogenic bacteria on skin from patients and personnel. Antiseptics differ from disinfectants in that they are applied to non intact skin and mucosa. Table 4 shows the most commonly used skin disinfectants and antiseptics in health care settings. In some preparations, agents are combined. 
Table 4 Commonly used skin disinfectants and antiseptics

\begin{tabular}{|l|l|}
\hline \multicolumn{1}{|c|}{ Biocides } & Most commonly used dilution \\
\hline Alcohols (ethanol, isopropanol, n-propanol) & $60 \%-95 \%$ \\
\hline Chlorhexidine gluconate & $\begin{array}{l}\text { Aqueous or detergent preparations } \\
\text { containing } 0.5 \text { or } 0.75 \% \\
\text { chlorhexidine } \\
\text { Alcohol preparations containing } \\
4 \% \text { chlorhexidine }\end{array}$ \\
\hline Chloroxylenol (parachlorometaxylenol: PCMX) & $0.3 \%-3.75 \%$ \\
\hline Hexachlorophene & $3 \%$ \\
\hline Iodophors (Povidone-iodine) & $7.5 \%-10 \%$ \\
\hline Quaternary ammonium compounds & \\
\hline Triclosan & $0.2-2 \%$ \\
\hline
\end{tabular}

Alcohols are the most frequently used antimicrobial components of handrubs (Kampf et al. 1999, Kampf et al. 2004, Kampf et al. 2008, Pittet et al. 2007). Alcohol-based handrubs are considered the most efficacious agents for reducing the number of bacteria on the hands of health care workers as a result of increased usage compliance and antimicrobial efficacy (Boyce and Pittet 2002). They are recommended for routine disinfection of hands for all clinical indications, except when hands are visibly soiled.

\subsubsection{Biocides in consumer products}

\subsubsection{General aspects}

Many different preservatives/antimicrobial substances/biocides are used in building materials, consumer products (such as cosmetics, household cleaning products, disinfectants, wipes etc.), and in furniture, curtains and wall papers etc. in home settings. However, the regular use of personal hygiene products (e.g. cosmetics, wipes), cleaning products, laundry detergents, pet disinfectants and general disinfectants are the major sources of exposure to biocides in home settings. The increasing use of biocidal products has been acknowledged and discussed by the International Forum on Home Hygiene (IFH, 2003).

\subsubsection{Cosmetics and personal care products}

In the EU, the use of preservatives ${ }^{16}$ or antimicrobials in cosmetics is regulated by the EU Directive 76/768/EEC ${ }^{17}$ (the so-called "Cosmetics Directive"). Fifty-seven chemicals listed in Annex VI of this Directive are permitted, with the restrictions laid down in the Annex, for the use as preservatives in cosmetic products. The function of these molecules in the cosmetics is the protection of the products from microbial degradation. Most of these

\footnotetext{
${ }^{16}$ Preservatives are substances which may be added to cosmetic products for the primary purpose of inhibiting the growth of micro-organisms in such products. Other substances used in the formulation of cosmetic products may also have anti-microbial properties and thus help in the preservation of the products, as for instance, many essential oils and some alcohols.

${ }^{17}$ Council Directive 76/768/EEC of 27 July 1976 on the approximation of the laws of the Member States relating to cosmetic products.
} 
substances are commonly used in the cosmetic products, but not all of them are included in Annex I of the Commission Regulation of 4 December 2007, listing the identified existing active substances for evaluation (Commission Regulation EC/1451/2007).

Besides the use of the 57 antimicrobial agents regulated as preservatives in cosmetic products by the Cosmetic Directive, many other antimicrobial agents are also used in cosmetic products. The purpose of these non-regulated antimicrobials in cosmetic products is not described.

\subsubsection{Household products}

Although biocidal products as defined by the Biocide Directive 98/8/EC are not commonly used in household products, the active ingredients of the biocidal products in categories 1-9 of the Directive are widely used in household products and other consumer products. Regular use of household products such as laundry detergents, cleaning products, pet disinfectants and general disinfectants are the major sources of exposure to biocides in home settings. Biocides present in these products may be from different chemical groups, but their mechanism of action may be similar (see section 3.5.2.1).

Biocides/antimicrobial agents used as preservatives in household cleaning products and laundry detergents may contain the same active ingredients as cosmetic products. However, the use of biocides/antimicrobial agents in household products is not regulated. Furthermore, certain biocides present as preservatives in diverse household products may also be present in household cleaning products, where they may serve as disinfectants.

Many of the ingredients used in detergent products, such as cationic surfactants, quaternary ammonium compounds and fragrances, possess antimicrobial properties. In a survey of industrial and institutional cleaning products in Denmark, only a limited number of biocides, besides antimicrobial surfactants and other ingredients, were found (Madsen et al. 2005). Cleaning product formulations for private homes may be similar to those used in industry and in public and private buildings.

Disinfectants in consumer products are used to control or to prevent growth of microorganisms. There is a great diversity in use and application types for these products e.g. liquids, granulates, powders, tablets, gasses etc.

Recently, surfaces coated with biocides have also been developed. These biocide-treated surfaces include a variety of active ingredients such as triclosan and metallic ions (see also section 3.3.1.1).

\subsubsection{Triclosan in consumer products and textiles}

Triclosan is used in cosmetics, cleaning products, paint, textiles and plastic products. The Danish EPA performed a survey of the use of triclosan in Denmark for the period 20002005 (Borling et al. 2005). The survey showed that the amount of triclosan in products on the Danish market had decreased from approx. 3.9 to 1.8 tonnes corresponding to a reduction of $54 \%$ in the period $2000-2004$. Cosmetics were the largest contributor to the amount of triclosan on the Danish market, as they constituted $99 \%$ of the total reported amount in the survey. The largest amount of triclosan in cosmetics was found in products for dental hygiene, including toothpaste. In this group, the amount had decreased by $37 \%$. Deodorant was the group of cosmetics with the greatest decrease in amount of triclosan $(79 \%)$. A recent survey revealed that $15 \%$ of the most commonly sold deodorants in the Danish market contained $<0.3 \%$ triclosan (Rastogi et al. 2007).

Clothing articles are treated with antibacterial compounds to avoid mal-odour produced by decomposition of sweat. Only one report could be identified addressing actual occurrence. Seventeen products from the Danish retail market were analysed for the content of some selected antibacterial compounds: triclosan, dichlorophen, Kathon 893, hexachlorophen, triclocarban and Kathon CG. Five of the selected products were found to 
contain $0.0007 \%-0.0195 \%$ triclosan. None of the other target substances could be detected in any of the investigated products (Rastogi et al. 2003).

\subsubsection{Biocides in food production}

Biocides are widely used in the food industry for the disinfection of production plants and of food containers, the control of microbial growth in food and drinks, and the decontamination of carcasses.

\subsubsection{Biocides as disinfectants}

Disinfection is regarded as a crucial step in achieving a defined, desired hygiene status in food production and processing areas, and in food processing plants. A variety of biocides are commonly used for the disinfection of equipment, containers, surfaces or pipework associated with the production, transport and storage of food or drink (including drinking water).

Disinfectants intended for use in the food-processing industry are regulated within the scope of Directive 98/8/EC on the placing of biocidal products on the market.

The use of disinfectant in water quality intended for human consumption is regulated by the so-called Drinking Water Directive $98 / 83 / \mathrm{EC}^{18}$. Biocides are used at the waterworks to maintain the microbiological quality of the water before and during its distribution, by sustaining the total counts of micro-organisms at an acceptable level and eliminating pathogenic micro-organisms.

For drinking water treatment, chlorine has been used worldwide for the past century for pre-chlorination at the point of entrance of raw water, disinfection and post-disinfection in the water distribution system. However, because of the formation of halogenated byproducts, pre-chlorination is no longer recommended and other oxidising agents such as ozone or chlorine-dioxide are more commonly used for disinfection. In some countries, post-disinfection is always performed with chlorine or chloramines.

\subsubsection{Biocides as food preservatives}

Preservatives are substances which prolong the shelf-life of foodstuffs by protecting them against deterioration caused by micro-organisms. These compounds are considered food additives and are regulated by the Food Additives Directive 89/107/EEC ${ }^{19}$. Their use in food must be explicitly authorised at European level and they must undergo a safety evaluation before authorisation for using the preservative as intended.

\subsubsection{Biocides in animal husbandry}

Proper cleaning and disinfection play a vital role in protecting food animals from endemic and zoonotic diseases, and thus indirectly protecting human health. It is impossible to give detailed accounts of all applications, but uses can essentially be divided into four broad categories:

- Cleaning and disinfection of farm buildings, particularly between batches of animals.

- Creating of barriers, such as in the use of foot dips outside animal houses and disinfecting vehicles and materials during outbreaks of infectious diseases.

\footnotetext{
${ }^{18}$ Council Directive 98/83/EC of 3 November 1998 on the quality of water intended for human consumption.

19 European Parliament and Council Directive No 95/2/EC of 20 February 1995 on food additives other than colours and sweeteners.
} 
- Direct application to animal surfaces such as teat dips.

- Preservation of specific products such as eggs or semen.

Table 5 Major biocides used in veterinary medicine and animal husbandry

\begin{tabular}{|l|}
\hline Veterinary use \\
\hline Na-dichloro-isocyanurate \\
\hline Na-p-toluene-sulfonchloramide (Halamid) \\
\hline $\mathrm{H}_{2} \mathrm{O}_{2}$ \\
\hline Acetic acid \\
\hline Quarternary ammonium chlorides \\
\hline Glutaraldehyde (in combinations) \\
\hline Formaldehyde (in combinations) \\
\hline Isopropanol (in combinations) \\
\hline Disinfection of instruments and animal facilities/houses \\
\hline Na-dichloro-isocyanurate \\
\hline $\mathrm{H}_{2} \mathrm{O}_{2}$ \\
\hline Acetic acid \\
\hline QAC: Dideceyl-dimethyl-ammonium $\mathrm{Cl}$ \\
\hline QAC: Alkyl-demethylbenzyl-ammonium $\mathrm{Cl}$ \\
\hline Glutaraldehyde (in combinations) \\
\hline Formaldehyde (in combinations) \\
\hline Isopropanol (in combinations) \\
\hline Disinfection of transporters/trucks \\
\hline Na-dichloro-isocyanurate \\
\hline $\mathrm{H}_{2} \mathrm{O}_{2}$ \\
\hline Acetic acid \\
\hline Quarternary ammonium chlorides \\
\hline QAC + KOH \\
\hline Glutaraldehyde (in combinations) \\
\hline Formaldehyde (in combinations) \\
\hline Isopropanol (in combinations) \\
\hline Disinfection of boots and tools \\
\hline Na- $p$-toluene-sulfonchloramide (Halamid) \\
\hline $\mathrm{H}_{2} \mathrm{O}_{2}$ / acetic acid \\
\hline
\end{tabular}

The use of biocides in animal husbandry follows the prerequisites set in the Biocides Directive 98/8/EC that also invite Member States to regulate the use of these agents. Consequently, some Member States have published lists of authorised substances which are not harmonised. At present, in the absence of a mandatory monitoring system, no 
exact data on the amounts of substances used can be obtained. Although it appears that only few disinfectant types are commonly used on a given farm, the same disinfectant brand may be used for extended periods of time (See Table 5).

\subsubsection{Biocides as feed preservatives}

Biocides are used as animal feed preservatives, with the aim of protecting feed against deterioration caused by micro-organisms. In the EU, feed preservatives are included in the category "technological additives" of feed additives under the Regulation (EC) $1831 / 2003$ on additives for use in animal nutrition ${ }^{20}$. Their use in food must be explicitly authorised at European level. Before authorisation they must undergo a safety evaluation by EFSA. Most of the authorised products for this purpose are organic acids added to feed or silage, to reduce the total microbial count or to control undesirable spoilage microrganisms.

\subsubsection{Biocides for specific applications}

Biocides as teat dips: The udders of animals used for milk production may be contaminated with faecal and other materials. Therefore, prior to milking, udders are cleaned with water that may contain biocides, although this is less common.

More frequently, after the milking process, so-called teat dips are applied to protect the milk duct and the entire udder from invading pathogens. Various chemicals are used for this purpose including chloroisocyanurates, which are organic chloramines, bronopol, quaternary ammonium compounds and iodine-based compounds (see Table 6).

In a guidance document (Doc-Biocides-2002/01) BPD (Biocidal Products according to Directive 98/8/EC) are defined as products used on animal skin during milking, such as teat dips or udder cleaning products, and may be used only after authorisation or registration in accordance with the procedures laid down in Directive 98/8/EC. Where a medical claim is made, disinfectants shall be treated as veterinary medicinal products and shall only be used if authorised in accordance with the provisions of Directive 2001/82/EC on veterinary medicinal products ${ }^{21}$.

Biocide use in fish farming: Under the prerequisites of Directive 98/8/EC a range of disinfectants are permitted for decontamination in fish farming, for example for fish eggs, ponds and equipment. These include iodophores, metallic salts, haloorganic compounds, aldehydes, hydrogen peroxide, quaternary ammonium compounds and antimicrobial dyes.

\footnotetext{
${ }^{20}$ Regulation (EC) No 1831/2003 of the European Parliament and of the Council of 22 September 2003 on additives for use in animal nutrition (Text with EEA relevance).

${ }^{21}$ Directive 2001/82/EC of the European Parliament and of the Council of 6 November 2001 on the Community code relating to veterinary medicinal products.
} 
Table 6 Components of (udder) teat dips used (or having been used) in dairy animals

\begin{tabular}{|l|l|}
\hline Solutions & \\
\hline lodophors (concentrates up to 10\%) & $1 \%$ iodine working solutions \\
\hline lodine (non-aqueous base) & $1 \%$ \\
\hline Na-hypochlorite & $4.2 \%$ \\
\hline Na-dichloro-s-triazenetrione & $0.6 \%$ \\
\hline Quarternary ammonium & $0.18 \%$ \\
\hline Chlorhexidine & $0.5 \%$ \\
\hline Bronopol & $0.2 \%$ \\
\hline Ceterylpyridinum chloride & $0.2 \%$ \\
\hline 8-hydroxyquinoline sulphate & $0.1 \%$ \\
\hline Paper towels with & \\
\hline Isopropanol & \\
\hline Ethanol & \\
\hline Alkyl benzene sulfonate & \\
\hline
\end{tabular}

\subsubsection{Biocides in foods of animal origin}

Because the use of antibiotics in animal production may give rise to residues in edible tissues such as milk, meat and eggs, Regulation $2377 / 90 / E^{22}$ requires that all antimicrobials obtain a pre-marketing approval, including an assessment of residue formation and of the potential effects on the human gut flora (EMEA 1999).

The use of biocides for the decontamination of carcasses is considered as a hygiene measure under Regulation (EC) 853/2004 on specific hygiene rules for food of animal origin $^{23}$ to remove surface bacterial contamination from products of animal origin, such as poultry carcasses. The use of these biocides must be authorised by the European Commission after a safety assessment performed by the European Food Safety Authority (EFSA). Following a request from the European Commission, the EFSA has examined several substances used elsewhere in the world to decontaminate poultry carcasses. This work has focused on four substances; chlorine dioxide, acidified sodium chlorite, trisodium phosphate and peroxyacids. In 2005, an opinion of the Scientific Panel on food additives, flavourings, processing aids and materials in contact with food concluded that these substances would not pose a safety concern within the proposed conditions of use (EFSA, 2005). The EFSA's BIOHAZ Panel was also asked to examine the efficacy of peroxyacids, the only type of substance whose efficacy has been assessed. Due to the lack of data, the BIOHAZ Panel was unable to conclude on whether this substance effectively killed or reduced pathogenic bacteria on poultry carcasses.

In 2008, the EFSA BIOHAZ Panel examined the possible development of antimicrobial resistance through the use of the same four substances to decontaminate poultry

\footnotetext{
22 Council Regulation (EEC) No 2377/90 of 26 June 1990 laying down a Community procedure for the establishment of maximum residue limits of veterinary medicinal products in foodstuffs of animal origin.

${ }^{23}$ Regulation (EC) No 853/2004 of the European Parliament and of the Council of 29 April 2004 laying down specific hygiene rules for food of animal origin.
} 
carcasses. This Panel concluded that no data exist to show that the use of these substances will lead to increased bacterial tolerance to these substances or increased resistance to other antimicrobial agents. However, some evidence indicates bacterial tolerance to other antimicrobial substances or biocides that were not the subject of this opinion (EFSA 2008a, EFSA 2008b).

The EFSA has now been asked by the Commission to produce technical guidance on monitoring and collecting data on antimicrobial resistance so that the uncertainties noted by the panel in its opinion on the four substances are addressed. The EFSA has proposed to examine this alongside safety and efficacy considerations, as data on antimicrobial resistance should not be assessed in isolation. The EFSA will work closely with the Community Reference Laboratory for Antimicrobial Resistance in developing its work (Information as cited on the EFSA website).

\subsubsection{Biocides in the environment}

Biocides may be used for a variety of applications, including water treatment, wastewater treatment or industrial use. These applications are addressed by the Biocidal Products Directive 98/8/EC, but in the absence of reporting requirements, the quantities used for these different purposes remain unknown.

Many wastewater treatment plants, especially those in coastal regions, include a final step of disinfection with chlorine. However, this practice is being questioned more and more frequently because of the toxicity of by-products for the marine fauna and the elimination of non pathogenic bacterial indicators of faecal contamination, whilst more resistant viruses and protozoa survive and may cause outbreaks for swimmers or seafood consumers.

Cooling towers are a new place for intensive use of disinfectants since the discovery of their role in the dissemination of contaminated aerosols (Legionella sp and legionellosis). Many disinfectants are now used in order to avoid contamination of the cooling fluid; their fate is aerosolization or elimination in the wastewater.

The use of biocides as antifouling agents in building materials, on antimicrobial surfaces, and in fuels and plastic materials is also gaining in importance, but the quantities used are unknown. It is important to note that an increasing number of uses are linked with nano-size particles of disinfectants (e.g. protection of the concrete facades against lichens and moulds) progressively released in the environment.

The development of antimicrobial surfaces using antimicrobial coating or impregnated surfaces is of great interest. Although there is an increasing number of companies developing such surfaces for a variety of industrial applications, most of these applications are aimed at the protection of the surfaces against environmental spoilage, especially against fungal micro-organisms. The use of biocides within these surfaces is for preservation of the product or the surfaces proper (e.g. caulk; wall paper, paint).

However, some surfaces will release a low concentration of a biocide and as such might contribute to a localised selective pressure. At present, surfaces that release biocides and the effect of localised selective pressure on the environmental microbial flora and on inhabitants exposed to biocide aerosols stemming from biocide impregnated surfaces has not been investigated. It is thus difficult at this stage to discern the impact of such surfaces in emerging resistance to biocides or antibiotics. 


\subsection{Resistance to biocides}

\subsubsection{Occurrence of resistance}

Bacterial resistance to biocides has been reported since the $1950 \mathrm{~s}$, particularly with the contamination of cationic biocide formulations (Adair et al. 1971, Chapman 2003, Russell 2002b). In most instances bacterial resistance emerged following the improper use or storage of the formulations, resulting in a decrease in the effective concentration (Centers for Disease Control 1974, Prince and Ayliffe 1972, Russell 2002b, Sanford 1970). Bacterial resistance to all known preservatives has also been reported (Chapman 1998, Chapman et al. 1998).

In the health care setting, bacterial resistance to biocides has long been reported with compounds such as: chlorhexidine (Stickler 1974); quaternary ammonium compounds (Gillespie et al. 1986, Romao et al. 2005); bisphenol, triclosan (Bamber and Neal 1999, Heath et al. 1998, Sasatsu et al. 1993); iodophor (O'Rourke et al. 2003); parabens (Flores et al. 1997, Hutchinson et al. 2004); and more reactive biocides such as glutaraldehyde (Fraud et al. 2001, Griffiths et al. 1997, Manzoor et al. 1999, Nomura et al. 2004, Van Klingeren and Pullen 1993, Walsh et al. 2001) and peroxygens (Dukan and Touati 1996, Greenberg et al. 1990, Greenberg and Demple 1989). In a recent study, Smith and Hunter reported that although biocides may be effective against planktonic populations of bacteria such as methicillin-resistant Staphylococcus aureus (MRSA) and Pseudomonas aeruginosa, some biocides currently used in hospitals are ineffective against nosocomial pathogens growing as biofilms attached to surfaces and fail to control this reservoir for hospital-acquired infections (Smith and Hunter 2008). Concerning triclosan, Tabak and colleagues reported that the tolerance of Salmonella in the biofilm was attributed to low diffusion through the extracellular matrix, while changes of gene expression might provide further resistance both to triclosan and to other antimicrobials (Tabak et al. 2007).

However, most of the evidence on bacterial resistance to biocides comes from laboratorybased experiments which investigated a wide range of agents such as: cationic biocides (Tattawasart et al. 1999, Thomas et al. 2000); isothiazolones (Winder et al. 2000); phenolics (McMurry et al. 1998b, McMurry et al. 1999); hydrogen peroxide and peracetic acid (Dukan and Touati 1996) and other compounds (Walsh et al. 2003).

\subsubsection{Biocide concentration and bacterial susceptibility}

The concentration of a biocide has been deemed to be the most important factor that affects its efficacy (Russell and McDonnell 2000). In the case of bacterial biofilms, the biocide concentration and consequently the bacterial susceptibility, is strongly affected by the reduced diffusion of active molecules through the biofilm (Anderson and O'Toole 2008, Lewis 2008, Maillard 2007, Tart and Wozniak 2008). Concentration is also central to the definition of bacterial resistance in practice. Therefore, the measurement of bacterial lethality rather than the measurement of bacterial growth inhibition is paramount.

Many reports on emerging bacterial resistance to biocides are based on the determination of minimum inhibitory concentrations (MICs). Using MICs to measure bacterial resistance is arguable since much higher concentrations of biocides are used in practice and, therefore, failing to achieve a reduction of bacterial numbers (i.e. lethality) because of elevated MICs is unlikely (Russell and McDonnell 2000). Indeed, some studies have shown that bacterial strains showing a significant increase in MICs to some biocides were nevertheless susceptible to higher (in use) concentrations of the same biocides (Lear et al. 2006, Thomas et al. 2005).

Thus, the determination of minimum bactericidal concentrations (MBCs) is a more appropriate methodology that allows the comparison of lethality between a standard and 
the resistant strains. Here the standard strains represent the population of bacteria which is normally susceptible to the biocide.

Likewise, the determination of the lethality of the in-use concentration of a biocide will indicate whether a bacterial strains is insusceptible (i.e. naturally resistant) or resistant (by comparison to a standard strain). The determination of the inactivation kinetic following exposure to a biocide, and in particular the shape of the inactivation curve, will provide information as to the nature of resistance of a population of cells and/or the interaction of the biocide with the cell population.

The determination of the lethality of a biocide must involve the use of a neutralising agent or the removal of the biocide. Failure to do so will provide an over-estimation of the lethality of the biocide.

MIC determinations have been used in many studies as an indicator of bacterial sensitivity change to a biocide (Russell and Mcdonnell 2000, Walsh et al. 2003). Bacteria showing an increased low-level of resistance/tolerance to a biocide might be selected by a low concentration of a biocide. Their level of resistance can increase through selection, for example by repeated exposure to a low concentration of a biocide or to increasing concentrations of a biocide (Abdel Malek et al. 2002, Langsrud et al. 2003, Maillard 2007, Tattawasart et al. 1999, Thomas et al. 2000, Walsh et al. 2003).

The determination of bacterial growth kinetics in the presence of a low concentration of a biocide can also provide indications of a change in bacterial phenotype (Gomez-Escalada et al. 2005a, Maillard 2007, Thomas et al. 2005).

Table 7 highlights the methodologies that have been used to measure bacterial resistance to biocides.

Table 7 Methodologies to measure bacterial resistance

\begin{tabular}{lcc}
\hline Methodology & \multicolumn{2}{c}{ Measuring } \\
& Resistance to a biocide & Change in phenotypes \\
\hline MBCs & Yes & Yes \\
\hline Bactericidal activity & Yes & Yes \\
\hline Inactivation kinetic & Yes & Yes \\
\hline MICs & No* & Yes \\
\hline Growth kinetic & No & Yes \\
\hline
\end{tabular}

* An increase in MIC might provide information about a trend towards insusceptibility

\subsubsection{Mechanisms of resistance to biocides}

\subsubsection{Principles}

Biocides have multiple target sites against microbial cells. Thus, the emergence of general bacterial resistance is unlikely to be caused either (i) by a specific modification of a target site or (ii) by a by-pass of a metabolic process. It emerges from a mechanism/process causing the decrease of the intracellular concentration of biocide under the threshold that is harmful to the bacterium. Several mechanisms based on this principle (mode of action) have been well-described including change in cell envelope, change in permeability, efflux and degradation. It is likely that these mechanisms operate synergistically although very few studies investigating multiple bacterial mechanisms of resistance following exposure to a biocide have been performed. 
The efficacy of biocides depends on a range of intrinsic and extrinsic factors, (EFSA, 2008a, Reuter 1984, Reuter 1989, Reuter 1994).

Intrinsic factors are characteristics of the biocidal agent and its application. Concentration and contact time are crucial. Furthermore, the combination of contact time and concentration determines the result in term of microbial reduction. This is called the CT concept, and within certain limits of time and concentration, there is a relationship with a defined constant characterising efficacy. Thus the same result could be obtained with a high concentration of disinfectant during a short contact time, or a lower concentration during a longer contact time. The stability of the active compounds of the biocide in the environment also influences the efficacy.

Extrinsic factors derive from the environment during application. The temperature of the environment is important, as most substances have a lower efficacy at low temperatures. The presence of proteins reduces efficacy as they interact with the substance. The mode of contact also influences the efficacy, as does the contact time (mechanical effects). The $\mathrm{pH}$ is another important factor. The concentration of the microorganisms, the age of the bacterial community and protection by attachment on particulate matter, and the presence of biofilms (see section 3.5.2.2) play an increasingly important role.

\subsubsection{Mechanisms of intrinsic bacterial resistance to biocides}

Several mechanisms conferring bacterial resistance to biocides have been described; some are inherent to the bacterium, other to the bacterial population. In addition, some of the resistance mechanisms are intrinsic (or innate) to the micro-organism while others have been acquired through forced mutations or through the acquisition of mobile genetic elements (Poole 2002a). Innate mechanisms can confer high-level bacterial resistance to biocides. In this case, the term unsusceptibility is used (see definition; section 3.1.1.1).

The most described intrinsic resistance mechanism is changes in the permeability of the cell envelope, also referred to as "permeability barrier". This is not only found in spores (Cloete, 2003, Russell 1990, Russell et al. 1997), but also in vegetative bacteria such as mycobacteria and to some extent in Gram-negative bacteria. The permeability barrier limits the amount of a biocide that enters the cell, thus decreasing the effective biocide concentration (Champlin et al. 2005, Denyer and Maillard 2002, Lambert 2002). In mycobacteria the presence of a mycoylacylarabinogalactan layer accounts for the impermeability to many antimicrobials (Lambert 2002, McNeil and Brennan 1991, Russell 1996, Russell et al. 1997). In addition, the presence and composition of the arabinogalactan/arabinomannan cell wall also plays a role in reducing the effective concentration of biocide that can penetrate within mycobacteria (Broadley et al. 1995, Hawkey 2004, Manzoor et al. 1999, Walsh et al. 2001).

The role of the lipopolysaccharides (LPS) as a permeability barrier in Gram-negative bacteria has been well documented (Ayres et al. 1998, Denyer and Maillard 2002, Fraud et al. 2003, McDonnell and Russell 1999, Munton and Russell 1970, Stickler 2004). There have also been a number of reports of reduced biocide efficacy following changes in other components of the outer membrane ultrastructure (Braoudaki and Hilton 2005, Tattawasart et al. 2000a, Tattawasart et al. 2000b) including proteins (Brözel and Cloete 1994, Gandhi et al. 1993, Winder et al. 2000), fatty acid composition (Guérin-Méchin et al. 1999, Guérin-Méchin et al. 2000, Jones et al. 1989, Méchin et al. 1999) and phospholipids (Boeris et al. 2007). It must be noted that in the above mentioned examples, an exposure to biocides was followed by changes in ultrastructure related to a decrease in biocidal susceptibility, usually at a low concentration (under the MIC value).

The charge property of the cell surface also plays a role in bacterial resistance mechanisms to positively charged biocides such as QACs (Bruinsma et al. 2006). It is likely that bacterial resistance emerges from a combination of mechanisms (Braoudaki and Hilton 2005, Tattawasart et al. 2000a, Tattawasart et al. 2000b), even though single specific mechanisms are often investigated. 
The presence of efflux pumps is another mechanism that has been well described in the literature. It has gained increased recognition as a resistance mechanism over the past decade. Efflux pumps decrease the intracellular concentration of toxic compounds, including biocides (Borges-Walmsley and Walmsley 2001, Brown et al. 1999, Levy 2002, McKeegan et al. 2003, Nikaido 1996, Paulsen et al. 1996a, Piddock 2006, Poole 2001, Poole 2002a, Putman et al. 2000). They are widespread among bacteria and five main classes have been identified: the small multidrug resistance (SMR) family (now part of the drug/metabolite transporter (DMT) superfamily), the major facilitator superfamily (MFS), the ATP-binding cassette (ABC) family, the resistance-nodulation-division (RND) family and the multidrug and toxic compound extrusion (MATE) family (Brown et al. 1999; Borges-Walmsley and Walmsley 2001, McKeegan et al. 2003, Piddock 2006, Poole 2001, Poole 2002b, Poole 2004).

The importance of efflux pumps in terms of bacterial resistance to biocides might be considered as modest since the increase in bacterial susceptibility to selected biocides as the results of the expression of efflux pumps is usually measured as an increase in MICs rather than as resistance to a high concentration of an active substance. Efflux pumps have been shown to reduce the efficacy of a number of biocides including QACs, phenolics parabens and intercalating agents (Davin-Regli et al. 2006, Heir et al. 1995, Heir et al. 1999, Leelaporn et al. 1994, Littlejohn et al. 1992, Lomovskaya and Lewis 1992, Randall et al. 2007, Sundheim et al. 1998, Tennent et al. 1989) notably in Staphylococcus aureus with identified pumps such as QacA-D (Littlejohn et al. 1992, Rouche et al. 1990, Wang et al. 2008), Smr (Lyon and Skurray 1987), QacG (Heir et al. 1999) and QacH (Heir et al. 1998), and in Gram-negative bacteria such as Pseudomonas aeruginosa, with MexAB-OprM, MexCD-Opr], MexEF-OprN and MexJK (Chuanchuen et al. 2002, Morita et al. 2003, Poole 2004, Schweizer 1998) and Escherichia coli with AcrABTolC, AcrEF-TolC and EmrE (McMurry et al. 1998a, Moken et al. 1997, Nishino and Yamagushi 2001, Poole 2004).

The enzymatic transformation of biocides has also been described as a resistance mechanism in bacteria, notably to heavy metals (e.g. silver and copper; enzymatic reduction of the cation to the metal, Cloete 2003); parabens (Valkova et al. 2001), aldehydes (formaldehyde dehydrogenase, Kummerle et al. 1996), peroxygens (catalase, super oxide dismutase and alkyl hydroperoxidases mopping up free radicals, Demple 1996). Environmental bio-degradation of various compounds has been well-described notably among Pseudomonads and complex microbial communities. However, the importance of degradation as a bacterial resistance mechanism to "in use" concentrations (high concentrations) of biocides remains unclear. As for efflux, increased resistance following degradation of biocides has been measured as an increase in MICs but not necessarily as a decreased in lethal activity.

The modification of target sites has been described on rare occasions and does not seem to be widespread among bacteria, although there is a paucity of information on this subject. The bisphenol triclosan has been shown to interact specifically with an enoyl-acyl reductase carrier protein at a low concentration (Heath et al. 1999, Levy et al. 1999, Roujeinikova et al. 1999, Stewart et al. 1999). The modification of this enzyme has been associated with low-level bacterial resistance (Heath et al. 2000, McMurry et al. 1999, Parikh et al. 2000). It has been noted that at a high concentration triclosan must interact with other targets within the cell, the alteration of which justified the lethal effect of the bisphenol (Gomez Escalada et al. 2005b).

\subsubsection{Mechanisms of acquired bacterial resistance to biocides}

The development of bacterial resistance through acquired mechanisms such as mutation and the acquisition of resistant determinants are of concern since a bacterium that was previously susceptible can become insusceptible to a compound or a group of compounds (Russell 2002a). The acquisition of resistant genes has been well described in the literature (Chapman 2003, Lyon and Skurray 1987, Silver et al. 1989, White and McDermott 2001) and it is particularly important to consider this as it might confer cross- 
or co-resistance on occasion (Bjorland et al. 2001, Chapman 2003, Kücken et al. 2000, Poole 2004).

However, there is little information on the effect of biocides on the transfer of genetic determinants. One study in particular highlighted that while some biocides at a subinhibitory (residual) concentration could inhibit genetic transfer, others increased genetic transfer efficiency (Pearce et al. 1999).

There have been some investigations on co-transfer of resistant markers in epidemic methicillin-resistant $S$. aureus following antibiotic treatment to decolonise patients (Cookson et al. 1991a). The authors reported that there was no evidence of increase in chlorhexidine MICs six years after the first isolation of the epidemic strains, although the strain carried a qac gene (Cookson 2005). However, this was not the case with triclosan, where clinical isolates of $S$. aureus showed high-level mupirocin resistance and low-level triclosan resistance (MIC 2-4 mg/L) (Cookson et al. 1991b). The authors described that resistance to both chemically unrelated compounds was transferred and cured together (Cookson 2005). Table 8 summarises the main bacterial mechanisms of resistance to biocides.

Table 8 Bacterial mechanisms of resistance to biocides

\begin{tabular}{|c|c|c|c|}
\hline Mechanisms & Nature & $\begin{array}{c}\text { Level of } \\
\text { susceptibility to } \\
\text { other biocides }^{1}\end{array}$ & $\begin{array}{c}\text { Cross- } \\
\text { resistance }\end{array}$ \\
\hline Permeability & intrinsic (acquired) & no & yes \\
\hline Efflux & intrinsic/acquired & reduced & yes \\
\hline Degradation & acquired/intrinsic & reduced & no \\
\hline Mutation (target site) & acquired & reduced & $\mathrm{no}^{2}$ \\
\hline Phenotypic change & Following exposure & reduced & yes \\
\hline Induction (stress response) & Following exposure & variable & yes \\
\hline
\end{tabular}

${ }^{1}$ to other biocides - level of susceptibility defined according to the concentration of biocides

2 not to other biocide, but cross-resistance with specific antibiotics

\subsubsection{Expression of genes conferring resistance}

The induction of bacterial resistance mechanisms following exposure to a low concentration of a biocide has been reported in a number of studies. The mechanisms involved include the over-expression of efflux pumps (Gilbert et al. 2003, Maira-Litrán et al. 2000, Randall et al. 2007), the over-expression of multigene systems such as soxRS and oxyR (Dukan and Touati 1996) and the production of guanosine 5'-diphosphate 3'diphosphate (ppGpp) (Greenway and England 1999) (see Table 9).

These mechanisms are parts of the stress-response systems in bacteria, for which more evidence is available in the literature. A decrease in growth rates and altered gene expression in Escherichia coli have been described (Brown and Williams 1985, Ma et al. 1994, Wright and Gilbert 1987) following stress conditions. Exposure to isothiazolones induced the reorganisation of metabolic processes in Pseudomonas aeruginosa (Abdel Malek et al. 2002). Moken et al. (1997) described the induction of the MDR phenotype and its relevance to cross-resistance between pine oil, triclosan and multiple antibiotics. More recently, Webber et al. (2008) showed that triclosan resistance in Salmonella Typhimurium can occur via distinct pathways (overexpression and mutagenesis of fab1; active efflux via $A c r A B-T o l C)$, and that mutants selected after a single exposure to triclosan are fit enough to compete with wild-type strains. Interestingly, within bacterial biofilms, triclosan also up-regulated the transcription of $a c r A B$, a gene encoding for the 
main efflux pump in Gram negative bacteria, of marA, the major regulator of the genetic cascade controlling multi-drug resistance and of the cellulose-synthesis coding genes bCSA and bcsE. Therefore, when present within biofilms, Salmonella can drastically alter its membrane permeability via decrease of porin synthesis, increased efflux and enhanced exopolysaccharides production (Tabak et al. 2007). This alteration of membrane permeability may induce a serious decrease of the susceptibility to various antimicrobial molecules including biocides and antibiotics.

In some circumstances, a specific mechanism has not been established and a phenotypic change leading to the emergence of resistance to several unrelated compounds in vitro has been reported following exposure to a low concentration of a biocide (Chapman 2003, Thomas et al. 2005, Walsh et al. 2003). The treatment of E. coli with PHMB induced the alteration of transcriptional activity in a number of genes, notably in the rhs gene involved in repair/binding of nucleic acid (Allen et al. 2006). Exposure to an oxidising biocide produced an alteration of protein expression in resistant $S$. enterica mutants consistent with the production of a stress response and in particular the expression of detoxifying enzyme. Exposure to phenol-based disinfectant also produced a change in protein expression consistent with the expression of an efflux pump system (Randall et al. 2007).

Quorum sensing might also have a role in the establishment of a resistant phenotype (Davies et al. 1998, Hassett et al. 1999, Shih and Huang 2002), although this might be biocide specific. MacLehose et al. (2004) provided evidence that homoserine lactone (HSL) mediated quorum sensing was not involved in Ps aeruginosa biofilm susceptibility to QAC and chlorhexidine, but could be involved with bronopol. Further evidence of the role of quorum sensing in the development of resistance is necessary (MacLehose et al. 2004).

\subsubsection{Resistance to biocides in specific applications}

\subsubsection{Resistance to biocides used in health care}

As early as 1966, bacterial resistance in Gram-negative bacilli to silver used in compresses in burn wounds was reported (Bridges et al. 1977, Cason et al. 1966, Klasen 2000, Moyer et al. 1965). In 1968, complications associated with silver nitrate compresses led to the use of silver sulphadiazine (silver combined with a sulphonamide) (Klasen 2000). In the 1970s, there were several reports of outbreaks of burn wound infection or colonisation by Gram-negative isolates resistant to silver sulphadiazine (Enterobacter cloacae) (Gayle et al. 1978), Providencia stuartii (Wenzel et al. 1976), Pseudomonas aeruginosa (Klasen 2000) and to silver nitrate (Pseudomonas aeruginosa) (Bridges et al. 1979), Salmonella Typhimurium) (McHugh et al. 1975). However, Percival et al. (2005) questioned the possibility of increasing silver resistance linked to an increase in antibiotic resistance in wound care. The induction of bacterial resistance has been decribed in almost all biocides, particularly in the less reactive ones such as quaternary ammonium compounds, bisbiguanides and phenolics, but also in the more reactive ones such as glutaraldehyde.

However, unlike antibiotic resistance, the issues relating to biocide resistance are considered to have a very low profile and priority (Cookson 2005). Despite the widespread use of disinfectant and antiseptic in health care settings, acquired resistance to current disinfectants in bacteria isolated from clinical specimens or the environment has rarely been well characterised. Emerging bacterial resistance to biocides has been well decribed in vitro; but evidence in practice is lacking (Cookson 2005, Maillard 2007, Russell 2002a, Weber and Rutala 2006).

Isolates with reduced susceptibility remain susceptible to clinically used concentrations of the disinfectants (Lear et al. 2006); the concentrations of disinfectants and antiseptic used in practice are substantially higher than the MICs of strains with reduced 
susceptibility (Weber and Rutala 2006). This finding is in constrast with antibiotic resistance, which has emerged over time, rendering a number of antibiotics clinically unusable.

However, after initial findings that the use of mupirocin resulted in a decolonization of patients carrying methicillin-resistant Staphylococcus aureus (MRSA), further studies were performed. Not only did they describe the appearance of mupirocin resistance of certain MRSA strains but also showed that MRSA strains carried a quaternary ammonium resistance gene ( $q a c A)$ located in a gentamicin resistance plasmid that encoded for an efflux mechanism resulting in low-level chlorhexidine resistance (Cookson et al. 1991a). Moreover, transferable triclosan resistance in MRSA has been described, occurring together with a high-level of mupirocin in a hospital environment (Cookson et al. 1991b).

These few data indicate a need for further investigations on the long-term use of biocides in hospital environments and the relation to resistance against antimicrobial agents (Cookson et al. 2005). Stickler and Jones (2008) described the possibility of emerging triclosan resistance in Proteus mirabilis and suggested that urinary flora of catheterized patients should be monitored for Proteus mirabilis strains with reduced susceptibility to triclosan in any clinical trial or subsequent clinical use of triclosan for the prevention of urinary catheter encrustation and blockage.

\subsubsection{Resistance to biocides used in consumer products}

Flores et al. (1997) isolated several bacterial strains resistant to a number of commonly used preservatives/biocides in cosmetic products. The bacterial strains isolated from the contaminated cosmetic products and their resistance to specific biocides are described in Table 9. It was also demonstrated that safe preservation of cosmetic products requires a mixture of biocides. The effect of these resistant bacteria has been only investigated for the deterioration of the cosmetics, but not for pathogenicity.

In another study, biocide resistant strains of Enterobacter gergoviae (Davin-Regli et al. 2006) and Pseudomonas aeruginosa were isolated from contaminated cosmetics and from the floors of the washing area of industrial plants for the manufacture of cosmetics (Ferrarese et al. 2003). It appeared that the extensive use of some biocides for preservation (parabens; formaldehyde; formaldehyde releasers, imidazolidinyl urea and 1,3-Dimethylol-5,5-dimethyl (DMDM) hydantoin; and phenoxy ethanol) had lead to the development of the resistant strains. These strains were responsible for the deterioration of the cosmetics. Pseudomonas aeruginosa is also isolated from different aqueous solutions including cosmetics, disinfectants, ointments, soaps, vaginal irrigations, eye drops and dialysis equipment and fluids (Morrison and Wenzel 1984, Na'was and Alkofahi 1994). As a result of the development of bacteria resistant to specific biocides, a mixture of biocides is commonly used for the safe preservation of cosmetics. This means that the consumer is exposed to more biocides, both qualitatively and quantitatively. It was shown that Pseudonomas aeruginosa isolated from cosmetics and several other types of products is pathogenic and resistant to several types of antibiotics (Scully et al. 1986).

On the other hand, Cole et al. (2003) claimed after a study on 1238 isolates collected from the homes of antibacterial product users and non-users, that the results showed a lack of cross-resistance to antibiotic and antibacterial agents in target bacteria, as well as increased prevalence of potential pathogens in the homes of non-users. It should be noted that in this study, the isolates were selected based on their antibiotic resistance and then tested for their biocide insusceptibility. With our current state of knowledge, it is generally accepted that antibiotic resistance in clinical isolates is not necessarily associated with resistance to biocides.

Meanwhile the large use of triclosan in many home and personal-care products including deodorants, soaps, oral rinces, toothpaste and cutting boards may be associated with the decreased susceptibility to triclosan in clinical specimens of $S$. aureus (Bamber and Neal 1999, Suller and Russel 2000). Investigators have also reported increased tolerance to triclosan due to mutations in efflux pumps of $E$. coli and $P$. aeruginosa, or in $M$. 
smegmatis (see review of Weber and Rutala 2006). Bacillus, Micrococcus and Staphylococcus were able to contaminate cosmetics protected with preservatives like parabens and phenoxy-ethanol (Flores and al. 1997).

In the laboratory, it has been possible to develop bacterial mutants with reduced susceptibility to disinfectants that also demonstrate decreased susceptibility to antibiotics. Similarly, wild-type strains with reduced susceptibility to disinfectants (principally quaternary ammonium compounds and triclosan) have been reported.

Therefore, there is accumulating evidence that biocide resistant bacteria can be found in consumer products, but to date there are no studies to indicate that they are linked to antibiotic resistance and/or the emergence of pathogenic microorganisms.

Table 9 Bacteria isolated from contaminated cosmetic products and their resistance to biocides (Flores et al. 1997)

\begin{tabular}{|l|c|c|c|c|c|c|}
\hline \multirow{2}{*}{ Bacteria } & \multicolumn{6}{|c|}{ Bacterial growth detected in the presence of biocides } \\
& \multicolumn{7}{|c|}{$\begin{array}{l}\text { Methyl } \\
\text { Paraben } \\
0.3 \%\end{array}$} & $\begin{array}{l}\text { Ethyl } \\
\text { Parabentration } \% \text { w/v) } \\
0.2 \%\end{array}$ & $\begin{array}{l}\text { Propyl } \\
\text { paraben } \\
0.2 \%\end{array}$ & $\begin{array}{l}\text { Butyl } \\
\text { paraben } \\
0.15 \%\end{array}$ & $\begin{array}{l}\text { Imidazoli- } \\
\text { dinnyl urea } \\
0.3 \%\end{array}$ & $\begin{array}{l}\text { Phenoxy } \\
\text { ethanol } \\
0.4 \%\end{array}$ \\
\cline { 2 - 8 } $\begin{array}{l}\text { Staphylococcus } \\
\text { aureus }\end{array}$ & + & + & + & - & - & + \\
\hline S. saprophyticus & + & + & + & & - & + \\
\hline S. epidermidis & + & + & - & - & - & + \\
\hline $\begin{array}{l}\text { Micrococcus } \\
\text { kristinae }\end{array}$ & + & - & - & - & - & + \\
\hline $\begin{array}{l}\text { M. nishinamiyaens- } \\
\text { is }\end{array}$ & + & - & + & + & - & + \\
\hline M. sedentarius & + & - & + & - & - & + \\
\hline M. roseus & + & - & - & - & - & + \\
\hline Bacillus badius & + & + & - & - & - & + \\
\hline B. brevis & + & - & - & - & - & + \\
\hline B. circulans & + & - & - & - & - & + \\
\hline B. coagulans & + & + & - & - & - & + \\
\hline B. megaterium & + & + & + & + & - & + \\
\hline B. lentus & + & - & - & - & - & + \\
\hline B. polimyxa & + & + & - & - & - & + \\
\hline B. pumilus & + & - & + & - & - & + \\
\hline
\end{tabular}

+ bacterial growth; - no bacterial growth

\subsubsection{Resistance to biocides used in food production}

Despite the widespread use of biocides in food production, data on resistance to biocides in microorganisms isolated in the plant or in the finished product are scarce. Meanwhile, there is some evidence of acquisition of a tolerance (if not resistance) for food-borne pathogens. Mokgatla et al. $(1998,2002)$ described a Salmonella strain growing in the presence of $28 \mathrm{mg} / \mathrm{L}^{-} \mathrm{HOCl}$ that was protecting itself by decreasing the level of species that could react with $\mathrm{HOCl}$ to generate toxic reactive oxygen radicals and by improving 
DNA damage repair mechanisms. These results are in agreement with the data of Aarestrup and Hasman (2004) who found that the use of chlorine might select resistant Salmonella bacteria.

Potenski et al. (2003) described mutants of Salmonella enteritidis selected following exposure to chlorine or sodium nitrite, sodium benzoate or acetic acid showing resistance to multiple antibiotics (tetracycline, chloramphenicol, nalidixic acid, ciprofloxacine), suggesting the mar operon mutation was responsible for resistance.

A recent study carried out by by Capita (2007) demonstrated that the use of acidified sodium chlorite may induce the selection in different serotypes of Salmonella a resistance against this biocide and a cross resistance to various antibiotics. This is also in accordance with the study of Oren-Gradel (2005) on the possible association between Salmonella persistence in poultry houses and resistance to commonly used disinfectants and a mutative role of the mar operon.

\subsubsection{Resistance to biocides used in animal husbandry}

Given the increasing use of biocides in animal facilities, there are more and more concerns that they may select for resistant pathogens. However, while numerous investigations addressed the appearance of antimicrobial resistance following the use of antibiotics in farm animals (EFSA 2007), data relating the occurrence of resistance to the use of disinfectants are limited.

Gradel et al. (2005) tested MIC values against five commercial disinfectants (formaldehyde, glutaraldehyde/benzalkonium chloride, an oxidizing compound (non specified), tar oil phenol, and an iodophor) commonly used in poultry premises in Denmark on nine different serotypes of Salmonella isolated from different poultry farms. No significant differences could be established between MICs from flocks using or not using a certain disinfectant. Adaptation and de-adaptation studies revealed mutants highly resistant to triclosan (mar-type resistance) but comparable results were not obtained for the five used disinfectants. The authors concluded that even the adaptation and de-adaptation experiments could not demonstrate altered MICs to the five disinfectants regularly used on poultry farms.

Comparable investigations were conducted by Randall et al. (2007). They studied particularly the susceptibility of Salmonella enteritica var Typhimurium isolates comprising wild-type and laboratory mutants that were exposed to a tar oil phenol, an oxidising compound or a dairy steriliser disinfectant (quaternary ammonium biocide). They could show that exposure to these disinfectants could induce the expression of $A c r A B$ and TolC efflux pumps, but that a single exposure was insufficient to select for mar-strains, associated with a reduced susceptibility to antibiotic such as B-lactams, chloramphenicol, fluoroquinolones and tetracyclines, and increased tolerance to organic solvents and decreased susceptibility to disinfectants such as pine oil (Baucheron et al. 2005, Randall and Woodward 2002).

Earlier studies of Oethinger et al. (1998) had shown an association between cyclohexane tolerance and fluoroquinolones resistance in clinical isolates of E.coli. An association between cyclohexane resistance in Salmonella of different serovars isolated from animal facilities (as well as from human hospitals) and an increased resistance to multiple antibiotics, disinfectants (ethidium bromide, cetrimide, cyclohexane, triclosan) and dyes (acridine orange) was also described by Randall et al. (2001). Ninety-five percent of the cyclohexane-resistant strains isolated originated from poultry, but originated from only one turkey-rearing company, and hence might not be representative. The cyclohexaneresistant strains were also significantly more resistant to triclosan and cetrimide than the cyclohexane-susceptible strains. An overall finding was that that the resistance to antibiotics and disinfectants is consistent with the over-expression of AcrAB, as described by other authors for E. coli (Ma et al. 1996, Moken et al. 1997). 
Recent investigations from Thailand (Chuanchuen et al. 2008) showed a high prevalence of antibiotic resistance in Salmonella enterica isolated from poultry and swine, but only very few variations of MICs to all disinfectants tested. Only $1.9 \%$ of the isolates were tolerant to cyclohexane. A recent study investigating the effect of cleaning and disinfection procedures in poultry slaughterhouses on the development of, or selection for biocide and antibiotic resistance in Campylobacter jejuni and C. coli showed that a very low number (1-2) of genotypes were recovered after cleaning and disinfection and that there was no increase in antibiotic resistance before and after exposure to the disinfection procedures (Peyrat et al. 2008). In two recent studies, Salmonella exposed to a range of common farm disinfectants was found to develop a low, but statistically significant, increased risk of selection of mutants with reduced susceptibility to ampicillin, ciprofloxacin and tetracycline. Some of the mutants selected were of the MDR phenotype (Karatzas et al. 2007; Karatzas et al. 2008).

In conclusion, there is understandable concern that the improper use of biocides in primary animal production could select for antibiotic-resistant bacteria. Indeed, laboratory-based studies have shown that this can occur, particularly when exposure to sub-optimal biocide concentrations is either prolonged or repeated. However, so far, these observations are not largely supported by field studies. There is a need to establish whether current cleaning and disinfection regimes in use in food animal production in the EU represent a real hazard with respect to the selection of antibiotic-resistant human and/or animal pathogens.

\subsubsection{Resistance to biocides used in foods of animal origin}

As mentioned above (see section 3.3.5), biocides may be used (and are already used in many third countries) for the disinfection and decontamination of foods of animal origin. There is a need to generate more data on the occurrence of biocidal-resistant bacteria on carcass surfaces and on foods of animal origin.

\subsubsection{Resistance to biocides that occur in the environment}

Laboratory experiments have demonstrated that biocides, present at low concentrations in the environment after use and discharge, may lead to an increased selective pressure towards disinfectant and antibiotic resistance. Thus, the study of Randall et al. (2004) performed with triclosan and a phenolic farm disinfectant illustrated that Salmonella enterica was able to tolerate relatively high concentrations of disinfectants and to develop cross-resistance to certain antibiotics.

The study from McBain et al. (2003b) on the microbial population dynamics and antimicrobial susceptibility during exposure of sink drains microcosms to triclosan, clearly demonstrated that triclosan exposure did not significantly lower total counts of drain biofilm bacteria but dynamically altered the bacterial composition. This change in population was caused by innate resistance or insusceptibility of some species able to degrade triclosan. Most importantly, the authors noted that the antibiotic susceptibility profile was not affected.

Lear et al. (2002) isolated many intrinsically resistant bacteria from factory settings where triclosan and chloroxylenol were produced. A small number of non Pseudomonads isolates (Acinetobacter and Citrobacter) from the same samples demonstrated an increased insusceptibility to triclosan but remained susceptible to its in-use concentration. However, these environmental bacterial isolates exposed to the biocide showed resistance to some unrelated antibiotics (Lear et al. 2006).

A number of papers have investigated antibiotic resistant bacterial strains in hospital wastewater (Baquero et al. 2008, Kümmerer 2004), where high concentrations of antibiotics and disinfectants are found. However, to date, no study seems to have focused on the emergence of biocide resistant bacteria in hospital environments other than wastewater. 


\subsection{Bacterial resistance mechanisms}

\subsubsection{Resistance mechanisms to antibiotics}

Resistance to antibiotics may result from innate (intrinsic) or acquired mechanisms.

Intrinsic resistance is a trait of a bacterial species. For example, the target of the antimicrobial agent may be absent in that species, the cell envelope (cell membranes and peptidoglycan) may have poor permeability for certain types of molecules or the bacterial species may produce enzymes that destroy the antimicrobial agent. These bacteria are clinically resistant, but should more accurately be referred to as "unsusceptible", as it is often merely a matter of increasing the concentrations of the antimicrobial agent to levels that may never be reached during therapy, or only at certain sites.

A bacterial strain can acquire resistance either by mutation or by the uptake of exogenous genes by horizontal transfer from other bacterial strains. Genes encoding enzymes that can modify the structure of an antimicrobial are commonly transferable (penicillinases and cephalosporinases (bla-genes), acetyl transferases modifying e.g. aminoglycosides (aac-genes), as are genes leading to target modification (erm-genes), methicillin-resistance (mecA-genes) and glycopeptide-resistance (van-genes). There are several mechanisms for horizontal gene transfer, mainly based on mobile genetic elements, which often function in concert (Dobrindt 2004). Large plasmids with many different genes can be transferred from bacterium to bacterium by conjugation. Transposons can carry several resistance genes. They cannot replicate by themselves, but can move within the genome, e.g. from plasmid to plasmid or from chromosome to plasmid. Integrons can also encode several resistance genes. They cannot move by themselves, but encode mechanisms both to capture new genes and to excise and move cassettes with genes within and from the integron. Integrons are commonly carried on plasmids (EFSA, 2005), but may also be chromosomally-integrated such as in Salmonella Typhimurium DT 104.

\subsubsection{Antibiotics, targets and activities}

The diverse antibiotic molecules used during antibiotherapy of bacterial infections may be classified according to their mechanism of action on bacterial cell. There are 4 major mechanisms: (1) alteration of cell envelope, (2) inhibition of protein synthesis, (3) inhibition with nucleic acid synthesis, and (4) inhibition of a metabolic pathway (see Table 10).

The B-lactams (penicillins, cephalosporins, carbapenems, etc), polymyxins, CAMPs and glycopeptides (vancomycin and teicoplanin) work by perturbing the bacterial cell wall synthesis or the membrane stability/integrity. B-lactam molecules block synthesis of the bacterial cell wall by interfering with the enzyme activity involved in the final step of peptidoglycan synthesis. Polymyxins and cationic antimicrobial peptides exert their inhibitory effects by increasing bacterial membrane permeability, causing leakage of bacterial contents (ions, ATP etc.). The cyclic lipopeptide daptomycin induces depolarisation of the outer membrane and subsequent cell death by inserting its lipid part into bacterial membrane. Vancomycin and teicoplanin interfere with the final crosslinking steps of pentapeptide units during cell wall synthesis preventing stable cell wall synthesis. 
Table 10 Mechanisms of action of antibiotics

\begin{tabular}{|c|c|c|c|c|}
\hline \multirow{2}{*}{ Action } & $\begin{array}{c}\text { Alteration of } \\
\text { bacterial } \\
\text { envelope }\end{array}$ & $\begin{array}{c}\text { Inhibition of } \\
\text { protein } \\
\text { synthesis }\end{array}$ & $\begin{array}{c}\text { Inhibition of } \\
\text { nucleic acid } \\
\text { synthesis }\end{array}$ & $\begin{array}{c}\text { Inhibition of } \\
\text { metabolic } \\
\text { pathway }\end{array}$ \\
\hline \multirow{4}{*}{$\begin{array}{c}\text { Antibiotam } \\
\text { family }\end{array}$} & Mlycopeptide & Phenicol, & $\begin{array}{c}\text { Ruinolone } \\
\text { Ansamycine, }\end{array}$ & Sulfamide \\
\cline { 2 - 5 } & $\begin{array}{c}\text { Polymyxin, } \\
\text { daptomycin }\end{array}$ & Oxazolidinone & & Nitro-imidazole \\
\cline { 2 - 5 } & CAMP & Aminoglycoside & & \\
\cline { 2 - 5 } & & $\begin{array}{c}\text { Cycline } \\
\text { (tetracycline) }\end{array}$ & & \\
\hline
\end{tabular}

MLS: macrolide, lincosamide, streptogramin

CAMP: cationic antimicrobial peptide

Macrolides, aminoglycosides, tetracyclines, chloramphenicol, streptogramins and oxazolidinones inhibit various steps involved in protein synthesis: macrolides, aminoglycosides, and tetracyclines bind to the subunits of the ribosome or to rRNA (e.g. S12 protein, 23S rRNA etc.), whereas chloramphenicol binds to the $50 \mathrm{~S}$ subunit interfering with the translation process.

Fluoroquinolones exert their antibacterial effects by disrupting DNA synthesis and causing lethal double-strand DNA breaks during DNA replication (inhibition of gyrase and topoisomerase activities) whereas sulfonamides and trimethoprim block the pathway for folic acid synthesis, which ultimately inhibits DNA synthesis. The drug combination of TMP, a folic acid analogue, plus sulfamethoxazole (a sulfonamide) inhibits steps in the enzymatic pathway for bacterial folate synthesis.

\subsubsection{Main bacterial mechanisms of antibiotic resistance}

Bacteria may resist antibiotic action by using several mechanisms. Some bacterial species are innately resistant to one class of antibiotics, e.g. bacteria are resistant due to their intrinsic envelope that limits the antibiotic penetration or to the presence of a low level of efflux systems that decrease intracellular antibiotic concentration (Nikaido, 2003; $\mathrm{Li}$ and Nikaido, 2004). In such cases, all strains of that bacterial species are likewise resistant to all the members of those antibacterial classes (see Definition section 3.1.1.1).

An ongoing and increasing concern is bacteria that become resistant: e.g. initially susceptible bacteria become resistant to antibiotics and consequently disseminate under the selective pressure of use of these antibiotics (which kill other competitive bacteria). Several mechanisms of antimicrobial resistance are readily spread to a variety of bacterial genera.

A simple technical definition of the various resistance mechanisms may be proposed for classification: mechanical barrier (altering the required intracellular dose of antibiotic); enzymatic barrier (expression of a detoxifying enzyme that modifymodifies the antibiotic); target protection barrier (mutation or expression of a molecule impairing the antibiotic recognition and activity) (see Table 11 ). 
Table 11 Major resistance mechanisms (Davin-Regli et al. 2008)

\begin{tabular}{|c|c|c|c|c|c|c|}
\hline Mechanism & \multicolumn{2}{|c|}{ Mechanical barrier } & \multicolumn{2}{|c|}{ Enzymatic barrier } & \multicolumn{2}{|c|}{$\begin{array}{c}\text { Target protection } \\
\text { barrier }\end{array}$} \\
\hline $\begin{array}{c}\text { Type of } \\
\text { activity }\end{array}$ & Influx & $\begin{array}{c}\text { Efflux, } \\
\text { active } \\
\text { expel }\end{array}$ & Cleavage & Alteration & $\begin{array}{c}\text { Target } \\
\text { mutation }\end{array}$ & $\begin{array}{c}\text { Protective } \\
\text { molecule, } \\
\text { new } \\
\text { molecules }\end{array}$ \\
\hline $\begin{array}{c}\text { Susceptible } \\
\text { antibiotic }\end{array}$ & $\begin{array}{c}\text { B-lactam, } \\
\text { Quinolone } \\
\text { etc. }\end{array}$ & $\begin{array}{c}\text { B-lactam, } \\
\text { Aminoside } \\
\text { etc. }\end{array}$ & B-lactam & $\begin{array}{c}\text { Phenicol, } \\
\text { aminoside } \\
\text { etc. }\end{array}$ & $\begin{array}{c}\text { Quinolone, } \\
\text { MLS etc. }\end{array}$ & $\begin{array}{c}\text { B-lactams, } \\
\text { quinolone }\end{array}$ \\
\hline
\end{tabular}

\section{Mechanical barrier mechanism}

- Bacteria may modify membrane permeability, such as a decrease of porin content or an alteration of the LPS structure, two responses that prevent the antibiotic access to the target at required concentrations (minimal inhibitory concentration).

- Alternatively or conjointly, bacteria may produce efflux pumps that extrude the antibacterial agent from the cell before it can reach its target site and exert its effect.

\section{Enzymatic barrier mechanism}

- Bacteria may acquire plasmid genes or over-expressed chromosomal genes encoding enzymes that cleave the antibacterial agent before it can have an effect, such as Blactamases, cephalosporinases etc.

- Bacteria may acquire several genes for other modifications of the antibiotic such as acetyltransferase, phosphotransferase etc.

\section{Target protection barrier mechanism}

- Bacteria may protect the antibiotic target by acquiring mutations that strongly decrease the affinity of the antibiotic for the target, by producing mimicked targets that lure antibiotics.

- Bacteria may synthesise a protective molecule masking the target access to antibiotics.

Consequently, susceptible bacteria may exhibit an efficient level of resistance to antibiotics via mutation and selection, by expressing special resistance mechanisms (down-regulation of porins, overproduction of efflux pumps etc.) in response to external stimuli, or by acquiring from other bacteria the genetic information that provides resistance mechanism (e.g. gene for enzyme, efflux transporter). The last event may occur by several genetic mechanisms including transformation, conjugation or transduction.

\subsubsection{Multi-drug resistant bacteria}

Many bacteria have become resistant to multiple classes of antibiotics (at least three unrelated antibiotic classes) and deploy multiple strategies to overcome the stress of antibiotic chemotherapy. Resistance is not necessarily limited to a single class of antibiotics. It can apply, simultaneously, to many chemically unrelated compounds to which the cell has never been exposed: this is termed « multi-drug resistance 》 (MDR).

Today, these MDR bacteria are a cause for serious concern in hospitals and other health care institutions where they are commonly detected. The major mechanism of MDR is the active transport of drugs from the cell to the environment by pumps which expel a broad spectrum of compounds that are noxious to the bacterium (including antibiotics, biocides 
etc.). In addition, the poly-specificity of efflux transporters confers a general resistance phenotype that can reinforce the effect, and/or drive the acquisition of additional mechanisms of resistance such as mutation of antibiotic targets or synthesis of enzymes that alter the drugs.

There is strong evidence for the role of AcrAB-TolC efflux in Enterobacteriaceae: the expression of this efflux pump is an important prerequisite for the selection of fluoroquinolone resistant mutants that exhibit mutated targets (mutation in gyrase and topoisomerase) in various Gram-negative bacteria such as Salmonella or Campylobacter, two major food-borne pathogens (Piddock 2006). These two mechanisms, conjointly expressed, confer a high resistance level against quinolones. Similar synergies have been recently reported for macrolides in Campylobacter and other examples may be mentioned with B-lactams, CAMPs, polymyxins, and Enterobactericeae (Davin-Regli et al. 2008, Piddock 2006).

In all of these cases, strains of bacteria carrying resistance factors are selected by the use of antimicrobial molecules which kill the susceptible strains but allow the newly resistant strains to survive and grow. Acquired resistance due to chromosomal mutation and selection is termed vertical evolution since the advantage will be conferred to a bacterial line. Bacteria also develop resistance through the acquisition of new genetic material from other resistant organisms. This is termed horizontal transfer, and may occur between strains of the same species or between different bacterial species or genera sharing a same ecological niche. Mechanisms of genetic exchange include conjugation, transduction, and transformation. For each of these processes, transposons facilitate the transfer and incorporation of the new resistance genes into the genome of the bacterial host or into plasmids.

\subsubsection{Common resistance mechanisms}

Considerable controversy surrounds the use of biocides in an ever increasing range of consumer products and the possibility that their indiscriminate use might reduce biocide effectiveness and alter susceptibilities towards antibiotics (Aiello et al. 2005, Aiello et al. 2007, Braoudaki and Hilton 2004b, Gilbert and McBain 2003, McBain et al. 2002, McBain et al. 2003, Pumbwe et al. 2007, Russell 2004a and b, Weber and Rutala 2006). These concerns have been based largely on the isolation of resistant mutants from in vitro monoculture experiments. Some of the evidence suggests that exposure to biocides may be leading to increased antibiotic resistance, but the number of studies in the clinical or environmental setting is low. However, a recent study performed in the community highlighted a significant relationship between high QAC MICs, high MICs to triclosan and resistance to one or more antibiotics (Carson et al. 2008).

Further research is needed to establish a correlation between biocide exposure(s) and development of antibiotic resistance. Biocides tend to act concurrently on multiple sites within the microorganism, and thus resistance is often mediated by non-specific means. Efflux pumps have been shown to act on a range of chemically dissimilar compounds and have been implicated in both biocide and antibiotic resistant bacteria (Maillard 2007, Poole 2007,). Cell wall changes by reducing permeability may also play a role in the observed resistance to biocides. The possibility of genetic linkage between genes for biocide resistance and for antibiotic resistance has also been described (Fraise 2002).

\subsubsection{Biocides and antibiotics share common resistance mechanisms}

Several publications and reviews have presented the cell target of biocides and the various mechanisms used by the bacterial cell to evade the toxic activity of biocides (for recent reviews see Denyer and Maillard 2002, Gilbert and Moore 2005, Lambert 2002, Lambert 2004, Maillard 2002, Maillard 2007, Poole 2004, Stickler 2004). It is important 
to note that antibiotic and biocide antibacterial actions show many similarities despite some differences in terms of target, killing, behaviour and clinical aspects (Poole 2007). Among the similarities, we can mention (i) the penetration/uptake through bacterial envelope by passive diffusion, (ii) the effect on the membrane integrity and morphology, (iii) the effect on diverse key steps of bacterial metabolism (replication, transcription, translation, transport, various enzymes). Faced with this toxic effect and stress, the response/adaptation of bacterial cells presents some similar defence mechanisms that can overlap the original functions to confer resistance against structurally non-related molecules. Among the biocide resistance strains intrinsic and acquired mechanisms are described (see section 3.1.3).

Intrinsic resistance is an innate property conferred by the bacterial genome (speciesdependant) and includes impermeability, efflux, biofilms and transformation of toxic compounds. To decrease the intracellular concentration of noxious molecules, Gramnegative bacteria can regulate the permeability of their membranes by decreasing the synthesis of porins (membrane pore-forming proteins involved in antibiotic uptake) and modifying the lipopolysaccharide structure (Nikaido 2003, Poole et al. 2002a) or overexpressing the efflux pumps (membrane proteinous complexes involved in antibiotic expulsion) (Poole 2007). These strategies are involved in the resistance against antibiotics and biocides (Thorrold et al. 2007). In parallel, the acquired resistance occurs via mutation and acquisition of mobile DNA (transposon, plasmids) coding for resistant elements (enzyme, transporter).

Similarly, the acquired processes may protect against antibiotics and biocides (Maillard 2007). In addition, some of the mechanisms that play a major role in resistance are controlled by diverse genetic cascade regulations that share common gene regulators (soxS, marA) (Poole 2007).

\subsubsection{Bacterial biofilms and resistance}

In practice, most bacteria are associated with surfaces and grow as biofilm rather than as planktonic cells. Bacterial biofilms have been consistently described as being more resistant to biocides and antibiotics than planktonic cells (Bisset et al. 2006, Gilbert et al. 2003, Maira-Litrán et al. 2000, Smith and Hunter 2008). The reasons for this decrease in susceptibility is a biofilm-associated phenotype (Ashby et al. 1994, Brown and Gilbert 1993, Das et al. 1998), including decreased metabolism, quiescence, reduced penetration due to the extracellular polymeric matrix (Pan et al. 2006), enzymatic inactivation of biocides (Giwercman et al. 1991, Huang et al. 1995, Sondossi et al. 1985), and the induction of multi-drug resistant operons and efflux pumps (Maira-Litrán et al. 2000).

Although bacteria within biofilms are undeniably more resistant to biocides and antibiotics, the link between the uses of biocides against bacterial biofilm and potential emerging antibiotic resistance is not straightforward. In a recent study investigating the use of chloraminated drinking water against Ps. aeruginosa biofilm, there was no evidence that the use of chloramine induced an increase in antibiotic resistance (Jurgens et al. 2008).

\subsubsection{Induction of antibiotic resistance by biocide molecules}

A key question is whether the use of biocides facilitates the selection of antibiotic resistant bacteria. It is quite difficult to obtain a clear response considering that (i) the only available data focus on specific molecules or specific bacteria and (ii) there is always a difference between the in vitro and in vivo analyses. However, some published data concerning the relationships between antibiotic resistance and biocide resistance can be mentioned.

Recent studies carried out on two important pathogens, Salmonella enterica and Stenotrophomonas maltophila described the effect of the bisphenol triclosan on emerging bacterial cross-resistance. In the first work concerning Salmonella, the authors reported 
that triclosan-selected strains are less susceptible to antibiotics than the wild type original strain (Karatzas et al. 2007). The overexpression of an efflux pump (SmeDEF), involved in antibiotic resistance, is demonstrated in the various triclosan-selected clones (Sánchez et al. 2005). A more recent study described the survival of $S$. enterica serovar Typhymurium following exposure to various disinfectants at a low concentration on the resulting changes in antibiotic profile (Randall et al. 2007). They concluded that growth of Salmonella with sub-inhibitory concentrations of biocides favours the emergence of strains resistant to different classes of antibiotics. In Stenotrophomonas, the authors analysed the effect of triclosan and phenolic farm disinfectants on the selection of antibiotic derivative strains (Sánchez et al. 2005). Other investigations described Pseudomonas aeruginosa overexpressing multi-drug efflux systems during exposure to chlorhexidine (Fraud et al. 2008). In the same way, the exposure of clinical isolates of Staphylococcus aureus results in the selection of strains which over-express several resistance genes (Huet et al. 2008).

Similar results have been reported with $S$. enterica and Escherichia coli (Braoudaki and Hilton 2004a). E. coli 0157 strains, involved in the hamburger disease, acquired highlevels of resistance to triclosan after only two sublethal exposures and when adapted, repeatedly demonstrated decreased susceptibilities to various antibiotics, including chloramphenicol, erythromycin, imipenem, tetracycline, and trimethoprim, as well as to a number of biocides. These observations raise concerns over the indiscriminate and often inappropriate use of biocides, especially triclosan, in situations where they are unnecessary, whereby they may highlight their potential role in contributing to the development of microbial resistance mechanisms. Moreover, a well-conducted study demonstrated that biocide (i.e. polyquaternium-1) and antibiotic resistance mechanisms were linked at the genetic level (Codling et al. 2004). A transcriptional study has demonstrated that paraquat is able to induce the expression of several genes involved in antibiotic resistance (Pomposiello et al. 2001).

\subsubsection{Regulation pathway and overlap between biocides and antibiotics: the sox regulon}

In E. coli, and S. enterica, mar and sox regulons play a key role for the induction of multi-drug resistance (Levy 2002, Poole 2007). The soxS protein is the direct activator of genes for resistance to both oxidants and antibiotics. In laboratory strains of $E$. coli and $S$. enterica, activation of the soxRS regulon with paraquat treatment increased resistance to ampicillin, nalidixic acid, chloramphenicol, and tetracycline. Moreover, the soxRS regulon was also connected to antibiotic resistance in clinical strains (Koutsolioutsou et al. 2005). Constitutive soxS expression contributed significantly to the quinolone resistance of an $S$. enterica clinical isolate, caused by a soxR mutation (repressor of sox regulon) that evidently arose during clinical treatment.

Sixteen per cent of fluoroquinolone-resistant, organic solvent-resistant clinical $E$. coli isolates exhibited constitutive soxS expression. Twenty-eight per cent of fluoroquinoloneresistant clinical and veterinary $E$. coli isolates exhibited constitutively elevated soxS expression. This moderate, multiple-antibiotic resistance is a hallmark of soxRS-mediated mechanisms that are involved in biocide and antibiotic resistance. This overlap is of interest when a bacterial strain (potential nosocomial pathogen) is exposed to biocides.

\subsection{Linkage between biocides usage and antibiotic resistance}

\subsubsection{Laboratory/in vitro}

There have been a number of laboratory-based investigations describing a possible linkage between biocide use and antibiotic resistance (Akimitsu et al. 1999, Braoudaki and Hilton 2004a, Braoudaki and Hilton 2004b, Chuanchuen et al. 2001, Russell et al. 1998, Tattawasart et al. 1999, Walsh et al. 2003). This concept is not novel and a 
number of studies indicate the possibility for such linkage following exposure to various biocides such as the bisphenol triclosan (Braoudaki and Hilton 2004a, Braoudaki and Hilton 2004b, Chuanchuen et al. 2001, McMurry et al. 1998a, Moken et al. 1997, Sánchez et al. 2005), the biguanide chlorhexidine (Kõljalg et al. 2002, Russell et al. 1998, Tattawasart et al. 1999), and quaternary ammonium compounds (Akimitsu et al. 1999, Walsh et al. 2003). In many laboratory-based studies, similar mechanisms have been implicated in resistance linkage such as impermeability (Tattawasart et al. 1999a), multi-drug efflux pumps (Levy 1992, Moken et al. 1997, Noguchi et al. 2002, Randall et al. 2007, Schweizer 1998, Zgurskaya and Nikaido 2000), over expression of multigene components or operons (Levy 1992) such as mar (McMurry et al. 1998b, Moken et al. 1997), soxRS and oxyR (Dukan and Touati 1996, McMurry et al. 1998a, Wang et al. 2001), and the alteration of a target site (McMurry et al. 1999).

The selective pressure exerted by exposure to biocides has been associated with the increasing incidence of resistance to antibiotics. For example, the use of cationic biocides has been blamed for the spread of the qac genes and thus for the widespread occurrence of multi-drug efflux pumps (Heir et al. 1998, Heir et al. 1999, Mitchell et al. 1998; Paulsen et al. 1996a, Paulsen et al. 1996b, Sundheim et al. 1998). Chlorination has been associated with a higher incidence of antibiotic resistance (Murray et al. 1984) and a number of studies have claimed a direct link between biocide exposure and antibiotic resistance (Aiello and Larson 2003, Akimitsu et al. 1999, Kunonga et al. 2000, Levy 2000, Moken et al. 1997). Another study showed that a single exposure to the preservatives sodium nitrite, sodium benzoate or acetic acid induced bacterial resistance to multiple antibiotics (tetracycline, chloramphenicol, nalidixic acid and ciprofloxacin), although clinical levels of resistance were not reached. The cross-resistance was linked to mar mutations (Potenski et al. 2003). More recently Randall et al. (2007) isolated a mutant of $S$. enterica showing antibiotic resistance following treatment with a low concentration of an aldehyde, oxidising, QAC or phenolic-based disinfectant. The change in the observed antibiotic susceptibility profile depended upon the disinfectant tested and the mutants isolated. Following exposure to an aldehyde-based disinfectant, isolated mutants that were resistant to ciprofloxacin exhibited either some type of efflux mechanism or a mutation in GyrA (Randall et al. 2007). The effect of biocides on the bacterial cell is complex and the emergence of bacterial cross-resistance following exposure to biocides might be strain specific rather than species or genus specific (Braoudaki and Hilton 2004b).

Other investigations have however failed to make a direct link between biocide exposure and antibiotic resistance, although the antibiotic susceptibility of the bacterial strain was altered (Lear et al. 2000, Lear et al. 2002, Nomura et al. 2004, Thomas et al. 2000, Thomas et al. 2005, Walsh et al. 2003, Winder et al. 2000). A decrease in E. coli susceptibility to triclosan following repeated exposure, but not necessarily to other Gramnegative bacteria has been reported (Ledder et al. 2006, McBain et al. 2004b). More importantly, when the decrease in susceptibility to triclosan was observed, it was not linked to a decrease in susceptibility to unrelated biocides and antibiotics.

The presence of conjugative plasmids has been associated with co-resistance between a number of biocides such as cationic compounds (Beveridge et al. 1997, Langsrud et al. 2003, Paulsen et al. 1996a) and metallic salts (e.g. organomercurials) (Misra 1992) and antibiotics.

\subsubsection{Consumer products}

The same or similar chemicals are sometimes used as preservatives in several household and personal hygiene products. Using the same antimicrobial agents (or similar molecules with respect to mechanism of action) in household products and personal hygiene products leads to exposing the bacterial flora on human skin and in the home environment repeatedly to certain biocides. This cumulative exposure may lead to 
reduced susceptibility of certain microbes to specific biocides (selected bacterial strains or acquired resistance under this selective pressure). However, currently available studies are inconclusive as to whether this type of bacterial exposure to biocides will lead to antibiotic resistance.

Biocides tend to act concurrently on multiple sites within the microorganism, and thus, resistance is often mediated by non-specific mechanisms. Efflux pumps have been shown to act on a range of chemically dissimilar compounds and have been implicated in both biocide- and antibiotic resistant bacteria. Cell wall changes by reducing permeability may also play a role in the observed resistance to biocides. The possibility of genetic linkage between genes for biocide resistance and those for antibiotic resistance has also been described (Fraise 2002). Although, the studies on antibiotic resistance to biocides used in the consumer products have focussed on some specific molecules (for example, triclosan, chlorohexidine, glutaraldehyde, p-chloro-m-xylenol, quartery ammonium compounds/benzalkonium chloride, pine oil and chlorine releasing compounds), the mechanism of actions of these molecules may also be applicable to the long list of biocides used in the consumer products.

Considerable controversy surrounds the use of biocides in an ever increasing range of consumer products and the possibility that their indiscriminate use might reduce biocide effectiveness and alter susceptibilities towards antibiotics (Aiello et al. 2005, Aiello et al. 2007, Braoudaki and Hilton 2004a and b, Gilbert and McBain 2003, McBain et al. 2003a, Pumbwe et al. 2007, Russell 2004a, Weber and Rutala 2006). These concerns have been based largely on the isolation of resistant mutants from in vitro monoculture experiments. Some of the evidence suggests that exposure to biocides may be leading to increased antibiotic resistance, but this has not yet been proven in a clinical setting (IFH 2003). Further research is needed to establish a correlation between biocide exposure(s) and development of antibiotic resistance.

\subsubsection{Veterinary aspects}

In the veterinary field, data relating to the occurence of bacterial resistance following exposure to biocides are limited. The sensitivity of $700 \mathrm{Gram}$-negative bacterial strains was tested towards four antiseptics (cetrimide, chlorhexidine, hexachlorophene, mercuric chloride) and six antibiotics (ampicillin, streptomycin, erythromycin, chloramphenicol, kanamycin and tetracycline) by Maris (1991). The statistical analysis of correlation showed high positive resistance links between antiseptics and between antiseptics and antibiotics, especially for Serratia marcescens and Alcaligenes. Likewise, the investigation of 310 Gram-positive strains isolated from milking cow udders revealed positive links between chlorhexidine usage and resistance to the five tested antibiotics (ampicillin, kanamycin, streptomycin, tetracycline, gentamycine) in Streptococcus, and between hexachlorophene and oxacillin in Bacillus (Martin and Maris 1995). These studies emphasize the need to develop research and surveillance programmes in the area of animal husbandry.

\subsection{Relationship between biocide bioavailability to bacteria and resistance selection}

\subsubsection{Measurement of the effects of biocides on the susceptibility to antibiotics}

The effect of biocides on antibiotic susceptibility in bacteria has been measured indirectly, whereby a bacterial population is treated first with a biocide and the surviving bacteria then investigated for their susceptibility to antibiotics. To our knowledge, there has been 
no investigation reporting the effect on bacteria of a combined treatment with biocide and antibiotic.

A number of protocols have been used to measure antibiotic susceptibility in bacterial isolates showing resistance, tolerance or increased insusceptibility to biocides. However, the large variation in the experimental parameters used generates a question about the validity of the selected protocols. Some studies based a change in antibiotic susceptibility profile on measurement of zone of inhibition (Tattawasart et al. 1999, Thomas et al. 2005). More meaningfully, other studies used standardised antibiotic susceptibility methodologies such as those given by the British Society for Antimicrobial Chemotherapy (BSAC) or Clinical and Laboratory Standards Institute (CLSI). However a limited number of studies have looked at an increase in antibiotic insusceptibility that would be associated with treatment failure (Lear et al. 2006).

This is a complex task as there are many possible interferences/biases due to the multiplicity of proposed protocols, the failure of clear comparative methodology and criteria (reference strain, reference molecule, reference experimental assay etc.), which generate a profusion of non-comparative and exploitable results (see section 3.12).

\subsubsection{Possible confounding factors in dose-effect relationships}

Bacteria that are resistant to inactivation by chemical disinfectants are commonly encountered in a diverse set of aquatic environments, but this apparent resistance has most often been attributed to protection by physical means, e.g. association with particulate matter or occlusion within a biofilm. Equally important are the genotypic provision of a protective capsule or spore, as well as external abiotic factors such as chemical reaction of the disinfectant with other molecules present in the aqueous environment (Berg et al. 1982).

Thus, when studying dose-effect relationships, it is of major importance to take into account antecedent growth conditions and external factors which may dramatically influence the results. The results of the experiments performed with $E$. coli as a model illustrated the influence of the qualitative nature of the growth environment, the degree of nutrient limitation, the temperature and the density of the microorganism on the resistance to disinfectants (Berg et al. 1982).

The population growing more rapidly could be hypothesized as more sensitive. The temperature has a relationship with lipid fluidity in the membrane (Nikaido 2003): a less permeable membrane could retard the leakage of other small constituants (like $\mathrm{K}^{+}$) critical for viability.

\subsubsection{Changes in microbiota following exposure to biocides}

Microcosms have been used to reproduce complex biofilm systems found in the environment, and to investigate changes in microbial population and susceptibility following exposure to biocides (McBain et al. 2004a, Moore et al. 2008). Using a drain microcosm, it was found that the use or repeated exposure to a QAC produces little changes to the population dynamic and does not alter the susceptibility profile of the microcosm (McBain et al. 2004a). However, a more recent study highlighted a clonal expansion of Pseudomonads to the detriment of Gram-positive species following QAC exposure and a decrease in biocide susceptibility for a proportion but not all test bacteria (Moore et al. 2008). Another study investigating the change in bacterial population in activated sludge following exposure to benzalkonium chloride (a QAC) showed a population shift and a selection of Pseudomonas spp following treatment (Kümmerer et al. 2002). A more recent study investigating the effect of triclosan in the development of bacterial biofilm on urinary catheter highlighted the selectivity of the bisphenol. While 
triclosan inhibited Proteus mirabilis, it had little effect on other common bacterial pathogens (Jones et al. 2006).

\subsection{Specific hazards}

\subsubsection{Direct and indirect hazards}

The issue of antibiotic resistance induced by biocidal products is addressed as either a direct hazard or as an indirect hazard through transfer of resistance mechanism(s).

The direct hazard is the selection and dissemination of a resistant bacterium expressing resistance mechanisms active against biocides, antibiotics, or both (e.g. selection of adapted bacteria under selective pressure and change of microflora in some ecological niches, dissemination of this emerging strain and transmission to humans).

The indirect hazard concerns the transfer of mobile genetic elements (plasmid, transposon etc.) carrying genes conferring resistance to biocide, antibiotic or both, to a naturally susceptible strain via genetic exchange (e.g. during contact with commensal flora).

In some cases, both hazards may act together: a resistant bacterium may transfer an additional genetic element to another resistant bacterium enhancing the resistance level. The transfer of genetic element involved in resistance can occur anywhere: in the environment (e.g. water, ground), in the animal, in the food or in the human body (with resident/commensal flora).

\subsubsection{Veterinary use and hazard}

The use of biocides in veterinary settings could induce resistance against the disinfectants used. This might explain why important zoonotic pathogens like Salmonella spp. disseminate between batches of animals. This may be particularly important where biocides are used at "industrial scale", for example when animal houses are cleaned and disinfected. Under such conditions areas in the house may not receive optimum levels of active agent. Under conditions like this, the chances of selecting bacteria with increased rsistance to the active ingredient are greater.

The same concerns could also apply to foot dips outside animal houses. The levels of the active agent could be diluted by rainfall and it is also quite common for the dips to contain a range of biological and other materials, which could serve to inactivate the active component. As with incorrect dilutions being applied, the chances of selecting resistant bacteria are increased.

If such bacteria are zoonotic like Campylobacter and Salmonella spp. it is possible that antibiotic therapy of infected humans could be compromised (EFSA 2008b). A recent study investigating the effect of cleaning and disinfection procedures in poultry slaughterhouses on the development of or selection for biocide and antibiotic resistance in Campylobacter jejuni and C. coli showed that a very low number (1-2) of genotypes were recovered after cleaning and disinfection under specified conditions and that there was no increase in antibiotic resistance before and after exposure to the disinfection procedures (Peyrat et al. 2008).

Studies, mainly laboratory-based, have shown that some disinfectants can select for bacteria with low level multiple drug resistance (MDR). In pathogens like E. coli and Salmonella spp., MDR can be due to up-regulation of the AcrABTolC efflux pump, although down-regulation of porins may also be involved. This low level resistance could be a possible stepping stone to higher-level antibiotic resistance due to the acquisition of additional resistance mechanisms (Davin-Regli et al. 2008, Piddock 2006). In two recent 
studies, Salmonella exposed to a range of common farm disinfectants were found to develop a low, but statistically significant, increased risk of selection of mutants with reduced susceptibility to ampicillin, ciprofloxacin and tetracycline. Some of the mutants selected were of the MDR phenotype (Karatzas et al. 2007, Karatzas et al. 2008).

These few data indicate that there is a need for futher studies addressing the potential interaction between the intensive and in some cases long-term use of biocides in animal facilities and the emergence of antimicrobial resistance.

The latter is also important in the light of trends towards an increasing use of antibiotics in modern (intensified) animal husbandy and the demonstrated transfer of resistance pathogens such as MRSA between animals and humans by direct contact and via the food chain (EFSA 2008b).

\subsubsection{Health care use and hazard}

Studying environmental isolates from automated endoscope washer disinfector (AWD) provides a different perspective. Micro-organisms are being isolated with increasing frequency from washer disinfectors and processed endoscopes (Fraser et al. 1992, Gillespie et al. 2000, Griffiths et al. 1997, Kressel and Kidd 2001, Maloney et al. 1994, Nomura et al. 2004, Schelenz and French 2000, Takigawa et al. 1995). There are several reports about the emergence of $2 \%$ glutaraldehyde resistant Mycobacterium chelonae (Griffiths et al. 1997, Kingeren and Pullen 1993, Nomura et al. 2004).

Other bacteria, such as vegetative cells of Bacillus subtilis, Microcooccus luteus, Streptococcus sanguinis, Streptococcus mutans, Staphylococcus intermedius, were isolated from AWD following a high level disinfection process using chlorine dioxide. It was noted that most of these isolates remained sensitive to another oxidising agent when their susceptibility was investigated using a standard suspension efficacy test (Martin et al. 2008). The low concentration of the disinfectant (Griffiths et al. 1997, Maillard 2007, van Klingeren and Pullen 1993) or the presence of biofilms (Babb 1993, Pajkos et al. 2004, Smith and Hunter 2008), are considered important factors in determining the reduced susceptibility to biocides.

The presence of bacterial biofilms is one of the main challenges in terms of antimicrobial resistance with relevance for medical pratice, particularly for medical devices (Donlan and Costerton 2002, Dunne 2002). Pajkos et al. (2004) ascribed the failure of high-level disinfection in endoscope reprocessing to the presence of biofilms which can be very common and extensive on surfaces of endoscope tubings. Shackelford et al. (2006) observed that even the effective high-level disinfectant ortho-phthalaldehyde showed reduced activity against mycobacterial biofilms in vitro, but not against Pseudomonas aeruginosa biofilms. Even though most HAI are caused by bacteria associated with biofilms, most laboratories do not use biofilm tests to assess the efficacy of biocides and no European standards for the testing of disinfectants against biofilms in health care applications exist (Cookson 2005).

The linkage between biocides and antibiotic resistance in health care settings is a topic of great concern. However, clinically relevant resistance was only occasionally demonstrated, and when present, involved antibiotics of limited current use (e.g. chloramphenicol resistance in $E$. coli and tetracycline resistance in $P$. aeruginosa) (Weber and Rutala 2006). With regard to washer disinfectors, Nomura et al. (2004) studied the susceptibility of Mycobacterium chelonae isolated from bronchoscope washing disinfectors to $2 \%$ glutaraldehyde and antibiotics, and found an association of glutaraldehyde with antibiotic resistance.

Several studies have been carried out to evaluate the susceptibility of antibiotic-resistant bacteria to disinfectants. Antibiotic-resistant bacterial isolates were found to be as susceptible to disinfectants as their antibiotic-susceptible counterparts (Anderson et al. 1997, Rutala et al. 1997, Sakagami et al. 2002). Based on these data, antibiotic 
resistance was not deemed to require changes in disinfection protocols (Byers et al. 1998, Rutala et al. 2000).

The evidence base relating to biocide resistance and its relation with antibiotic resistance needs to be improved. An international consensus on the correct tests for determing biocide resistance and well designed surveillance systems are required. Antibiotic use and resistance should be continuously monitored. Reference and research laboratories should evaluate biocide resistance in any important new or multiple antibiotic resistant organisms (Cookson 2005).

The need for proper use of disinfectant and antiseptics should be stressed and health care workers should be trained to comply with clear and agreed policies and practices, avoiding unnecessary and incorrect use of biocides (e.g. choice of the appropriate product on the basis of the risk assessment; application of the product with regard to proper duration, concentration, $\mathrm{pH}$ or temperature; removal of organic debris before disinfection). A more appropriate use of antibiotics for therapy and prophylaxis also needs to be implemented. Gilbert and McBain (2004) believed that the risk associated with overuse of biocides in the health care environment is overstated, but recommended that to improve hygiene, applications that have demonstrable benefits should be emphasised.

\subsubsection{Environment and hazard}

Prior to determination of multi-resistance in micro-organisms in the environment it is of essence to determine whether or not biologically meaningful, i.e. not simply measurable, concentrations of biocides occur in the immediate environment such as sewage treatment plants and their immediate outflows.

One of the best examined examples remains triclosan, for which $79 \%$ of the incoming triclosan in sewage treatment plants was shown to be removed via biodegradation and $15 \%$ via sorption to activated sludge, thus resulting in approximately $6 \%$ of the incoming triclosan being released into the receiving streams (Singer et al. 2002). Despite this rather high removal rate in sewage treatment plants, effluent concentrations of triclosan ranged between $42-213 \mathrm{ng} / \mathrm{L}$, thus resulting in concentrations of $11-98 \mathrm{ng} / \mathrm{L}$ in receiving waters for the particular sewage treatment systems investigated. The latter concentrations represent the lower range of triclosan concentrations reported from previous investigations in wastewaters $(0.07-14000 \mu \mathrm{g} / \mathrm{L})$, possibly reflecting major differences in the technical capabilities of sewage treatment systems as well as in analytical capability (Jungclaus et al. 1978, Lindström et al. 2002, Lopez-Avila and Hites 1980, McAvoy et al. 2002). Correspondingly, between 50-2300 ng/L triclosan are reported for surface waters (streams) (Kolpin et al. 2002, Lindström et al. 2002), in seawater (50-150 ng/L) (Okumura and Nishikawa 1996), and in sediments $(1-35 \mu \mathrm{g} / \mathrm{kg})$ (Steffen and Lach 2000).

A comparable environmental investigation determined the density, heterotrophic activity, and biodegradation capabilities of heterotrophic bacteria in situ in a lake ecosystem following exposure to long-chain $\left(\mathrm{C}_{12}\right.$ to $\mathrm{C}_{18}$ ) quaternary ammonium compounds (QACs) (Ventullo and Larson 1986). Monoalkyl and dialkyl substituted QACs were tested over a range of concentrations ( 0.001 to $10 \mathrm{mg} / \mathrm{liter})$ and demonstrated that none of the QACs tested had significant adverse effects on bacterial densities in either acute $(3 \mathrm{~h})$ or chronic (21 day) studies. Moreover, chronic exposure of lake microbial communities to a specific monoalkyl QAC resulted in an adaptive response and recovery of heterotrophic activity. This adaptive capability was investigated further by Nishihara et al. (2000), who demonstrated that Pseudomonas fluorescens TN4 isolated from sewage treatment plants degraded didecyl-dimethyl-ammonium chloride (DDAC) to produce decyl-dimethyl-amine and subsequently, dimethylamine, as the intermediates. 
The TN4 strain also assimilated other quaternary ammonium compounds (QACs), alkyltrimethyl- and alkyl-benzyl-dimethyl-ammonium salts, but not alkylpyridinium salts. TN4 was highly resistant to these QACs and degraded them using an n-dealkylation process (Nishihara et al. 2000). Despite this adaptive response and probably because of the enormous consumption of these compounds, high concentrations of QACs, especially $\mathrm{C}_{12}$ chain benzalkonium chloride $\left(B A C-C_{12}\right)$ as well as long C-chain dialkyl-dimethylammonium chloride (DDAC- $\mathrm{C}_{18}$ ), can be found in sediments of surface waters with a maximum concentration of $3.6 \mathrm{mg} / \mathrm{kg}$ and $2.1 \mathrm{mg} / \mathrm{kg}$, respectively (Martínez-Carballo et al. 2007).

The above data demonstrate that significant amounts of biocides readily reach both the immediate environment (kitchen sink) and the more distant environment (sewage treatment plants and surface waters). The question of whether these environmental concentrations will lead to resistance in micro-organisms was addressed for triclosan by McBain et al. (2004a) using a gradient plate technique. They exposed several bacterial strains, including inter alia Streptococcus oralis, Streptococcus sangula, Streptococcus mutans, Neisseria subflava and triclosan resistant Escherichia coli (ATCC 8739) to increasing, sublethal concentrations of triclosan. MIC values towards chlorhexidine, metronidazole and tretracyclin were determined before and after biocide exposure. The experiments failed to demonstrate a biologically significant induction of drug resistance in triclosan-exposed bacteria, beyond that demonstrated for E. coli, thus suggesting that triclosan-induced drug resistance is not generally readily inducible nor is it transferred across bacterial species.

A similar investigation by McBain et al. (2004b) investigated the effects of short-term (12 days) and long-term (3 months) QAC-containing detergent exposure on biofilms from house-hold sink drains. Denaturing gradient gel electrophoresis analysis identified the major microcosm genera as Pseudomonas, Pseudoalteromonas, Erwinia and Enterobacter, and demonstrated that aeromonads increased in abundance under $10-50 \%$ QAC-containing detergent exposure. Long-term QAC-containing detergent exposure did not significantly change the pattern of antimicrobial susceptibility, thus suggesting that even though antimicrobial susceptibility changes (multi-resistance) have been reported in isolated bacterial cultures, such changes do not necessarily occur within complex microorganism communities.

\subsubsection{Relationship between biocide resistance and antibiotic resistance}

In laboratory experiments, emerging resistance to antibiotics following biocide exposure has been described and generally followed five main principles:

1. Cross-resistance: selection for genes encoding resistance to both the biocidal substance and one or more therapeutic antibiotic classes. The term 'cross-resistant' is used to denote a strain possessing a resistance mechanism that enables it to survive the effects of several antimicrobial molecules.

2. Change in the physiological response of the bacterium following biocide exposure, resulting in a decrease in susceptibility to both biocidal substance and antibiotics.

3. Co-resistance: selection for clones or mobile elements also carrying antimicrobial resistance. Co-resistance refers to genetic determinants conferring resistance present on the same extrachromosomal element, transferred and expressed jointly in a new bacterial host.

4. Indirect selection for bacterial sub-population following biocide exposure resulting in a decrease in susceptibility to both biocidal substance and antibiotics. 


\section{Enhanced DNA repair e.g. by activating a $\operatorname{SOS}^{24}$ response in bacteria.}

Unfortunately there is no complete report in the literature reporting at the same time on all five principles. Instead researchers have usually limited their investigations to one or two principles, potentially missing some important information on linkage between biocide and antibiotic resistance.

In antibiotics, cross-resistance has been described well. Antibiotics are a diverse group of molecules, commonly ordered in classes with similar structures and modes of action. Within a class, the target in the bacterial cell and the mode of action of the antibiotics is the same or similar. Therefore, some mechanisms of resistance will confer resistance to most or all members of a class, i.e. cross-resistance. Cross-resistance may also occur in relation to unrelated classes, if the target overlaps (as in the case of macrolides and lincosamides) or if the mechanism of resistance is of low specificity.

In very few instances cross-resistance between biocides and antibiotics has been described. Such resistance involved mainly efflux pumps mediating reduced susceptibility to both classes of antimicrobial agents (Levy 2002, Piddock 2006, Thorrold et al. 2007). However, in other instances changes in cell envelope (reduction in porins and changes in LPS and other lipids) has been described (Denyer and Maillard 2002, Nikaido 2003, Tkachenko et al. 2007). Finally, the role of bacterial biofilm in conferring resistance to both antibiotics and biocides cannot be ignored.

Co-resistance can occur when mechanisms encoding resistance or reduced susceptibility are genetically linked. Genes conferring antimicrobial resistance are frequently contained in larger genetic elements such as integrons, transposons or plasmids, and as such may be 'linked' to other, unrelated resistance genes. In such cases, multiple resistance genes may be transferred in a single event. Consequently, selection for one resistance gene will also select for the other resistance gene(s). For example, this is the case for tolerance to quaternary ammonium compounds in Gram-negative bacteria. The qac-genes are often together with sul1 genes encoding sulphonamide resistance located as part of mobile genetic elements which also can harbour various other resistance genes (Sidhu et al. 2001, Sidhu et al. 2002). Resistance genes can be located on mobile genetic elements or in the bacterial chromosome. Co-resistance has also been described in Salmonella enterica with metallic salts such as organomercurials (Levings 2007). Exposure to a biocide causes major stress. Thus, it must be expected that a biocide can initiate a SOS response in a bacterium, promoting horizontal gene transfer of resistance genes (Beaber et al. 2004, Ubeda et al. 2005).

In laboratory settings, the use of biocides has been shown to select indirectly for resistance to antibiotics by causing a clonal drift in the bacterial population towards bacterial cells that are more resistant. As an example the emergence of multi-drug resistant Salmonella enterica serovar Typhimurium DT104 caused an overall increase in the occurrence of resistance to antibiotics among Salmonella from food animals and humans in several countries (Doublet et al. 2003, Doublet et al. 2008).

\subsubsection{Tonnages and exposure}

To assess the general exposure of human and the environment, knowledge about production and uses of various biocides is required. However, information concerning production and use of biocides in the open literature is sparse. The WG attempted to get such information by publishing a Call for Information on an EU Website, and by contacting various DGs within the European Commission as well as relevant Member State Authorities. No useful information in this respect was obtained from any side. In

\footnotetext{
${ }^{24}$ SOS response is an inducible DNA repair system that allows bacteria to survive sudden increases in DNA damage.
} 
the absence of adequate knowledge on product and use of biocides, an alternative strategy for exposure assessments was required.

A practical approach may be based upon the exposure concentrations and frequency of exposure, considering the aggregate exposure when relevant. In the case of the bacterial flora in the home environment, repeated exposures to biocides in cleaning products, disinfection products and other relevant products could be considered to be a continuous selective pressure allowing the potential emergence of well-adapted strains.

Environmental concentrations of many biocides in air, water and soil are reported in open literature and various databases. A continuous exposure of bacterial flora by biocides in natural environments should be considered for the estimation of development of antibiotic resistance.

\subsubsection{Appearance of resistance in practice}

It is clear from in vitro studies that bacterial resistance can develop rapidly following exposure to a biocide. The initial stress response caused by a biocide, which does not demonstrate a lethal action, is rapid and has been exemplified by the initiation of a SOS response or has been indirectly demonstrated by looking at growth curve in the presence of a biocide (Gomez-Escalada et al. 2005a). It is difficult to ascertain how wide spread the development of bacterial resistance to a biocide is in practice mainly due to the paucity of information available. Since one of the compounding factors for the development of resistance is the concentration of a biocide, one can speculate that where a low concentration of a biocide is present, the resulting selective pressure will result in a change of (i) bacterial community, (ii) bacterial population or (iii) bacterial phenotype. However, without further evidence notably from in situ investigation, the overall risk of emerging resistance can only be assessed from in vitro derived evidence. It is also clear that a number of mechanisms will provide the bacteria with the ability to survive biocide and antibiotic exposure. If this has been demonstrated in laboratory investigations to some extent, there is an overall lack of information from the practice. However, when clinical and environmental isolates are investigated in laboratory investigations, these tend to show better survival ability to antimicrobials than their standard culture collection bacterial counterparts.

\subsection{Examples of biological hazards}

The following sections present two possible events occurring amongst many. One is based on genetic dissemination of resistance genes, the other on the modification of the physiological state of the cells (biofilm).

\subsubsection{Genetic dissemination of resistance genes}

Mobile genetic elements (MGEs) play an important role in the evolution of bacteria. They allow the rearrangement or exchange of DNA between species, thereby increasing genetic diversity and flexibility of genomes (Dobrindt et al. 2004, Ochman et al. 2000). Among the various types of MGEs, genomic islands (GEI) take up a distinct position, because they are integrated in the chromosome of the bacterial host and thus potentially stably maintained. Those GEI that are mobile can excise from their chromosomal location, can induce self-transfer and reintegrate into a new host cell's chromosome are designated as integrated and conjugative elements. GEI can carry large regions (50-400 $\mathrm{kb}$ ) with variable auxilliary functions that potentially benefit the host, such as growth in the presence of antibiotics or heavy metals, invasion of eukaryotic tissues via virulence factors, and exclusive growth with aromatic compounds (Dobrindt et al. 2004, Gaillard et al. 2008). 
In a 2002 study, several staphylococcal clinical isolates resistant to the quaternary ammonium compound (qac)-based disinfectant benzalkonium chloride ( $83 \%$ of resistant strains exhibit plasmid-borne qacA/B and qacC genes), have been checked for antibiotic susceptibilities (Sidhu et al. 2002). A genetic linkage was reported between resistance to benzalkonium chloride products and penicillin and $44 \%$ of the plasmid-encoded Blactamase resistance was linked to disinfectant resistance genes. In addition, the frequencies of resistance to a range of antibiotics were significantly higher among qacresistant than among qac-susceptible bacteria. Moreover, some isolates harbored multiresistance plasmids that contain qac, bla and tet resistant genes. The results are compatible with selective advantages of isolates carrying both disinfectant and antibiotic resistance genes and the data indicate that the presence of qac genes in staphylococci results in the selection of antibiotic-resistant bacteria (Paulsen 1998). Previous investigators have also reported a genetic linkage between disinfectant (qac) and antibiotic resistance genes (blaZ, aacA-aphD, dfrA, and ble) on the same staphylococcal plasmids from clinics and food environments (Sidhu et al. 2001, Sidhu et al. 2002) as well as the geographical dissemination of resistance genes among staphylococci (Bjorland et al. 2001, Noguchi et al. 2005). These conclusions are important because there are few investigations in this field.

The Salmonella genomic island 1 (SGI1) is an integrative mobilizable element originally identified in epidemic multidrug-resistant Salmonella enterica serovar Typhimurium DT104 (Doublet et al. 2003, Doublet et al. 2008). SGI1 contains a complex integron, which confers various multidrug resistance phenotypes due to its genetic plasticity. A multiple-antibiotic-resistant Salmonella enterica strain isolated from the environment was found to contain SGI1-K, a variant form of the Salmonella genomic island 1 (SGI1with an adjacent resistance module confering resistance towards mercury (Levings et al. 2007).

OqxAB, a plasmid-encoded multi-drug efflux pump identified in Escherichia coli of porcine origin and tested for substrate specificity, demonstrated a wide substrate specificity including animal growth promoters, antimicrobials, disinfectants and detergents (Hansen et al. 2005). The OqXAB pump can be transferred between Enterobacteriaceae (Salmonella Typhimurium, Klebsiella pneumoniae, Kluyvera sp. and Enterobacter aerogenes), conferring reduced susceptibility to various substrates including chloramphenicol, ciprofloxacin and olaquindox (Hansen et al. 2007).

Similar mobile elements containing biocide and antibiotic resistance genes have been reported in clinical isolates of another major human pathogen, Pseudomonas aeruginosa (Laraki 1999, Sekiguchi 2005, Sekiguchi 2007, Wang et al. 2007).

Consequently, the segregation/transfer of biocide and antibiotic resistance genes as integrative mobile genetic elements (MGEs) is a significant hazard for the selection and dissemination of MDR bacteria.

The uncontrolled use of biocides may recruit bacteria containing this type of genetic element and favor the vertical and horizontal spreading of the mobile elements to other bacteria (intra- or inter-specie) sharing the same ecological niches.

In this respect, soil bacteria could be a natural reservoir of resistance genes allowing the dissemination and rearrangement of genetic elements (Dantas et al. 2008).

\subsubsection{Biofilms}

Bacteria are able to adapt to shifts in nutrient availability, environmental stresses, and presence of inhibitory compounds as well as to immune defenses. One particularly important example of bacterial adaptation through systematised gene expression is the ability to grow as part of a sessile community, referred to as a biofilm. Biofilms are communal structures of microorganisms encased in an exopolymeric coat that form on both natural and abiotic surfaces (Hall-Stoodley et al. 2004). It is now recognized that biofilm formation is an important aspect of many, if not most bacterial diseases, including native valve endocarditis, osteomyelitis, dental caries, middle ear infections, medical 
device-related infections, ocular implant infections, and chronic lung infections in cystic fibrosis patients (Lynch et al. 2008)

When bacterial cells are in biofilm state, they demonstrate adaptive resistance in response to antimicrobial stress more effectively than corresponding planktonic populations. Antibiotic concentrations necessary to inhibit bacterial strains in steady-state biofilms were up to 10-1000 times greater than the concentrations needed to inhibit the same strains grown planktonically (Lewis 2001). Thus, in the presence of therapeutically available antibiotic concentrations, significantly higher proportions of the biofilms remained viable as the biofilms reached steady-state growth (Sedlacek and Walker 2007).

Moreover, bacteria inside biofilms resist better to biocidal agents. Examples are the reduced susceptibility to triclosan observed in Salmonella (Tabak et al. 2007) and in Proteus/Providencia (Stickler and Jones 2008, Williams and Stickler 2008), increased survival after exposure to quaternary ammonium compounds in Enterobacter sakasakii (Kim et al. 2007) and resistance to peroxides of Listeria cells in biofilms (Pan et al. 2006).

The resistance to clinically relevant antibiotics and to biocides could be related to common mechanisms which include: a localised high concentration of bacteria in the biofilm, modified physiological state of bacterial cell in the biofilm, decreased growth rate, restricted penetration of antimicrobials into a biofilm due to the presence of extracellular products (exopolymers and extracellular enzymes, and expression of possible resistance genes (Lewis 2001).

Although several authors report interaction between bacterial biofilm physiological state and resistance to antibiotics or biocide, and these resistances probably share common mechanisms, very little information is available on the cross resistance of sessile bacteria to antibiotics and biocide.

In one study (Jurgens et al. 2008), the aim of which was to determine if exposure of Pseudomonas aeruginosa biofilms to chloraminated drinking water could lead to individual bacteria with resistance to antibiotics, it has been demonstrated that exposure to chloramine does not increase antibiotic resistance in this bacterial species.

\subsection{Risk assessment}

The selection of resistant or insusceptible bacteria following exposure to a biocide should be considered. A number of studies highlighted selection for resistant bacteria clones although the antibiotic phenotype was not necessarily determined. Several laboratory scale investigations demonstrated the selection for bacteria showing an increased tolerance to a biocide following treatment with a low concentration of a biocide (Abdel Malek et al. 2002, Langsrud et al. 2003, Tattawasart et al. 1999, Thomas et al. 2000, Walsh et al. 2003). Gaze et al. (2005) reported QAC selection in the natural environment following QAC exposure. Recently the effect of triclosan in selecting for small colony variants of $S$. aureus was described, highlighting a potential detrimental effect for strain identification and subsequent miss-diagnosis in a clinical context (Seaman et al. 2007).

Antibiotic use is still the major cause of antibiotic resistance in clinical practice. Since antibiotic resistance remains a major concern and decreases our ability to treat infections, appropriate infection control strategies are paramount and involve prevention through good hygiene which encompass the appropriate use of biocides (OJEC 1999, Department of Health 2000). 


\subsubsection{Categorisation of potential factors involved in the biological risk}

\subsubsection{Predisposition of bacterial species to acquire resistance}

Horizontal gene transfer, a fundamental mechanism for the evolution of microbial genomes, is the main cause of dissemination of resistance determinants. This nonparental transfer of genetic material from one organism to another, such as from one bacterium to another or from viruses to bacteria, is pervasive and plays a relevant role in accelerating the spread of antibiotic resistance (for details see sections 3.4/3.5/3.9). The three mechanisms of horizontal gene transfer identified are transduction, transformation and conjugation.

Transduction involves the accidental packaging of cellular DNA into bacteriophage particles during replication. Transformation is the uptake of free DNA by a bacterial cell and its stable integration into the bacterial genome, but bacterial conjugation is the most efficient system of horizontal gene transfer in bacteria.

In this process, DNA is transferred from donor to recipient bacteria by specialised machinery: the conjugation apparatus, which includes molecular mechanisms responsible for intimate cell-cell contact and for the transfer of mobile genetic elements. As components of the horizontal gene pool, mobile genetic elements include insertion sequences, transposons, integrons, bacteriophages, genomic islands (such as pathogenicity islands), plasmids and combinations of these elements.

Although mechanisms of gene transfer occur in both bacteria and archaea, some bacterial groups seem to have developed highly efficient mechanisms for gene transfer. While gaps in information make it difficult to categorise bacterial species according to their efficiency in conjugative gene transfer, the available scientific information still allows the definition of three categories related to this potential risk:

a. High: bacterial species for which highly specialised mechanisms for high frequency gene transfer have been described (e.g. Enterococcus Enterobacteriaceae); high probability of exchange between unrelated species or to virulent strains.

b. Medium: bacterial species for which narrow range (intra-generic) mechanisms for gene transfer have been described. (e.g. Lactococcus)

c. Low: bacterial species for which no mechanism of high frequency conjugation has been identified (e.g. Bacillus).

\subsubsection{Induction of antibiotic resistance gene via genetic cascade}

Several genetic cascades control the induction of the expression of general/non-specific resistance mechanisms including efflux pumps and permeability change. Among them, genetic activators such as SosS or MarA can be activated by several chemicals such as biocide molecules (Blanchard et al. 2007, Davin-Regli et al. 2008, Pomposiello et al, 2001). Taking into account this chemical activation, biocides may induce the expression of antibiotic resistance cascades in susceptible strains generating a decrease of antibiotic susceptibility, or, select bacteria which express the corresponding genes.

In addition, in integrative elements such as transposons, plasmids etc. several genes involved in biocide and antibiotic resistance co-segregate (Dobrindt 2004; Gaillard 2008). This genetic linkage favors the selection and the dissemination of resistant bacteria carrying these mobiles elements. Moreover, the transfer of such key genes will be increased under selective pressure such as the presence of biocides. 


\subsubsection{Type of antimicrobial (intrinsic potential for generating resistance)}

Based on our current state of knowledge and literature based evidence from mainly in vitro studies, bacteria have been shown to be able to withstand biocide exposure. The mechanisms by which bacteria can escape damage from biocides are complex and multiple, and are governed by a number of factors inherent to the biocide (e.g. concentration, contact time etc.) and to the bacteria (e.g. type, metabolic activity).

However, some biocides, because of the nature of their interaction with the bacteria, would be more prone to induce resistance/tolerance. This group of high-risk biocides contains the quaternary ammonium compounds, biguanides (i.e. surface active agents) and phenolics. Metallic salts, such as silver could also be added to this list based on practice-based evidence from the 1960s-1970s.

Highly reactive biocides such as oxidising agents and alkylating agents would present a low risk when emerging bacterial resistance is concerned. This means that resistance is unlikely but not impossible. Examples of resistance to these biocides have been described, but they resulted mainly from an inappropriate usage of the biocide.

Finally, for a number of biocides used heavily in consumer products and in the food industry (e.g. isothiazolones, anilides, diamidines, inorganic acids and their esters, alcohols), there is little information available on emerging resistance/tolerance when bacteria are exposed to their in-use concentrations. However, because of the nature of their interaction with the bacterial cell and their antimicrobial efficacy, these biocides would have to be classified for the time being as being of a medium risk in terms of emerging bacterial resistance until they can be properly assessed.

\subsubsection{Concentration/persistence}

This point is very difficult to evaluate due to the missing data for the tonnages used and the distribution of the many molecules.

\subsubsection{Form of growth}

Bacteria are able to grow either free in media (planktonic status) or as part of a sessile community, forming biofilms. This represents a protected mode of growth that allows cells to survive in hostile environments (see section 3.7.3).

The presence of conditions which allow the formation of bacterial biofilm could be considered as a potential risk for the development of cross-resistance between antibiotics and biocides. Examples are:

- Prosthetic materials, implants, catheters;

- Food and chemical plants;

- Water and wastewater treatment plants (filters, flocks, trickling filters).

\subsubsection{Environmental factors}

The environmental factors which may play a role in the bacterial response (adaptation) may include: the type of bacterial community, temperature, oxygen level, nutrient levels, $\mathrm{pH}$ of the medium, detergents, exposure time etc. All these factors may influence the growth, the metabolism/physiology of the bacterial cell and the division cycle which are key points in the bacterial susceptibility. In addition, they also are involved in the transfer of genetic elements, the quorum sensing (transduction of cell-cell signal) and the formation of biofilm (see above). 


\subsubsection{Prevalence of bacterial species}

This important point is related to:

- The biological aspects, including the bacterial species submitted to selective pressure, involved in the transmission of MGE and directly involved in the biological hazard (final host) (see example of biological hazard 3.9.1-2 );

- The respective concentration of biocides (as active stress agent) and the time of contact (point 4);

- The types of biocides present in the bacterial environment and their chemical properties (stability, affinity for bacterial target, bioavailability etc.).

\subsubsection{Risk factors for resistance to antimicrobials}

The large and indiscriminate use of (biocidal) chemical compounds will increase the wide dissemination of mobile genetic elements (see section 3.9.1). This is already often the case, for example in agriculture, breeding, intensive farming and rearing. As biocidal substances are used in numerous domestic and industrial products and applications, they come in direct contact with the soil and the associated microflora via wastes, faeces etc. Soil is a general reservoir of many environmental bacteria and opportunistic pathogens (Gram-negative and -positive bacteria) containing a large diversity of mobile genetic elements that contain resistance genes.

Among this microflora several Gram-negative and -positive bacteria may be (i) selected because the genes involved in biocide resistance are actively present on the chromosome (genetic island) or on mobile elements (plasmids), or (ii) because the bacteria is able to acquire corresponding mobile genetic elements from the neighbouring bacteria. Under the presence of biocides, and due to the presence of resistance gene targeting both antibiotics and biocides on mobiles genetic elements, genetic rearrangements are favoured inducing the intra and inter-species dissemination of such key genes.

This risk concerns not only the soil bacteria but also the bacteria that colonize the various farm animals (Campylobacter, Enterococcus, Salmonella etc.) which are in contact with environmental bacteria (Pseudomonas etc.) containing these mobile genetic elements. Consequently, the risk can spread to food-borne pathogens which are frequently detected in animals. For example, the dissemination of resistance genes may affect Campylobacter, Escherichia, Salmonella and several mobile genetic elements containg biocide and antibiotic resistance genes have been described (see section 3.7.2).

The dissemination of mobile genetic elements conferring the resistance against biocideantibiotic is clearly evidenced, the possibility that this event concerns important foodborne pathogens is also reported, the human exposure to this event is also important (via food-borne pathogens or nosocomial infections).

To conclude, the hazard exists for several human pathogens and this may concern a significant part of the population.

\subsubsection{Requirement for new methodologies for risk assessment of the effect of biocide usage on antibiotic resistance}

Protocols for testing the antimicrobial efficacy of biocides are essential to provide reliable information on the efficacy of an antimicrobial product and provide assurance for the end users. Variability in results observed in the literature often resides in the differences in protocols used, some tests being less stringent than others (Kampf et al. 2003; Marchetti et al. 2003, Messager et al. 2004), but also the non-respect of test preparation (notably inoculum) and conditions (Jacquet and Reynaud 1994, Taylor et al. 1999). 
There are no internationally agreed standard protocols and often countries have their own government laboratory testing with their own standards, although in Europe, CEN/TC 216 (the European Committee for Standardisation) aims to produce current and future European disinfectant testing standards (Holah 2003). Test methodology can range from basic preliminary suspension tests to more complex protocols that simulate conditions in practice. The purpose of antimicrobial efficacy testing is to determine a pass/fail criterion for a given biocide under specific conditions. The design of efficacy test protocols for biocides is complex notably because of the number of factors that need to be controlled. These factors can be divided into those depending upon the microorganism (e.g. test strain, preparation of inocula, detection and count of survivors) and those depending upon the test method (e.g. quenching antimicrobial activity, physical parameters). There are a number of protocols available for testing the antimicrobial efficacy of biocides (Lambert 2004).

One of the major limitations of efficacy test protocols is their reproducibility and robustness (Bloomfield and Looney 1992, Bloomfield et al. 1994, Bloomfield et al. 1994, Borgmann-Strahsen 2003, Kampf and Ostermeyer 2002, Kneale 2003, Langsrud and Sundheim 1998, Tilt and Hamilton 1999). In addition, practical tests conducted in laboratory conditions that aimed to simulate conditions in the field, might sometimes be too rigid and do not allow much flexibility which impinge on the ability to set parameters reflecting conditions found in practice. On the other hand tests in loco are costly and difficult to standardise since parameters cannot be controlled accurately in the field. These tests remain poorly reproducible and their outcomes might be contentious, although they would provide key information on the antimicrobial efficacy of biocides to the manufacturers and end users.

There are no standardised testing protocols that measure both biocide and antibiotic resistance in bacteria. Often environmental and clinical isolates have been tested for their susceptibility to biocides and antibiotics in separate efficacy test protocols. Undoubtedly, the use of a range of diverse protocols, some based on MIC determination (as discussed previously), adds to the variability in information in the literature. Thus there is an urgent need for the design of a standardised test to determine both biocide and antibiotic resistance in bacterial isolates.

In addition, the role of bacterial biofilm in resistance to both biocides and antibiotic has been shown. Furthermore, bacterial biofilms have been deemed to provide a better representation of how bacteria are present in the environment. However, most laboratories are not using biofilm tests to assess the efficacy of biocides (Cookson 2005). There are currently no European standards for the testing of disinfectants against biofilms for health care applications. This is particulalrly pertinent since there is evidence that the complete elimination of a biofilm is difficult and might not happened even where stringent cleaning procedure are in place (Pajkos et al. 2004).

However, since bacteria (and notably environmental/clinical isolates) grown as a biofilm are more resilient to antimicrobial action (Kimiran-Erdem et al. 2007), one of the problems associated with biofilm efficacy test, apart the type of protocol to be used, is that higher a concentration of a biocide will most probably have to be used to ensure efficacy. This will lead to increase in costs for the manufacturer and increase in levels of biocide released in the environment.

\subsubsection{Quantitative approach}

\section{A) Specific use situations}

The preceding discussion indicates that, on mechanistic grounds, it is reasonable to assume that under certain circumstances, frequent exposure to minimum selective concentrations will trigger antibiotic resistance. 
The likelihood of this occurring and its relative importance will depend on:

- How the biocide is used i.e. the exposure conditions (type of surface, concentration in use etc.).

- The microbial pathogens exposed.

- Environmental factors that may favour the selection of resistant pathogens.

- Exposure time.

Assessment of exposure is inevitably specific to usage. Key parameters are the duration of exposure and remaining concentration. Two particular situations need particular consideration:

- Frequent release/application of one or more biocides that enable non-lethal concentrations or sub-inhibitory concentration to be maintained in pathogen rich locations.

- Biocides that are environmentally persistent and can maintain a residual concentration below the minimum inhibitory concentration because they can maintain selective pressure.

The relative susceptibility of bacteria is the consequence of intrinsic and acquired resistance mechanisms (see sections 3.4 and 3.5). It is now clear that intrinsic resistance is an evolutionary advantage for bacteria: it has evolved to maintain a minimal protection against harmfull compounds and is genetically conserved (vertical transmission). For instance, low permeability of the bacterial envelope or efficient polyselective efflux pumps allows bacterial cells to survive harmful chemical and physicial stresses. The level of un-susceptibility depends on the bacterial genera and sometimes species, and can increase with (over)expression of specific genes following exposure to environmental factors and specific stresses (toxic agents etc.). In addition, the presence of overlapping cascades of regulation controlling resistance genes may increase the resistance level. The acquisition of new resistant determinants (acquired resistance; horizontal transfer) may be beneficial to the bacteria under specific stressful conditions, but may have an environmental cost when no selective pressure is present.

ii) Other environmental factors that may influence resistance

All factors acting on bacterial physiology (see section 3.10.1.6) can modulate the level of bacterial susceptibility and trigger or favor the selection or emergence of resistant strains. For instance, oxygen may de-repress the Sox operon which is a part of the regulation cascade inducing the expression of the efflux mechanism; $\mathrm{pH}$ and divalent cations may induce some changes in the envelope structure (e.g. proteins, lipopolysaccharide) decreasing the penetration of antibacterial molecules. All environmental factors (chemical, physical, biological etc.) which alter the normal permeability of the envelope are likely to promote a change in susceptibility.

The relative contribution of biocides to pathogen resistance.

It is important to consider the relative contribution of the use of a particular biocide compared with that of antibiotics. In situations where there is extensive use of antibiotics this exposure plays inevitably a dominant role in emerging antibiotic resistance. However, the use of biocides in such settings (e.g. hospitals) may also contribute to the selection of bacterial genera and species that are less susceptible to the biocide used and show cross-resistance to certain antibiotics. 
In other situations such as food manufacturing there may be extensive use of biocides with minimal or no use of antibiotics. Consequently, it is appropriate to consider the risk from biocide exposure in the emergence or development of resistant bacterial strains.

\section{B) Assessment of the generic risk}

Assessment of the generic risk within the European Union requires information on:

- The current and likely future uses of biocides in the EU. This includes the tonnage of particular biocides in current use. Regrettably, the industry has been unwilling to provide this information and hence any assessment of the generic risk is impossible at present.

- The minimum selective concentrations of each of these biocides.

\subsection{Conclusions}

There is convincing evidence that common mechanisms that confer resistance to biocides and antibiotics are present in bacteria and that bacteria can acquire resistance through the integration of mobile genetic elements. These elements carry independent genes conferring specific resistance to biocides and antibiotics.

Biocides are used in numerous formulations (for household use, industrial use, veterinary use etc.). Components of the formulations might increase their efficacy, and hence play a role in decreasing the development of bacterial resistance.

The few studies carried out in the environment agree on their limitations in terms of identifying and characterising cross-resistance in situ and conclude that more research is needed in this field.

Biocides are invaluable compounds that provide society with numerous benefits. They play an important role in the control of bacteria in a variety of applications. They are a precious resource that must be managed to avoid any loss in activity for as long as possible. Therefore, in order to preserve the role of biocides in infection control and hygiene, it is paramount to prevent the emergence of bacterial resistance and crossresistance through their appropriate and prudent use.

\subsection{Gaps in knowledge}

In the course of this work, several important gaps have been noted:

- Environmental studies focussing on the identification and characterisation of resistance and cross-resistance to antibiotics following use and misuse of biocides.

- In vitro studies demonstrate that some biocides used at sub-lethal concentrations trigger the emergence of antibiotic resistance and/or select bacteria resistant to antibiotics. Despite this mechanistic evidence from in vitro data, epidemiological data indicating public health relevance are lacking.

- Exposure of bacteria to biocides and/or their metabolites in various matrices could not be assessed due to lack of information on production and use volumes; lack of mechanistic studies at a small scale.

- Despite the regulatory requirements to study the environmental stability of individual products, data on the fate and concentrations of biocides in the environment are sparse. No validated methodologies are available for the determination of the doseresponse relationship and of the threshold triggering the emergence of antibiotic resistance and/or the selection of resistant bacteria. 
- The role of bacterial biofilm in resistance to both biocides and antibiotics has been shown. Furthermore, bacterial biofilms are very common in the environment. Yet most laboratories are not using biofilm tests to assess the efficacy of biocides (Cookson 2005). There are currently no European standards for the testing of disinfectants against biofilms for health care applications.

\subsection{Recommendations}

Prudent use guidelines for biocides in their various applications should be evaluated and harmonized. In addition, surveillance programmes investigating bacterial resistance to biocides are recommended.

There are currently no clear and well-referenced criteria or standards for the evaluation of the capability of a biocide to induce/select for antibiotic resistance. Therefore, tools need to be developed to define the "minimal selecting concentration": the minimal concentration of a biocide which is able to select or trigger the emergence/expression of a resistance mechanism concerning an antibiotic class in a defined bacterium.

It should be noted that biocidal products are complex formulations (including various active ingredients) which potentiate the activity of individual active ingredients. It is important to take into account the evolution of the European regulation: n'1451/2007 ( $4^{\text {th }}$ December 2007) and the recent European decision $\left(2008 / 809 / C E-14^{\text {th }}\right.$ October 2008) with the suppression of numerous active substances. The impact of this decision on decreasing the overall activity of a formulation should be considered in future risk assessments.

Considering the high uncertainty in the in vivo evaluation of the effects of biocides on the emergence of antibiotic resistance, reporting of production and use of biocides should be promoted.

Environmental monitoring programmes for undesirable substances should include biocides. 


\section{OPINION}

Within the scope of this mandate, this opinion is focussed on substances that are primarily active against bacteria and does exclude for example, antifungal and antiprotozoal agents.

1.a Does current scientific evidence indicate that the use of certain active substances in biocidal products in various settings as mentioned above can contribute to the occurrence of antibiotic resistant bacteria, both in humans and in the environment?

Yes, current scientific evidence (including bacteriological, biochemical and genetic data) does indicate that the use or misuse of certain active substances in biocidal products in various settings may contribute to the increased occurrence of antibiotic resistant bacteria, both in humans and in the environment.

1.b If so, how does this effect compare to resistance due to application of medicinal products or veterinary medicinal products and other relevant applications? ${ }^{25}$

Some of the mechanisms involved are similar to those involved in resistance to antibiotics. In specific situations such as hospital and veterinary environments where both biocides and antibiotics are used, it is not possible to discriminate the origin of antimicrobial resistance. The current scarcity of information means that it is difficult to quantify the impact of biocides on the selection, survival and spread of multi-resistant strains.

\section{2.a If yes, which types of active substances create the highest risks for increasing antibiotic resistance?}

The most studied biocides, triclosan and quaternary ammonium compounds, are probably instrumental in maintaining a selective pressure favouring the presence of mobile genetic elements harbouring specific genes involved in the resistance to biocides and antibiotics (see sections 3.4/3.9). However, the scarcity of available data on the other biocidal compounds prevents reaching a definitive answer as to their role in selecting for, or maintaining bacterial antibiotic resistance. With the presence of overlapping cascades of regulation that control resistance genes that are activated by external stresses, it is important to determine the capacity of biocides to trigger this process.

\section{2.b If yes, which modes of action create the highest risks for increasing} antibiotic resistance?

Some mechanisms of resistance are common to both biocides and antibiotics (e.g. efflux pumps, permeability changes, biofilms). The selective pressure exerted by biocides may favour the expression of these mechanisms of resistance.

The existence of horizontal gene transfer, and in particular the presence of mobile genetic elements, creates the highest risks for increasing antibiotic resistance. The organisation of these mobile genetic elements (i.e. presence of multiple resistance genes) and their dissemination as a result of selective pressure represent the highest risks. The

\footnotetext{
25 The SCENIHR is asked to consider in particular the possible risk that exposure to biocides or active substances in biocidal products may favour the emergence or selection of cross resistance mechanisms (in bacterial species) that may decrease the efficacy of antibiotic molecules during therapy.
} 
formation of biofilms could also contribute to a potential high risk for the development of cross resistance between antibiotics and biocides.

\section{2.c If yes, which types of areas of application create the highest risks for increasing antibiotic resistance?}

Any application that encompasses the widespread regular use of biocides at sub-lethal concentrations maintains a continuous selective pressure and thus increases the risk of selecting resistant bacteria. This may occur in a number of uses including hospitals, food production and cosmetics manufacturing etc.

3. If yes, what is the extent of the resulting antibiotic resistance and the relative contribution of the different applications to the risk of increasing antibiotic resistance?

Quantitative data on exposure and standard protocols (not available at present) are required to answer this question.

In order to determine the precise impact and prevalence of a given application, the dose, specific environment (e.g. water, level of soiling etc.), stability of compound activity or structure, potentiation or antagonism with other molecules (e.g. formulation components), must be obtained to measure the risk for each biocide for specific applications. This is a gigantic task which might not be practical. Prediction models through the use of standard protocols (see below) are a better alternative.

\section{How can the development of antibiotic resistance due to the use of active substances in biocidal products be examined? Could the Committee advise on the methodologies?}

There are currently no accepted standard protocols for the evaluation of antimicrobial resistance induced or selected by biocide. Such standards must be developed to provide informative data for biocidal product development and usage, and for regulatory bodies.

The Committee strongly recommends the development of (a) standard protocol(s) for the quantitative assessment of biocide induced resistance and cross-resistance. Such protocol(s) should combine repeated biocide exposures at sub-lethal (including residual) concentrations with existing standardised antibiotics susceptibility tests.

The quantitative assessment can take the form of the new concept of "minimal selective concentration" which is the lowest concentration at which a biocide is able to select or induce the emergence/expression of a resistance mechanism concerning an antibiotic class in a defined bacterium for a specific duration of exposure. This protocol should be used together with a standardised efficacy test to assess sub-lethal concentrations on suboptimal contact times.

\section{Please identify relevant gaps in scientific knowledge and suggest major research needs.}

Additional studies are needed on the mechanisms of cross-resistance, emergence of biocide-induced antibiotic resistance in different fields of application (e.g. health care, veterinary uses, food production, cosmetics, consumer products).

Standardised methodologies for the evaluation of the capability of a biocide to induce/select for antibiotic resistance must also be developed.

Standardised methodologies for the surveillance of resistance and cross-resistance are also needed, in conjunction with data on the use of biocides. 
Surveillance programmes must be developed to monitor the level of resistance and crossresistance of environmental isolates in all areas of biocide usage, in particular the health care setting, veterinary setting and food industry.

Exposure studies that encompass concentration, environmental conditions (e.g. water, soiling, exposure time, temperature, $\mathrm{pH}$ etc.), change in microbial population and the dissemination of resistant determinants (horizontal transfer), are necessary to identify and measure the risks for emerging resistance and cross-resistance in bacteria following biocide exposure. 


\section{COMMENTS RECEIVED DURING THE PUBLIC CONSULTATION}

A public consultation on this opinion was opened on the website of the EU non-food scientific committees from 4 November to 30 November 2008. Information about the public consultation was broadly communicated to national authorities, international organisations and other stakeholders.

In total, 13 contributions were received of which five were from public authorities, five from industry, one from academia and two from individuals (one associated with academia and the other with a public authority). Two of the submissions from industry were identical.

All the material submitted was relevant, contained specific comments and referred to peer-reviewed scientific literature. As a result, each submission was carefully considered by the Working Group. Only three submissions from industry disagreed with the preliminary opinion and the submission from academia showed some disagreement.

The document has been revised to take account of the relevant comments and the literature has been updated with relevant publications. The scientific rationale was clarified and strengthened in certain respects. The opinion, however, remained essentially unchanged. 
6. MINORITY OPINION None 


\section{LIST OF ABBREVIATIONS}

\begin{tabular}{|c|c|}
\hline$A B C$ & ATP-Binding Cassette \\
\hline ATP & Adenosine Triphosphate \\
\hline AWD & Automated Endoscope Washer Disinfector \\
\hline $\mathrm{BAC}-\mathrm{C}_{12}$ & $\mathrm{C}_{12}$ chain bennzalkonium chloride \\
\hline BIOHAZ & Panel of the European Food Safety Authority \\
\hline BIT & 1,2-Benzisothiazolin-3-one \\
\hline BPD & Biocidal Products According to Directive 98/8/EC \\
\hline BSAC & British Society for Antimicrobial Chemotherapy \\
\hline CAMP & Cationic Antimicrobial Peptides \\
\hline CLSI & Clinical and Laboratory Standards Institute \\
\hline CMIT & 5-Chloro-2-methyl-4-isothiazolin-3-one \\
\hline CT & Contact Time \\
\hline DCMX & Dichlorometaxylenol \\
\hline DDAC & Didecyl-dimethyl-ammonium chloride \\
\hline DDAC- $_{18}$ & $\mathrm{C}_{18}$ chain dialkyl-dimethyl-ammonium chloride \\
\hline DG & Directorate General \\
\hline DHA & Dehydroacetic acid \\
\hline DMT & Drug/Metabolite Transporter \\
\hline DNA & Deoxyribonucleic Acid \\
\hline EARSS & European Antimicrobial Resistance Surveillance System \\
\hline EASAC & European Academies Science Advisory Council \\
\hline $\mathrm{EC}$ & European Commission \\
\hline ECDC & European Centre for Disease prevention and Control \\
\hline ECG & Electrocardiogram \\
\hline ECHA & European Chemicals Agency \\
\hline EDTA & Ethylenediamine Tetraacetic Acid \\
\hline EEA & European Environment Agency \\
\hline EFSA & European Food Safety Authority \\
\hline EMEA & European Medicines Agency \\
\hline EPA & Environmental Protection Agency \\
\hline ETO & Ethylene Oxide \\
\hline EU & European Union \\
\hline GEI & Genomic islands \\
\hline $\mathrm{h}$ & Hour \\
\hline HAI & Health Care-Associated Infection \\
\hline HSL & Homoserine Lactone \\
\hline IFH & International Forum on Home Hygiene \\
\hline
\end{tabular}


Antibiotic Resistance Effects of Biocides

\begin{tabular}{|c|c|}
\hline $\mathrm{Kb}$ & Kilobases \\
\hline LPS & Lipopolysaccharides \\
\hline MATE & Multidrug and Toxic Compound Extrusion \\
\hline MBC & Minimum Biocidal Concentration \\
\hline MDR & Multi-Drug Resistant \\
\hline MFS & Major Facilitator Superfamily \\
\hline MGE & Mobile genetic element \\
\hline MIC & Minimum Inhibitory Concentration \\
\hline MIT & 2-Methyl-4-isothiazolin-3-one \\
\hline MR & Multiple Resistance \\
\hline MRSA & Methicillin-Resistant Staphylococcus Aureus \\
\hline ОВРСР & Orthobenzylparachlorophenol \\
\hline PCMX & Parachlorometaxylenol \\
\hline PHMB & Polyhexamethylene biguanide \\
\hline PMA & Phenylmercuric Acetate \\
\hline PMN & Phenylmercuric Nitrate \\
\hline ppGpp & Guanosine 5'-Diphosphate 3'-Diphosphate \\
\hline QAC & Quaternary Ammonium Chloride \\
\hline RNA & Ribonucleic Acid \\
\hline RND & Resistance-Nodulation-Division \\
\hline rRNA & Ribosomal RNA \\
\hline SCCP & Scientific Committee on Consumer Products \\
\hline SCENIHR & Scientific Committee on Emerging and Newly Identified Health Risks \\
\hline SCHER & Scientific Committee on Health and Environmental Risks \\
\hline SGI-1 & Salmonella genomic island 1 \\
\hline SMR & Small Multidrug Resistance \\
\hline US-EPA & US Environmental Protection Agency \\
\hline US-FDA & US Food and Drug Administration \\
\hline VRE & Vancomycin-Resistant Enterococci \\
\hline WG & Working Group \\
\hline WHO & World Health Organisation \\
\hline$\mu \mathrm{g}$ & Microgram \\
\hline$\mu \mathrm{g} / \mathrm{kg}$ & Microgram per kilogram \\
\hline$\mu \mathrm{g} / \mathrm{l}$ & Microgram per litre \\
\hline $\mathrm{Ng} / \mathrm{l}$ & Nanogram per litre \\
\hline
\end{tabular}




\section{REFERENCES}

Aarestrup FM, Hasman H. Susceptibiliy of different species isolated from food animals to copper sulphate, zinc chloride and antimicrobiol substances used for disinfection. Vet Microbiol 2004; 100:83-9.

Abdel Malek SM, Al-Adham IS, Winder CL, Buuljens TE, Gartland KM, Collier PJ. Antimicrobial susceptibility changes and T-OMP shifts in pythione-passaged planktonic cultures of Pseudomonas aeruginosa PAO1. J Appl Microbiol 2002; 92:729-36.

Adair FW, Geftic SG, Gelzer J. Resistance of Pseudomonas to quaternary ammonium compounds. Appl Microbiol 1971; 21:1058-63.

Aiello $A E$, Larson $E$. Antibacterial cleaning and hygiene products as an emerging risk factor for antibiotic resistance in the community. Lancet Infect Dis 2003; 3:501-6.

Aiello AE, Marshall B, Levy SB, Della-Latta P, Lin SX, Larson E. Antibacterial cleaning products and drug resistance. Emerg Infect Dis 2005; 11:1565-70.

Aiello $A E$, Larson EL, Levy SB. Consumer antibacterial soaps: effective or just risky? Clin Infect Dis 2007; 45 (Suppl 2):137-47.

Airey $\mathrm{P}$, Verran J. Potential use of copper as a hygienic surface; problems associated with cumulative soiling and cleaning. J Hosp Infect 2007; 67:271-7.

Akimitsu $N$, Hamamoto $H$, Inoue $R$, Shoji $M$, Akamine A, Takemori $K$, et al. Increase in resistance of methicillin-resistant Staphylococcus aureus to $\beta$-lactams caused by mutations conferring resistance to benzalkonium chloride, a disinfectant widely used in hospitals. Antimicrob Agents Chemother 1999; 43:3042-3.

Alakomi HL, Paananen A, Suihko ML, Helander IM, Saarela M. Weakening effect of cell permeabilizers on Gram-negative bacteria causing biodeterioration. Appl Environ Microbiol 2006; 72:4695-703.

Allen MJ, White GF, Morby AP. The response of Escherichia coli to exposure to the biocide polyhexamethylene biguanide. Microbiology 2006; 152:989-1000.

Allerberger F, Ayliffe G, Bassetti M, Braveny I, Bucher A, Damani N, et al. Routine surface disinfection in health care facilities: should we do it? Am J Infect Control 2002; 30:318-9.

Anderson RL, Carr JH, Bond WW, Favero MS. Susceptibility of vancomycin-resistant enterococci to environmental disinfectants. Infect Control Hosp Epidemiol 1997; 18:195-9.

Anderson GG, O'Toole GA. Innate and induced resistance mechanisms of bacterial biofilms. Curr Top Microbiol Immunol 2008; 322:85-105.

Ashby MJ, Neale JE, Knott SJ, Critchley IA. Effect of antibiotics on non-growing planktonic cells and biofilms of Escherichia coli. J Antimicrob Chemother 1994; 33:443-52.

Ayres HM, Payne DN, Furr JR, Russell AD. Effect of permeabilizing agents on antibacterial activity against a simple Pseudomonas aeruginosa biofilm. Lett Appl Microbiol 1998; 27:79-82.

Ayres HM, Furr JR, Russell AD. Effect of permeabilizers on antibiotic sensitivity of Pseudomonas aeruginosa. Lett Appl Microbiol 1999; 28:13-6.

Babb JR. Disinfection and sterilization of endoscopes. Current Opinion in Infectious Diseases 1993; 6:532-7.

Bamber AI, Neal TJ. An assessment of triclosan susceptibility in methicillin resistant and methicillin sensitive Staphylococcus aureus. J Hosp Infect 1999; 41:107-9.

Baquero F, Martínez JL, Cantón R. Antibiotics and antibiotic resistance in water environments. Curr Opin Biotechnol 2008, 19:260-5.

Baucheron S, Mouline C, Praud K, Chaslus-Dancla E, Cloeckaert A. TolC but not AcrB is essential for multridrug-resistant Salmonella enterica serotype Typhimurium colonization of chicks. J. Antimicrob Chemotherapy 2005; 55:707-12.

Beaber JW, Hochhut B, Waldor MK. SOS response promotes horizontal dissemination of antibiotic resistance genes. Nature 2004; 427:72-4.

Berg JD, Matin A, Roberts PV. Effect of antecedent growth condition on sensitivity of Escherichia coli to chlorine dioxide. Appl Environ Microbiol 1982; 44:814-9. 
Beveridge TJ, Hughes MN, Lee H, Leung KT, Poole RK, Savvaidis I, et al. Metal-microbe interactions: contemporary approaches. Adv Microb Physiol 1997; 38:177-243.

Birnie CR, Malamud D, Schnaare RL. Antimicrobial evaluation of N-alkyl betaines and N-alkyl-N,Ndimethylamine oxides with variations in chain length. Antimicrob Agents Chemother 2000: 44:2514-7.

Bisset L, Cossart YE, Selby W, West R, Catterson D, O'Hara K, et al. A prospective study of the efficacy of routine decontamination for gastrointestinal endoscopes and the risk factors for failure. Am J Infect Control 2006; 34:274-80.

Bjorland J, Sunde M, Waage S. Plasmid-borne smr gene causes resistance to quaternary ammonium compounds in bovine Staphylococcus aureus. J Clin Microbiol 2001; 39:3999-4004.

Blanchard JL, Wholey WY, Conlon EM, Pomposiello PJ. Rapid changes in gene expression dynamics in response to superoxide reveal SoxRS-dependent and independent transcriptional networks. PLoS ONE 2007; 2:e1186.

Bloomfield SF, Looney E. Evaluation of the repeatability and reproducibility of European suspension test methods for antimicrobial activity of disinfectants and antiseptics. J Appl Bacteriol $1992 ; 73: 87-93$.

Bloomfield SF, Arthur M, Van Klingeren B, Pullen W, Holah JT, Elton R. An evaluation of the repeatability and reproducibility of a surface test for the activity of disinfectants. J Appl Bacteriol 1994; 76:86-94.

Boeris PS, Domenech CE, Lucchesi GI. Modification of phospholipid composition in Pseudomonas putida A ATCC 12633 induced by contact with tetradecyltrimethylammonium. J Appl Microbiol 2007; 103:1048-54.

Borges-Walmsley MI, Walmsley AR. The structure and function of drug pumps. Trends Microbiol 2001; 9:71-9.

Borgmann-Strahsen R. Comparative assessment of different biocides in swimming pool water. Int Biodeter Biodegrad 2003; 51:291-7.

Borling $\mathrm{P}$, Engelund B, Sørensen H. Kortlægning af triclosan Kortlægning af kemiske stoffer $\mathrm{i}$ forbrugerprodukter. Nr. 732006. Danish EPA: Copenhagen; 2005.

Boyce JM, Pittet D. Guideline for Hand Hygiene in Health-Care Settings. Recommendations of the Health Care Infection Control Practices Advisory Committee and the HICPAC/SHEA/APIC/IDSA Hand Hygiene Task Force. Society for Healthcare Epidemiology of America/Association for Professionals in Infection Control/Infectious Diseases Society of America. MMWR Recomm Rep 2002; 51 (RR-16):1-45, quiz CE1-4.

Boyce JM. Environmental contamination makes an important contribution to hospital infection. J Hosp Infect 2007; 65 (Suppl 2):50-4.

Braoudaki M, Hilton AC. Adaptive resistance to biocides in Salmonella enterica and Escherichia coli O157 and cross-resistance to antimicrobial agents. J Clin Microbiol 2004a; 42:73-8.

Braoudaki M, Hilton AC. Low level of cross-resistance between triclosan and antibiotics in Escherichia coli K-12 and E. coli O5 compared to E. coli O157. FEMS Microbiol Lett 2004b; 235:305-9.

Braoudaki M, Hilton AC. Mechanisms of resistance in Salmonella enterica adapted to ertythromycin, benzalkonium chloride and triclosan. Int J Antimicrob Agents 2005; 25:31-7.

Bridges K, Lowbury EJ. Drug-resistance in relation to use of sliver sulfadiazine cream in a burns unit. J Clin Pathol 1977; 30:160-4.

Bridges K, Kidson A, Lowbury EJ, Wilkins MD. Gentamicin- and silver-resistant pseudomonas in a burns unit. Br Med J 1979; 1:446-9.

Broadley SJ, Jenkins PA, Furr JR, Russell AD. Potentiation of the effects of chlorhexidine diacetate and cetylpyridinium chloride on mycobacteria by ethambutol. J Med Microbiol 1995; 43:458-60.

Brown MR, Williams $P$. Influence of substrate limitation and growth-phase on sensitivity to antimicrobial agents. J Antimicrob Chemother 1985; 15 (Suppl A):7-14.

Brown MR, Gilbert P. Sensitivity of biofilms to antimicrobial agents. J Appl Bacteriol 1993; 74 (Suppl):87S-97S. 
Brown MH, Paulsen IT, Skurray RA. The multidrug efflux protein NorM is a prototype of a new family of transporters. Mol Microbiol 1999; 31:394-5.

Brözel VS, Cloete TE. Resistance of Pseudomonas aeruginosa to isothiazolone. J Appl Bacteriol $1994 ; 76: 576-82$.

Bruinsma GM, Rustema-Abbing M, van der Mei HC, Lakkis C, Busscher HJ. Resistance to a polyquaternium-1 lens care solution and isoelectric points of Pseudomonas aeruginosa strains. J Antimicrob Chemother 2006; 57:764-6.

Byers KE, Durbin LJ, Simonton BM, Anglim AM, Adal KA, Farr BM. Disinfection of hospital rooms contaminated with vancomycin-resistant Enterococcus faecium. Infect Control Hosp Epidemiol $1998 ; 19: 261-4$.

Calafat AM, Ye X, Wong LY, Reidy JA, and Needham LL. Exposure of the U.S. population to bisphenol A and 4-tertiary-octylphenol: 2003-2004. Environ Health Perspect 2008; 116:39-44.

Capita R. Variation in Salmonella resistance to poultry chemical decontaminants based on serotype, phage type and antibiotic resistance patterns. J Food Prot 2007; 70:1835-43.

Carson RT, Larson E, Levy SB, Marshall BM, Aiello AE. Use of antibacterial consumer products containing quaternary ammonium compounds and drug resistance in the community. J Antimicrob Chemother 2008; 62:1160-2.

Cason JS, Jackson DM, Lowbury EJ, Ricketts CR. Antiseptic and aseptic prophylaxis for burns: use of silver nitrate and of isolators. Br Med J 1966; 2:1288-94.

Centers for Disease Control. Disinfectant or infectant: the label doesn't always say. National Nosocomial Infections Study; 1974. Fourth Quarter; 1973:18-23.

Champlin FR, Ellison ML, Bullard JW, Conrad RS. Effect of outer membrane permeabilisation on intrinsic resistance to low triclosan levels in Pseudomonas aeruginosa. Int J Antimicrob Agents 2005; 26:159-64

Chapman JS. Characterizing bacterial resistance to preservatives and disinfectants. Int Biodet Biodeg 1998; 41:241-5.

Chapman JS, DiehI MA, Fearnside KB. Preservative tolerance and resistance. Int J Cosmet Sci. 1998 Feb;20(1):31-9.

Chapman JS. Disinfectant resistance mechanisms, cross-resistance, and co-resistance. Int Biodeter Biodegrad 2003; 51:271-6.

Chuanchuen R, Beinlich K, Hoang TT, Becher A, Karkhoff-Schweizer RR, Schweizer HP. Crossresistance between triclosan and antibiotics in Pseudomonas aeruginosa is mediated by multidrug efflux pumps: exposure of a susceptible mutant strain to triclosan selects nxfB mutants overexpressing MexCD-Opr]. Antimicrob Agents Chemother 2001; 45:428-32.

Chuanchuen R, Narasaki CT, Schweizer HP. The MexJK efflux pump of Pseudomonas aeruginosa requires OprM for antibiotic efflux but not for effect of triclosan. J Bacteriol 2002; 184:5036-44.

Chuanchuen R, Pathanasophon P, Khemtong S, Wannaprasat W, Padungtod P. Susceptibilities of antimicrobials and disinfectants in Salmonella isolates obtained form poultry and swine in Thailand. J Vet Med Sci 2008; 70:595-601.

Cloete TE. Resistance mechanisms of bacteria to antimicrobial compounds. Int Biodet Biodegrad 2003; 51:277-82.

Codling $C E$, Jones BV, Mahenthiralingam E, Russell AD, Maillard J-Y. Identification of genes involved in the susceptibility of Serratia marcescens to polyquaternium-1. J Antimicrob Chemother 2004, 54:370-5.

Cole EC, Addison RM, Rubino JR, Leese KE, Dulaney PD, Newell MS, et al. Investigation of antibiotic and antibacterial agent cross-resistance in target bacteria from homes of antibacterial product users and non users. J Appl Microbiol 2003; 95:664-76.

Commission Regulation (EC) No 1451/2007 of 4 December 2007 on the second phase of the 10year work programme referred to in Article 16(2) of Directive 98/8/EC of the European Parliament and of the Council concerning the placing of biocidal products on the market. Official Journal of the European Union, L 325 of 11.12.2007; p.3-64. 
Cookson BD, Bolton MC, Platt JH. Chlorhexidine resistance in methicillin-resistant Staphylococcus aureus or just an elevated MIC? An in vitro and in vivo assessment. Antimicrob Agents Chemother 1991a; 35:1997-2002.

Cookson BD, Farrelly $H$, Stapleton P, Garvey RP, Price MR. Transferable resistance to triclosan in MRSA. Lancet 1991b; 337:1548-9.

Cookson B. Clinical significance of emergence of bacterial antimicrobial resistance in the hospital environment. J Appl Microbiol 2005; 99:989-96.

Council Directive 76/68/EEC of 27th July on the approximation of the laws of Member States relating to cosmetic products. EC Official J., No. L262, 27.9.1976, p.169.

Dancer SJ. How do we assess hospital cleaning? A proposal for microbiological standards for surface hygiene in hospitals. J Hosp Infect 2004; 56:10-5.

Dantas G, Sommer MO, Oluwasegun RD, Church GM. Bacteria subsisting on antibiotics. Science $2008 ; 320: 100-3$

Das JR, Bhakoo M, Jones MV, Gilbert P. Changes in the biocide susceptibility of Staphylococcus epidermidis and Escherichia coli cells associated with rapid attachment to plastic surfaces. J Appl Microbiol 1998; 84:852-8.

Davies DG, Parsek MR, Pearson JP, Iglewski BH, Costerton JW, Greenberg EP. The involvement of cell-to-cell signals in the development of a bacterial biofilm. Science $1998 ; 280: 295-8$.

Davin-Regli A, Chollet R, Bredin J, Chevalier J, Lepine F, Pagès JM. Enterobacter gergoviae and the prevalence of efflux in parabens resistance. J Antimicrob Chemother 2006; 57:757-60.

Davin-Regli A, Bolla JM, James CJ, Lavigne JP, Chevalier J, Garnotel E, et al. Membrane permeability and regulation of drug "influx and efflux" in enterobacterial pathogens. Current Drug Targets 2008; 9: 750-9.

Demple B. Redox signaling and gene control in the Escherichia coli soxRS oxidative stress regulon - a review. Gene 1996; 179:53-7.

Denyer SP, Maillard J-Y. Cellular impermeability and uptake of biocides and antibiotics in Gramnegative bacteria. J Appl Microbiol 2002; 92 (Suppl):35S-45S.

Depardieu F, Podglajen I, Leclercq R, Collatz E, Courvalin P. Modes and modulations of antibiotic resistance gene expression. Clin Microbiol Rev 2007; 20:79-114.

Department of Health. UK antimicrobial resistance strategy and action plan. London, UK; 2000.

Dettenkoffer M, Wenzler S, Amthor S, Antes G, Motschall E, Daschner FD. Does disinfection of environmental surfaces influence nosocomial infection rates? A systematic review. Am J Infect Control 2004; 32:84-9.

Dharan S, Mourouga P, Copin P, Bessmer G, Tschanz B, Pittet D. Routine disinfection of patients' environmental surfaces. Myth or reality? J Hosp Infect 1999; 42:113-7.

Dobrindt $U$, Hochhut B, Hentschel $U$, Hacker J. Genomic islands in pathogenic and environmental micro-organisms. Nat Rev Microbiol 2004; 2:414-24.

Donlan RM, Costerton JW. Biofilms: survival mechanisms of clinically relevant microorganisms. Clin Microbiol Rev 2002; 15:167-93.

Doublet B, Lailler R, Meunier D, Brisabois A, Boyd D, Mulvey MR, et al. Variant Salmonella genomic island 1 antibiotic resistance gene cluster in Salmonella enterica serovar Albany. Emerg Infect Dis. 2003; 9:585-91.

Doublet B, Golding GR, Mulvey MR, Cloeckaert A. Secondary chromosomal attachment site and tandem integration of the mobilizable Salmonella genomic island 1. PLoS ONE 2008; 3:e2060.

Dukan S, Touati D. Hypochlorous acid stress in Escherichia coli: resistance, DNA damage, and comparison with hydrogen peroxide stress. J Bacteriol 1996; 178:6145-50.

Dunne WM Jr. Bacterial adhesion: seen any good biofilms lately? Clin Microbiol Rev 2002; 15: 155-66.

Dye C, Schlabach M, Green J, Remberger M, Kaj L, Palm-Cousins A, et al. Bronopol, resorcinol, mcresol and triclosan in the Nordic environment. Nordic Council of Ministers, Copenhagen. TemaNord 2007; 585. 
EARSS $^{26}$ (European Antimicrobial Resistance Surveillance System). Annual Report 2005. Available from: URL: http://www.rivm.nl/earss/ (accessed 25 February 2009)

EASAC (European Academies Science Advisory Council). Tackling antibacterial resistance in Europe, 2007. available from URL:

http://www.easac.eu/document.asp?id=68\&pageno=1\&detail=1\&parent=31 (accessed 25 February 2009)

EFSA (European Food Safety Authority). Opinion of the Scientific Panel on food additives, flavourings, processing aids and materials in contact with food (AFC) related to treatment of poultry carcasses with chlorine dioxide, acidified sodium chlorite, trisodium phosphate and peroxyacids, Published: 16 January 2006, Adopted: 6 December 2005, 2005. Available at URL: http://www.efsa.europa.eu/EFSA/efsa locale-1178620753812 1178620765475.htm (accessed 25 February 2009)

EFSA. Community summary reports on trend and sources of zoonoses, zoonotic agents, antimicrobial resistance and food borne outbreaks in the European Union 2007. Available from: URL: $\quad$ http://www.efsa.europa.eu/EFSA/efsa_locale-1178620753812_1211902269834.htm (accessed 25 February 2009)

EFSA. Assessment of the possible effect of the four antimicrobial treatment substances on the emergence of antimicrobial resistance. Scientific Opinion of the Panel on Biological Hazards; 2008a. Published: 2 April 2008; Adopted: 6 March 2008. Available at URL: http://www.efsa.europa.eu/EFSA/efsa locale-1178620753812 1178697425124.htm (accessed 25 February 2009)

EFSA. Scientific opinion of the panel on biological hazards on a request from the European Food Safety Authority on foodborne antimicrobial resistance as a biological hazard. The EFSA Journal 2008b; 765:1-87.

EMEA (European Medicines Agency) 1999 EMEA/CVMP/342/99 Final Report. Antibiotic Resistance in the European Union associated with Therapeutic Use of Veterinary Medicines - Report and Qualitative Risk Assessment by the Committee for Veterinary Medicinal Products. Available from URL: http://www.emea.europa.eu/pdfs/vet/regaffair/034299ENC.pdf (accessed 25 February 2009)

Falagas ME, Bliziotis IA. Pandrug-resistant Gram-negative bacteria: the dawn of the post-antibiotic era? Int J Antimicrob Agents 2007; 29:630-6.

Ferrarese L, Paglia R, Ghirardini A. Bacterial resistance in cosmetics industrial plant: connected problems and their solution. Ann Microbiol 2003; 53:477-90.

Flores M, Morillo M, Crespo ML. Deterioration of raw materials and cosmetic products by preservative resistant micro-organisms. Int Biodeterior Biodegrad 1997; 40:157-60.

Fraise AP. Biocide abuse and antimicrobial resistance - a cause for concern? J Antimicrob Chemother 2002; 49:11-12.

Fraser VJ, Jones M, Murray PR, Medoff G, Zhang Y, Wallace RJ Jr. Contamination of flexible fiberoptic bronchoscopeswith Mycobacterium chelonae linked to an automated bronchoscope disinfection machine. Am Rev Respir Dis 1992; 145:853-5.

Fraud S, Maillard J-Y, Russell AD. Comparison of the mycobactericidal activity of orthophthalaldehyde, glutaraldehyde and other dialdehydes by a quantitative suspension test. J Hosp Infect $2001 ; 48: 214-21$.

Fraud S, Hann AC, Maillard J-Y, Russell AD. Effects of ortho-phthalaldehyde, glutaraldehyde and chlorhexidine diacetate on Mycobacterium chelonae and $M$. abscessus strains with modified permeability. J Antimicrob Chemother 2003; 51: 575-84.

Fraud S, Campigotto AJ, Chen Z, Poole K. MexCD-Opr] multidrug efflux system of Pseudomonas aeruginosa: involvement in chlorhexidine resistance and induction by membrane-damaging agents dependent upon the AlgU stress response sigma factor. Antimicrob Agents Chemother 2008; $52: 4478-82$.

\footnotetext{
${ }^{26}$ The European Antimicrobial Resistance Surveillance System (EARSS), funded by DG SANCO of the European Commission is an international network of national surveillance systems which collects comparable and validated antimicrobial susceptibility data for public health action.
} 
Gaillard M, Pernet N, Vogne C, Hagenbüchle O, van der Meer JR. Host and invader impact of transfer of the clc genomic island into Pseudomonas aeruginosa PAO1. Proc Natl Acad Sci USA. 2008; 105:7058-63.

Gandhi PA, Sawant AD, Wilson LA, Ahearn DG. Adaptation and growth of Serratia marcescens in contact lens disinfectant solution containing chlorhexidine gluconate. Appl Environ Microbiol 1993; 59:183-8.

Gayle WE, Mayhall CG, Lamb VA, Apollo E, Haynes BW Jr. Resistant Enterobacter cloacae in a burn center: the ineffectiveness of silver sulfadiazine. J Trauma 1978; 18:317-23.

Gaze WH, Abdouslam N, Hawkey PM, Wellington EM. Incidence of class-1 integrons in a quaternary ammonium compound-polluted environment. Antimicrob Agents Chemother 2005; 49:1802-7.

Gilbert P, McBain AJ. Potential Impact of increased use of biocides in consumer products on prevalence of antibiotic resistance. Clin Microbiol Rev 2003; 16:189-208.

Gilbert P, McBain AJ, Rickard AH. Formation of microbial biofilm in hygienic situations: a problem of control. Int Biodeter Biodegrad 2003; 51:245-8.

Gilbert P, McBain A. Live and let die. Microbiol Today 2004; 31:61-4.

Gilbert P, Moore LE. Cationic antsieptics: diversity of action under a common epithet. J Appl Microbiol 2005; 99:703-15.

Gillespie MT, May JW, Skurray RA. Plasmid-encoded resistance to acriflavine and quaternary ammonium compounds in methicillin-resistant Staphylococcus aureus. FEMS Microbiol Lett 1986; 34:47-51.

Gillespie TG, Hogg L, Budge E, Duncan A, Coia JE. Mycobacterium chelonae isolated from rinse water within and endoscope washer-disinfector. J Hosp Infect 2000; 45:332-4.

Giwercman B, Jensen ET, Hoiby N, Kharazmi A, Costerton JW. Induction of beta-lactamase production in Pseudomonas aeruginosa biofilm. Antimicrob Agents Chemother 1991; 35:1008-10.

Gomez Escalada M, Russell AD, Maillard J-Y, Ochs D. Triclosan-bacteria interactions: single or multiple target sites? Lett Appl Microbiol 2005a; 41:476-81.

Gomez Escalada M, Harwood JL, - JY, Ochs D. Triclosan inhibition of fatty acid synthesis and its effect on growth of E. coli and Ps. aeruginosa. J Antimicrob Chemother 2005b; 55:879-82.

Gradel KO, Randall L, Sayers AR, Davies RH. Possible associations between Salmonella persistence in poultry houses and resistance to commonly used disinfectants and a putative role of mar. Vet Microbiol 2005; 107:127-38.

Greenberg JT, Demple B. A global response induced in Escherichia coli by redox cycling agents overlaps with that induced by peroxide stress. J Bacteriol 1989; 171:3933-9.

Greenberg JT, Monach P, Chou JH, Josephy PD, Demple B. Positive control of a global antioxidant defense regulon activated by superoxide-generating agents in Escherichia coli. Proc Nat Acad Sci USA $1990 ; 87: 6181-5$.

Greenway DL, England RR. The intrinsic resistance of Escherichia coli to various antimicrobial agents requires ppGpp and sigma s. Lett Appl Microbiol 1999; 29:323-6.

Griffith CJ, Cooper RA, Gilmore J, Davies C, Lewis M. An evaluation of hospital cleaning regimes and standards. J Hosp Infect 2000; 45:19-28.

Griffiths PA, Babb JR, Bradley CR, Fraise AP. Glutaraldehyde-resistant Mycobacterium chelonae from endoscope washer disinfectors. J Appl Microbiol 1997; 82:519-26.

Guérin-Méchin L, Dubois-Brissonnet F, Heyd B, Leveau JY. Specific variations of fatty acid composition of Pseudomonas aeruginosa ATCC 15442 induced by quaternary ammonium compounds and relation with resistance to bactericidal activity. J Appl Microbiol 1999; 87:735-42.

Guérin-Méchin L, Dubois-Brissonnet F, Heyd B, Leveau JY. Quaternary ammonium compounds stresses induce specific variations in fatty acid composition of Pseudomonas aeruginosa. Inter J Food Microbiol 2000; 55:157-9.

Hall-Stoodley L, Costerton JW, Stoodley P. Bacterial biofilms: from the natural environment to infectious diseases. Nat Rev Microbiol. 2004; 2:95-108. 
Hammond SA, Morgan JR, Russell AD. Comparative susceptibility of hospital isolates of gramnegative bacteria to antiseptics and disinfectants. J Hosp Infect 1987; 9:255-64.

Hansen LH, Sørensen SJ, Jørgensen HS, Jensen LB. The prevalence of the OqxAB multidrug efflux pump amongst olaquindox-resistant Escherichia coli in pigs. Microb Drug Resist 2005; 11:378-82.

Hansen LH, Jensen LB, Sørensen HI, Sørensen SJ. Substrate specificity of the OqxAB multidrug resistance pump in Escherichia coli and selected enteric bacteria. J Antimicrob Chemother 2007; $60: 145-7$.

Harbarth S, Samore $\mathrm{MH}$. Antimicrobial resistance determinants and future control. Emerg Infect Dis 2005; 11:794-801.

Hassett DJ, Ma JF, Elkins JG, MCDermott TR, Ochsner UA, West SE, et al. Quorum sensing in Pseudomonas aeruginosa controls expression of catalase and superoxide dismutase genes and mediates biofilm susceptibility to hydrogen peroxide. Mol Microbiol 1999; 34:1082-93.

Hawkey PM. Mycobactericidal agents. In: Fraise AP, Lambert PA, Maillard J-Y, editors. Principles and practice of disinfection, preservation and sterilization. 4th ed. Oxford: Blackwell Scientific Publication; 2004. p.191-204.

Heath RJ, Yu YT, Shapiro MA, Olson E, Rock CO. Broad spectrum antimicrobial biocides target the FabI component of fatty acid synthesis. J Biol Chem 1998; 273:30316-20.

Heath RJ, Rubin JR, Holland DR, Zhang E, Snow ME, Rock CO. Mechanism of triclosan inhibition of bacterial fatty acid synthesis. J Biol Chem 1999; 274:11110-4.

Heath RJ, Li J, Roland GE, Rock CO. Inhibition of the Staphylococcus aureus NADPH-dependent Enoyl-acyl carrier protein reductase by triclosan and hexachlorophene. J Biol Biochem 2000; 275: 4654-9.

Heir E, Sundheim G, Holck AL. Resistance to quaternary ammonium compounds in Staphylococcus spp. isolated from the food industry and nucleotide sequence of the resistance plasmid pST827. J Appl Bacteriol 1995; 79:149-56.

Heir E, Sundheim G, Holck AL. The Staphylococcus qacH gene product: a new member of the SMR family encoding multidrug resistance. FEMS Microbiol Lett 1998; 163:49-56.

Heir E, Sundheim G, Holck AL. The qacG gene on plasmid pST94 confers resistance to quaternary ammonium compounds in staphylococci isolated from the food industry. J Appl Microbiol 1999; $86: 378-88$.

Holah JT. CEN/TC216: its role in producing current and future European disinfectant testing standards. Int Biodegrad Biodeter 2003; 51:239-43.

Hota B. Contamination, disinfection and cross-colonization: are hospital surfaces reservoirs for nosocomial infection? Clin Infect Dis 2004; 39:1182-9.

Huang CT, Yu FP, McFeters GA, Stewart PS. Nonuniform spatial patterns of respiratory activity within biofilms during disinfection. Appl Environ Microbiol 1995; 61: 2252-6.

Huet AA, Raygada JL, Mendiratta K, Seo SM, Kaatz GW. Multidrug efflux pump overexpression in Staphylococcus aureus after single and multiple in vitro exposures to biocides and dyes. Microbiology 2008; 154:3144-53.

Hutchinson J, Runge W, Mulvey M, Norris G, Yetman M, Valkova N, et al. Burkholderia cepacia infections associated with intrinsically contaminated ultrasound gel: The role of microbial degradation of parabens. Infect Control Hosp Epidemiol 2004; 25:291-6.

IFH (International Scientific Forum for Home Hygiene): Biocide usage and antimicrobial resistance in home settings: an update. October 2003.

Jacquet C, Reynaud A. Difference in the sensitivity to eight disinfectants of Listeria monocytogenes strains as related to their origin. Int J food Microbiol 1994; 22:79-83.

Jansen WT, van der Bruggen JT, Verhoef J, Fluit AC. Bacterial resistance: a sensitive issue complexity of the challenge and containment strategy in Europe. Drug Resist Updat 2006; 9:12333.

Jones GL, Muller CT, O'Reilly M, Stickler DJ. Effect of triclosan on the development of bacterial biofilms by urinary tract pathogens on urinary catheters. J Antimicrob Chemother 2006; 57:26672. 
Jones MW, Herd TM, Christie HJ. Resistance of Pseudomonas aeruginosa to amphoteric and quaternary ammonium biocides. Microbios 1989; 58:49-61.

Jungclaus GA, Lopez-Avila V, Hites RA. Organic compounds in industrial wastewater: a case study of their environmental impact. Environ Sci Technol 1978; 12:88-96.

Jurgens DJ, Sattar SA, Mah TF. Chloraminated drinking water does not generate bacterial resistance to antibiotics in Pseudomonas aeruginosa biofilms. Lett Appl Microbiol 2008; 46:562-7.

Kampf G, Höfer M, Wendt C. Efficacy of hand disinfectants against vancomycin-resistant enterococci in vitro. J Hosp Infect 1999; 42:143-50.

Kampf G, Ostermeyer C. Intra-laboratory reproducibility of the hand hygiene reference procedures of EN 1499 (hygienic handwash) and EN 1500 (hygienic hand disinfection). J Hosp Infect 2002; 52:219-24.

Kampf G, Meyer B, Goroncy-Bermes P. Comparison of two test methods for the determination of sufficient antimicrobial activity of three commonly used alcohol-based hand rubs for hygienic hand disinfection. J Hosp Infect 2003; 55:220-5.

Kampf G, Kramer A. Epidemiologic background of hand hygiene and evaluation of the most important agents for scrubs and rubs. Clin Microbiol Rev 2004; 17:863-93.

Kampf G, Reichel M, Feil Y, Eggerstedt S, Kaulfers PM. Influence of rub-in technique on required application time and hand coverage in hygienic hand disinfection. BMC Infect Dis 2008; 8:149.

Karatzas KA, Webber MA, Jorgensen F, Woodward MJ, Piddock LJ, Humphrey TJ. Prolonged treatment of Salmonella enterica serovar Typhimurium with commercial disinfectants selects for multiple antibiotic resistance, increased efflux and reduced invasiveness. J Antimicrob Chemother 2007; 60:947-55.

Karatzas KA, Randall LP, Webber M, Piddock LJ, Humphrey TJ, Woodward MJ, et al. Phenotypic and proteomic characterization of multiply antibiotic-resistant variants of Salmonella enterica serovar Typhimurium selected following exposure to disinfectants. Appl Environ Microbiol 2008; $74: 1508-16$.

Kim H, Ryu JH, Beuchat LR. Effectiveness of disinfectants in killing Enterobacter sakazakii in suspension, dried on the surface of stainless steel, and in a biofilm. Appl Environ Microbiol 2007; 73:1256-65.

Kimiran-erdem A, Sanli-Yurudu NO, Cotuk A. Efficacy of a quaternary ammonium compound against planktonic and sessile populations of different Legionella pneumophilia strains. Ann Microbiol 2007; 57:121-5.

Kingeren B, Pullen W. Glutaraldehyde resistant mycobacteria from bronchoscope washers. J Hosp Infect 1993; 25:147-9.

Klasen $\mathrm{HJ}$. A historical review of the use of silver in the treatment of burns. II. Renewed interest for silver. Burns 2000; 26:131-8.

Kneale $C$. Problems and pitfalls in the evaluation and design of new biocides for plastics applications. Polym Polym Compos 2003; 11:219-28.

Kõljalg S, Naaber P, Mikelsaar M. Antibiotic resistance as an indicator of bacterial chlorhexidine susceptibility. J Hosp Infect 2002; 51:106-13.

Kolpin DW, Furlong ET, Meyer MT, Thurmann EM, Zaugg SD, Barber LB, et al. Pharmaceuticals, hormones and other organic wastewater contaminants in U.S. streams, 1999-2000: a national reconnaissance. Environ Sci Technol 2002; 36:1202-11.

Koutsolioutsou A, Pena-Llopis S, Demple B. Constitutive soxR mutations contribute to multipleantibiotic resistance in clinical Escherichia coli isolates. Antimicrob Agents Chemother 2005; 49:2746-52.

Kressel A, Kidd F. Pseudo-outbreak of Mycobacterium chelonae and Methylobacterium mesophilicum caused by contamination of an automated endoscopy washer. Infect Control Hosp Epidemiol 2001; 22:414-8.

Kücken D, Feucht $\mathrm{HH}$, Kaulfers PM. Association of qacE and qacE $\Delta 1$ with multiple resistance to antibiotics and antiseptics in clinical isolates of Gram-negative bacteria. FEMS Microbiol Lett 2000; 183:95-8. 
Kunonga NI, Sobieski RJ, Crupper SS. Prevalence of the multiple antibiotic resistance operon (marRAB) in the genus Salmonella. FEMS Microbiol Lett 2000; 187:155-60.

Kümmerer $\mathrm{K}$, Al-Ahmad A, Henninger A. Use of chemotaxonomy to study the influence of benzalkonium chloride on bacterial populations in biodegradation testing. Acta Hydrochim Hydrobiol 2002; 30:171-8.

Kümmerer K. Resistance in the environment. J Antimicrob Chemother 2004; 54:311-20.

Kummerle N, Feucht $\mathrm{HH}$, Kaulfers PM. Plasmid-mediated formaldehyde resistance in Escherichia coli: characterization of resistance gene. Antimicrob Agents Chemother 1996; 40:2276-9.

Lambert PA. Cellular impermeability and uptake of biocides and antibiotics in Gram-positive bacteria and mycobacteria. J Appl Microbiol 2002; 92 (Suppl):S46-S55.

Lambert RJ. Evaluation of antimicrobial efficacy. In: Fraise AP, Lambert PA and Maillard J-Y, editors. Principles and practice of disinfection, preservation and sterilization. 4th ed. Oxford: Blackwell Science; 2004. p.345-60.

Langsrud S, Sidhu MS, Heir E, Holck AL. Bacterial disinfectant resistance - a challenge for the food industry. Int Biodeter Biodegrad 2003; 51:283-90.

Langsrud S, Sundheim G. Factors influencing a suspension test method for antimicrobial activity of disinfectants. J Appl Microbiol 1998; 85:1006-12.

Laraki N, Galleni M, Thamm I, Riccio ML, Amicosante G, Frère JM, et al. Structure of In31, a blaIMP-containing Pseudomonas aeruginosa integron phyletically related to In5, which carries an unusual array of gene cassettes. Antimicrob Agents Chemother 1999; 43:890-901.

Lear JC, Maillard J-Y, Goddard PA, Dettmar PW, Russell AD. Isolation and study of chloroxylenoland triclosan-resistant strains of bacteria. J Pharm Pharmacol 2000; 52 (Suppl):126.

Lear JC, Maillard J-Y, Dettmar PW, Goddard PA, Russell AD. Chloroxylenol- and triclosan- tolerant bacteria from industrial sources. J Ind Microbiol Biotechnol 2002; 29:238-42.

Lear JC, Maillard J-Y, Dettmar PW, Goddard PA, Russell AD. Chloroxylenol- and triclosan-tolerant bacteria from industrial sources - susceptibility to antibiotics and other biocides. Int Biodeter Biodegrad 2006; 57:51-6.

Ledder RG, Gilbert P, Willis C, McBain AJ. Effects of chronic triclosan exposure upon the antimicrobial susceptibility of 40 ex-situ environmental and human isolates. J Appl Microbiol 2006; 100:1132-40.

Leelaporn A, Paulsen IT, Tennent JM, Littlejohn TG, Skurray RA. Multidrug resistance to antiseptics and disinfectants in coagulase-negative staphylococci. J Med Microbiol 1994; 40:214-20.

Levings RS, Partridge SR, Djordjevic SP, Hall RM. SGI1-K, a variant of the SGI1 genomic island carrying a mercury resistance region, in Salmonella enterica serovar Kentucky. Antimicrob Agents Chemother 2007; 51:317-23.

Levy CW, Roujeinikova A, Sedclnikova S. Baker PJ, Stuitje R, Slabast AR, et al. Molecular basis of triclosan activity. Nature 1999; 398:384-5.

Levy SB. Active efflux mechanisms for antimicrobial resistance. Antimicrob Agents Chemother $1992 ; 36: 695-703$.

Levy SB. Antibiotic and antiseptic resistance: impact on public health. Pediatr Infect Dis J 2000; 19 (Suppl):120-2.

Levy SB. Active efflux, a common mechanism for biocide and antibiotic resistance. J Appl Microbiol 2002; 92 (Suppl):65-71.

Lewis, K. Riddle of biofilm resistance. Antimicrob Agents Chemother 2001; 45:999-1007.

Lewis K. Multidrug tolerance of biofilms and persister cells. Curr Top Microbiol Immunol. 2008; 322:107-31.

Li XZ, Nikaido H. Efflux-mediated drug resistance in bacteria. Drugs 2004; 64:159-204.

Lindström A, Buerge IJ, Poiger T, Bergqvist P, Müller MD, Buser H. Occurrance and environmental behavior of the bactericide triclosan and its methyl derivative in surface waters and in wastewater. Environ Sci Technol 2002; 36:2322-9. 
Littlejohn TG, Paulsen IP, Gillespie M, Tennent JM, Midgely M, Jones IG, et al. Substrate specificity and energetics of antiseptic and disinfectant resistance in Staphylococcus aureus. FEMS Microbiol Lett 1992; 95:259-66.

Lomovskaya O, Lewis K. Emr, an Escherichia coli locus for multidrug resistance. Proc Natl Acad Sci USA $1992 ; 89: 8938-42$.

Lopez-Avila V, Hites RA. Organic compounds in industrial wastewater. Their transport into sediments. Environ Sci Technol 1980; 14:1382-90.

Lynch SA, Robertson GT. Bacterial and fungal biofilm infections. Ann Rev Med 2008; 59:415-28.

Lyon BR, Skurray RA. Antimicrobial resistance of Staphylococcus aureus: genetic basis. Microbiol Rev 1987; 51:88-134.

Ma D, Cook DN, Hearst JE, Nikaido H. Efflux pumps and drug resistance in Gram-negative bacteria. Trends Microbiol 1994; 2:489-93.

Ma D, Alberti M, Lynch C, Nikaido H, Hearst JE. The local repressor AcrR plays a modulating role in the regulation of the $a c r A B$ genes of $E$. coli by global stress signals. Mol Microbiol 1996; 19:10112.

MacLehose HG, Gilbert P, Allison DG. Biofilms, homoserine lactones and biocide susceptibility. J Antimicrob Chemother 2004; 53:180-4.

Madsen T, Andersen TT, Nylén D, Pratt CH. Miljø- og sundhedsvurdering af kemiske stoffer $\mathrm{i}$ industrielle og institutionsanvendte rengøringsmidler. Miljøprojekt Nr. 1047, 2005. Danish EPA, Copenhagen.

Maillard J-Y. Bacterial target sites for biocidal action. J Appl Microbiol 2002; 92 (Suppl):16S-27S.

Maillard J-Y. Antimicrobial biocides in the health care environment: efficacy, policies, management and perceived problems. Ther Clin Risk Manag 2005; 1:307-20.

Maillard J-Y. Bacterial resistance to biocides in the health care environment: should it be of genuine concern? J Hosp Infect 2007; 65 (Suppl 2):60-72.

Maira-Litrán T, Allison DG, Gilbert P. An evaluation of the potential of the multiple antibiotic resistance operon (mar) and the multidrug efflux pump acrAB to moderate resistance towards ciprofloxacin in Escherichia coli biofilms. J Antimicrob Chemother 2000; 45:789-95.

Maloney S, Welbel S, Daves B, Adams K, Becker S, Bland L, et al. Mycobacterium abscessus pseudoinfection traced to an automated endoscope washer: utility of epidemiologic and laboratory investigation. J Infect Dis 1994; 169:1166-9.

Manzoor SE, Lambert PA, Griffiths PA, Gill MJ, Fraise AP. Reduced glutaraldehyde susceptibility in Mycobacterium chelonae associated with altered cell wall polysaccharides. J Antimicrob Chemother $1999 ; 43: 759-65$.

Marchetti MG, Kampf G, Finzi G, Salvatorelli G. Evaluation of the bactericidal effect of five products for surgical hand disinfection according to prEN 12054 and prEN 12791. J Hosp Infect 2003; 54:63-7.

Maris P. Resistance of 700 Gram negative bacterial strains to antiseptics and antibiotics. Ann Rech Vet $1991 ; 22: 11-23$.

Martin $\mathrm{H}$, Maris $\mathrm{P}$. Antiseptic and antibiotic resistance of 310 gram-positive strains isolated from udders after use of post-milking teat germicides. Vet Res 1995; 26:43-56.

Martin DJ, Denyer SP, McDonnell G, Maillard J-Y. Resistance and cross-resistance to oxidising agents of bacterial isolates from endoscope washer disinfectors. J Hosp Infect 2008; 69:377-83.

Martínez-Carballo E, González-Barreiro C, Sitka A, Kreuzinger N, Scharf S, Gans O. Determination of selected quaternary ammonium compounds by liquid chromatography with mass spectrometry. Part II. Application to sediment and sludge samples in Austria. Environ Pollution 2007; 146:543-7.

McAvoy DC, Schatovitz B, Jacob M, Hauk A, Eckhoff W. Measurement of triclosan in wastewater treatment systems. Environ Toxicol Chem 2002; 21:1323-9.

McBain AJ, Rickard AH, Gilbert P. Possible implications of biocide accumulation in the environment on the prevalence of bacterial antibiotic resistance. J Indust Microbiol Biotechnol 2002; 9:326-30. 
McBain AJ, Gilbert P, Allison DG. Biofilms and biocides: are there implications of antibiotic resistance? Rev Environ Sci Technol 2003a; 2:141-6.

MacBain AJ, Bartolo RG, Catrenich CE, Charbonneau D, Ledder RG, Price BB. Exposure of sink drain microcosms to triclosan: population dynamics and antimicrobial susceptibility. Appl Environ Microbiol 2003b; 69:5433-42.

McBain AJ, Ledder RG, Moore LE, Catrenich CE, Gilbert P. Effects of quaternary-ammonium based formulations on bacterial community dynamics and antimicrobial susceptibility. Appl Environ Microbiol 2004a; 70:3449-56.

McBain AJ, Ledder RG, Sreenivasan P, Gilbert P. Selection for high-level resistance by chronic triclosan exposure is not universal. J Antimicrob Chemother 2004b; 53:772-7.

McDonnell G, Russell AD. Antiseptics and disinfectants: activity, action and resistance. Clin Microbiol Rev 1999; 12:147-79.

McHugh GL, Moellering RC, Hopkins CC, Swartz MN. Salmonella typhymurium resistant to silver nitrate, chloramphenicol and ampicillin. Lancet 1975; 1:235-40.

McKeegan KS, Borges-Walmsley MI, Walmsley AR. The structure and function of drug pumps: an update. Trends Microbiol 2003; 11:21-9.

McMurry LM, Oethinger M, Levy SB. Triclosan targets lipid synthesis. Nature, London 1998a; 394:531-2.

McMurry LM, Oethinger M, Levy SB. Overexpression of marA, soxS, or acrAB produces resistance to triclosan in laboratory and clinical strains of Escherichia coli. FEMS Microbiol Lett 1998b; 166:305-9.

McMurry LM, McDermott PF, Levy SB. Genetic evidence that InhA of Mycobacterium smegmatis is a target for triclosan. Antimicrob Agent Chemother 1999; 43:711-3.

McNeil MR, Brennan PJ. Structure, function and biogenesis of the cell envelope of mycobacteria in relation to bacterial physiology, pathogenesis and drug resistance; some thoughts and possibilities arising from recent structural information. Res Microbiol 1991; 142:451-63.

Méchin L, Dubois-Brissonnet F, Heyd B, Leveau JY. Adaptation of Pseudomonas aeruginosa ATCC 15442 to didecyldimethylammonium bromide induces changes in membrane fatty acid composition and in resistance of cells. J Appl Microbiol 1999; 86:859-66.

Mehtar S, Wiid I, Todorov SD. The antimicrobial activity of copper and copper alloys against nosocomial pathogens and Mycobacterium tuberculosis isolated from health care facilities in the Western Cape: an in-vitro study. J Hosp Infect 2008; 68:45-51.

Messager S, Goddard PA, Dettmar PW, Maillard J-Y. Comparison of two in vivo and two ex vivo tests to assess the antibacterial activity of several antiseptcics. J Hosp Infect 2004; 58:115-21.

Misra TK. Bacterial resistances to inorganic mercury salts and organomercurials. Plasmid 1992; 27:4-16.

Mitchell BA, Brown MH, Skurray RA. QacA multidrug efflux pump from Staphylococcus aureus: comparative analysis of resistance to diamidines, biguanides and guanylhydrazones. Antimicrob Agents Chemother 1998; 42:475-7.

Moken MC, McMurry LM, Levy SB. Selection of multiple-antibiotic-resistant (Mar) mutants of Escherichia coli by using the disinfectant pine oil: Roles of the mar and acrAB loci. Antimicrob Agents Chemother 1997; 41:2770-2.

Mokgatla RM, Brözel VS, Gouws PA. Isolation of Salmonella resistant to hypochlorous acid from a poultry abattoir. Lett Appl Microbiol 1998; 27:379-82.

Mokgatla RM, Gouws PA, Brözel VS. Mechanisms contributing to hypochlorous acid resistance of a Salmonella isolate from a poultry-pocessing plant. J Appl Microbiol 2002; 92:566-73.

Moore LE, Ledder RG, Gilbert P, McBain AJ. In vitro study of the effect of cationic biocides on bacterial population dynamics and susceptibility. Appl Environ Microbiol 2008; 74:4825-34.

Morita Y, Murata T, Mima T, Shiota S, Kuroda T, Mizushima T, et al. Induction of mexCD-opr] operon for a multidrug efflux pump by disinfectants in wild-type Pseudomonas aeruginosa PAO1. J Antimicrob Chemother 2003; 51:991-4. 
Morrisson AJ Jr, Wenzel RP. Epidemiology of infections due to Pseudomonas aeruginosa. Rev Infect Dis 1984; 6 (Suppl 3):S627-42.

Moyer CA, Brentano L, Gravens DL, Margraf HW, Monafo WW Jr. Treatment of large human burns with 0.5\% silver nitrate solution. Arch Surg 1965; 90:812-67.

Munton TJ, Russell AD. Effect of glutaraldehyde on protoplasts of Bacillus megaterium. J Gen Microbiol 1970; 63:367-70.

Murray GE, Tobins RS, Junkins B, Kushner DJ. Effect of chlorination on antibiotic-resistance profiles of sewage-related bacteria. Appl Environ Microbiol 1984; 48:73-7.

Na'was T, Alkofahi A. Microbial contamination and preservative efficacy of topical Creams. J Clin Pharm Ther 1994; 19:41-6.

Nikaido $\mathrm{H}$. Molecular basis of bacterial outer membrane permeability revisited. Microbiol Mol Biol Rev 2003; 67:593-656.

Nishihara T, Okamoto T, Nishiyama N. Biodegradation of didecyl-dimethyl-ammonium chloride by Pseudomonas fluorescens TN4 isolated from activated sludge. J Appl Microbiol 2000; 88:641-7.

Nishino K, Yamagushi A. Analysis of a complete library of putative drug transporter genes in Escherichia coli. J Bacteriol 2001; 183:5803-12.

Noguchi N, Tamura M, Narui K, Wakasugi K, Sasatsu M. Frequency and genetic characterization of multidrug-resistant mutants of Staphylococcus aureus after selection with individual antiseptics and fluoroquinolones. Biol Pharm Bull 2002; 25:1129-32.

Noguchi N, Suwa J, Narui K, Sasatsu M, Ito T, Hiramatsu K, et al. Susceptibilities to antiseptic agents and distribution of antiseptic-resistance genes qacA/B and smr of methicillin-resistant Staphylococcus aureus isolated in Asia during 1998 and 1999. J Med Microbiol 2005; 54:557-65.

Nomura K, Ogawa M, Miyamoto H, Muratani T, Taniguchi H. Antibiotic susceptibility of glutaraldehyde tolerant Mycoibacetrium chelonae from bronchoscope washing machine. Am J Infect Control 2004; 32:185-8.

Noyce JO, Michels $\mathrm{H}$, Keevil CW. Potential use of copper surfaces to reduce survival of epidemic meticillin-resistant Staphylococcus aureus in the health care environment. J Hops Infect 2006; 63:289-97.

Ochman H, Lawrence JG, Groisman EA. Lateral gene transfer and the nature of bacterial innovation. Nature 2000; 405:299-304.

Oethinger M, Kern WV, Goldman JD, Levy SB. Association of organic solvent tolerance and fluoroquinolone resistance in clinical isolates of Escherichia coli. Mol Microbiol 1998; 16:45-55.

OJEC (Official Journal of the European Community). Council resolution of 8 June 1999 on antibiotic resistance, 'A strategy against nicrobial threat. OJEC 1999; C195:1-3.

Okumura T, Nishikawa Y. Gas chromatography-mass spectrometry determination of triclosans in water, sediment and fish samples via methylation with diazomethane. Analytica Chimica Acta $1996 ; 325: 175-84$.

Oren-Gradel K, Randall L, Sayers AR, Davies RH. Possible association between Salmonella persistence in poultry houses and resistance to commonly used disinfectants and a putative rule of mar. Vet Microbiol 2005; 107:127-38.

O'Rourke E, Runyan D, O'Leary J, Stern J. Contaminated iodophor in the operating room. Am J Infect Control 2003; 31:255-6.

Pajkos A, Vickery $K$, Cossart $Y$. Is biofilm accumulation on endoscope tubing a contributor to the failure of cleaning and decontamination? J Hosp Infect 2004; 58:224-9.

Pan Y, Breidt F, Kathariou S. Resistance of Listeria monocytogenes biofilms to sanitizing agents in a simulated food processing environment. Appl Environ Microbiol 2006; 72:7711-7.

Parikh SL, Xiao G, Tonge PJ. Inhibition of InhA, enoyl reductase from Mycobacterium tuberculosis, by triclosan and isoniazid. Biochemistry 2000; 39:7645-50.

Paulsen IT, Brown MH, Skurray RA. Proton-dependent multidrug efflux systems. Microbiol Rev 1996a; 60:575-608. 
Paulsen IT, Skurray RA, Tam R, Saier MH, Turner RJ, Wiener JH, et al. The SMR family: a novel family of multidrug efflux proteins involved with the efflux of lipophilic drugs. Mol Microbiol 1996b; 19:1167-75.

Paulsen IT, Brown MH, Skurray RA. Characterization of the earliest known Staphylococcus aureus plasmid encoding a multidrug efflux system. J Bacteriol 1998; 180:3477-9.

Pearce H, Messager S, Maillard J-Y. Effect of biocides commonly used in the hospital environment on the transfer of antibiotic-resistance genes in Staphylococcus aureus. J Hosp Infect 1999; 43:101-8.

Percival SL, Bowler PG, Russell D. Vacetrial resistance to silver in wound care. J Hosp Infect 2005; $60: 1-7$

Peyrat MB, Soumet C, Maris P, Sanders P. Phenotypes and genotypes of campylobacter strains isolated after cleaning and disinfection in poultry slaughterhouses. Vet Microbiol 2008; 128:31326.

Piddock LJ. Clinically relevant chromosomally encoded multidrug resistance efflux pump in bacteria. Clin Microbiol Rev 2006; 19:382-402.

Pittet D, Allegranzi B, Sax H. Hand hygiene. In: Jarvis W, editor. Bennett \& Brachman's Hospital Infections. Phiadelphia: Lippincott Williams \& Wilkins; 2007. p.31-44.

Pomposiello PJ, Bennik MH, Demple B. Genome-wide transcriptional profiling of the Escherichia coli responses to superoxide stress and sodium salicylate. J Bacteriol 2001; 183:3890-902.

Poole K. Multidrug resistance in Gram-negative bacteria. Curr Opin Microbiol 2001; 4:500-8.

Poole K. Mechanisms of bacterial biocide and antibiotic resistance. J Appl Microbiol 2002a; 92 (Suppl):55-64.

Poole K., Outer membranes and efflux: the path to multidrug resistance in Gram-negative bacteria. Curr Pharm Biotechnol 2002b; 3:77-98.

Poole K. Acquired resistance. In: Fraise AP, Lambert PA, Maillard J-Y, editors. Principles and practice of disinfection, preservation and sterilization. 4th ed. Oxford: Blackwell Scientific Publication; 2004. p.170-83.

Poole K. Efflux pumps as antimicrobial resistance mechanisms. Ann Med 2007; 39:162-76.

Potenski CJ, Gandhi M, Matthews KR. Exposure of Salmonella Enteritidis to chlorine or food preservatives increases susceptibility to antibiotics. FEMS Microbiol Lett 2003; 220:181-6.

Prince J, Ayliffe GA. In-use testing of disinfectants in hospitals. J Clin Pathol 1972; 25:586-9.

Pumbwe L, Skilbeck CA, Wexler HM. Induction of multiple antibiotic resistance in Bacteroides fragilis by benzene and benzene-derived active compounds of commonly used analgesics, antiseptics and cleaning agents. J Antimicrob Chemother 2007; 60:1288-97.

Putman M, van Veen HW, Degener JE, Konings WN. Antibiotic resistance: era of the multidrug pump. Mol Microbiol 2000; 36:772-3.

Randall LP, Colles SW, Sayers AR, Woodward MJ. Association between cyclohexane resistance in Salmonella of differente serovars and increased resistance to multiple antibiotics, disinfectants and dyes. J Med Microbiol 2001; 50:919-24.

Randall LP, Woodward MJ. The multiple antibiotic resistance (mar) locus and its significance. Res Vet Sci. 2002 Apr;72(2):87-93.

Randall LP, Cooles SW, Piddock LJ, Woodward MJ, Effect of triclosan or a phenolic farm disinfectant on the selection of antibiotic-resistant Salmonella enterica. J Antimicrob Chemother. 2004, 54:621-7.

Randall LP, Cooles SW, Coldham NG, Penuela EG, Mott AC, Woodward, MJ, et al. Commonly used farm disinfectants can select for mutant Salmonella enterica serovar Typhimurium with decreased susceptibility to biocides and antibiotics without compromising virulence. J Antimicrob Chemother 2007; 60:1273-80.

Rastogi SC, Krongaard T, Jensen GH. Antibacterial compounds in clothing articles. Survey of Chemicals in Consumer Products No. 24, 2003, Danish EPA, Copenhagen. 
Rastogi SC, Jensen GJ and Johansen JD. Survey and risk assessment of chemical substances in deodorants. Survey of Chemicals in Consumer Products No. 86, 2007, Danish EPA, Copenhagen.

Reuter G. Cleaning and disinfection in food hygiene. Fleischwirtschaft 1984; 64:668-8.

Reuter G. Requirements on the efficiacy of disinfectants in the food-processingarea. Zentralblatt Fur Bakteriologie Mikrobiologie Und Hygiene Serie B-Umwelthygiene Krankenhaushygiene Arbeitshygiene Präventive Medizin. 1989; 187:564-77.

Reuter G. The effectiveness of cleaning and disinfection during meat production and processing Influence factors and use recommendations. Fleischwirtschaft $1994 ; 74: 808-13$.

Romao CM, de Faria YN, Pereira LR, Asensi MD. Susceptibility of clinical isolates of multiresistant Pseudomonas aeruginosa to a hospital disinfectant and molecular typing. Memorias Do Instituto Oswaldo Cruz 2005; 100:541-8.

Rouche DA, Cram DS, Di Bernadino D, Littlejohn TG, Skurray RA. Efflux-mediated antiseptic gene qacA in Staphylococcus aureus: common ancestry with tetracycline and sugar transport proteins. Mol Microbiol 1990; 4:2051-62.

Roujeinikova A, Levy CW, Rowsell S, Sedelnikova S, Baker PJ, Minshull CA, et al. Crystallographic analysis of triclosan bound to enoyl reductase. J Mol Biol 1999; 294:527-35.

Russell AD. Bacterial spores and chemical sporicidal agents. Clin Microbiol Rev 1990; 3:99-119.

Russell AD. Activity of biocides against mycobacteria. J Appl Bacteriol 1996; 81:87-101.

Russell AD, Furr JR, Maillard J-Y. Microbial susceptibility and resistance to biocides: an understanding. ASM News 1997; 63:481-7.

Russell AD, Tattawasart U, Maillard J-Y, Furr JR. Possible link between bacterial resistance and use of antibiotics and biocides. Antimicrob Agents Chemother 1998; 42:2151.

Russell AD, McDonnell G. Concentration: a major factor in studying biocidal action. J Hosp Infect $2000 ; 44: 1-3$.

Russell AD. Antibiotic and biocide resistance in bacteria: comments and conclusion. J Appl Microbiol 2002a; 92 (Suppl):171-3.

Russell AD. Introduction of biocides into clinical practice and the impact on antibiotic-resistant bacteria. J Appl Microbiol 2002b; 92 (Suppl):121-35.

Russell AD. Biocide use and antibiotic resistance: the relevance of laboratory findings to clinical environmental situations. Lancet Infect Dis 2003; 3:794-803.

Russell AD. Bacterial adaptation and resistance to antiseptics, disinfectants and preservatives is not a new phenomenon. J Hosp Infect 2004a; 57:97-104.

Russell AD. Whither triclosan? J Antimicrob Chemother 2004b; 53:693-5.

Rutala WA. APIC guideline for selection and use of disinfectants. 1994, 1995, and 1996 APIC Guidelines Committee. Association for Professionals in Infection Control and Epidemiology Inc. Am J Infect Control 1996; 24:313-42.

Rutala WA, Stiegel MM, Sarubbi FA, Weber DJ. Susceptibility of antibiotic-susceptible and antibiotic-resistant hospital bacteria to disinfectants. Infect Control Hosp Epidemiol 1997; 18:41721.

Rutala WA, Weber DJ, Gergen MF. Studies on the disinfection of VRE-contaminated surfaces. Infect Control Hosp Epidemiol 2000; 21:548.

Rutala WA, Weber DJ. Surface disinfection: should we do it? J Hosp Infect 2001; 48 (Suppl A):648.

Rutala WA, Weber DJ. The benefits of surface disinfection. Am J Infect Control 2004; 32:226-31.

Rutala WA, Weber DJ. Sterilization and disinfection. In: Jarvis W, editor. Bennett \& Brachman's Hospital Infections. Phiadelphia: Lippincott Williams \& Wilkins; 2007. p.303-17.

Sakagami Y, Kajimura K. Bactericidal activities of disinfectants against vancomycin-resistant enterococci. J Hosp Infect 2002; 50:140-4. 
Sánchez P, Linares JF, Moreno E, Martinez JL. The biocide triclosan selects Stenotrophomonas maltophilia mutants that overproduce the SmeDEF multidrug efflux pump. Antimicrob Agents Chemother 2005; 49:781-2.

Sanford JP. Disinfectants that don't. Ann Intern Med 1970: 72:282-3.

Santo CE, Taudte N, Nies DH, Grass G. Contribution of copper ion resistance to survival of Escherichia coli on metallic copper surfaces. Appl Environ Microbiol 2008; 74:977-86.

Sasatsu M, Shimizu K, Noguchi N, Kono M. Triclosan-resistant Staphylococcus aureus. Lancet 1993; 341:756.

Schelenz S, French G. An outbreak of multidrug-resistant Pseudomonas aeruginosa infection associated with contamination of bronchoscopes and an endoscope washer-disinfector. J Hosp Infect $2000 ; 46: 23-30$.

Schweizer HP. Intrinsic resistance to inhibitors of fatty acid biosynthesis in Pseudomonas aeruginosa is due to efflux: application of a novel technique for generation of unmarked chromosomal mutations for the study of efflux systems. Antimicrob Agents Chemother 1998; 42:394-8.

Scully BE, Parry MF, Neu HC, Mandell W. Oral ciprofloxane therapy of infextions to Pseudonomas aeruginosa. Lancet 1986; 1: 819-22.

Seaman P, Ochs D, Day MJ. Small-colony variants: a novel mechanism for triclosan resistance in methicillin-resistant Staphylococcus aureus. J Antimicrob Chemother 2007; 59:43-50.

Sedlacek MJ, Walker C. Antibiotic resistance in an in vitro subgingival biofilm model. Oral Microbiol Immunol 2007; 22:333.

Sekiguchi J, Asagi T, Miyoshi-Akiyama T, Fujino T, Kobayashi I, Morita K, et al. Multidrug-resistant Pseudomonas aeruginosa strain that caused an outbreak in a neurosurgery ward and its aac (6')Iae gene cassette encoding a novel aminoglycoside acetyltransferase. Antimicrob Agents Chemother 2005; 49:3734-42.

Sekiguchi J, Asagi T, Miyoshi-Akiyama T, Kasai A, Mizuguchi Y, Araake M, et al. Outbreaks of multidrug-resistant Pseudomonas aeruginosa in community hospitals in Japan. J Clin Microbiol 2007; 45:979-89.

Shackelford JCN, Hanlon GW, Maillard J-Y. Use of a new alginate film test to study the bactericidal efficacy of the high-level disinfectant ortho-phthalaldehyde. J Antimicrob Chemother 2006; 57:335-8.

Sheldon AT Jr. Antiseptic "resistance": real or perceived threat? Clin Infect Dis 2005; 40:1650-6.

Shih PC, Huang CT. Effects of quorum-sensing deficiency on Pseudomonas aeruginosa biofilm formation and antibiotic resistance. J Antimicrob Chemother 2002; 49:309-14.

Sidhu MS, Heir E, Sørum H, Holck A. Genetic linkage between resistance to quaternary ammonium compounds and beta-lactam antibiotics in food-related Staphylococcus spp. Microb Drug Resist 2001; 7:363-71.

Sidhu MS, Heir E, Leegaard T, Wiger K, Holck A. Frequency of disinfectant resistance genes and genetic linkage with beta-lactamase transposon Tn552 among clinical staphylococci. Antimicrob Agents Chemother 2002; 46:2797-803.

Silver S, Nucifora G, Chu L, Misra TK. Bacterial ATPases - primary pumps for exploring toxic cations and anions. Trends Biochem Sci 1989; 14:76-80.

Singer H, Müller S, Tixier C, Pillonel L. Triclosan: Occurrence and fate of widely used biocide in the aquatic environment: field measurements in wastewater treatment plants, surface waters, and lake sediments, Environ Sci Technol 2002; 36:4998-5004.

Smith K, Hunter IS. Efficacy of common hospital biocides with biofilms of multi-drug resistant clinical isolates. J Med Microbiol 2008; 57:966-73.

Sondossi M, Rossmoore HW, Wireman JW. Observations of resistance and cross-resistance to formaldehyde and a formaldehyde condenstae biocide in pseudomonas aeruginosa. Int Biodeter $1985 ; 21: 105-6$.

Spaulding EH. Chemical disinfection of medical and surgical materials. In: Lawrence C, Block SS, editors. Disinfection, sterilization and preservation. Philadelphia: Lea \& Febiger; 1968. p.517-31. 
Steffen D, Lach G. "Oberirdische Gewässer", Niedersächsisches Landesamt für Ökologie, Hildesheim, Oktober 2000.

Stewart MJ, Parikh S, Xiao G, Tonge PJ, Kisher C. Structural basis and mechanisms of enoyl reductase inhibition by triclosan. J Mol Biol 1999; 290:859-65.

Stickler DJ. Chlorhexidine resistance in Proteus mirabilis. J Clin Pathol 1974; 27:284-7.

Stickler DJ. Intrinsic resistance of Gram-negative bacteria. In: Fraise AP, Lambert PA, Maillard J-Y, editors. Principles and Practice of Disinfection, Preservation and Sterilization 4th edn. Oxford: Blackwell Scientific Publication; 2004. p.154-69.

Stickler DJ, Jones GL. Reduced Susceptibility of Proteus mirabilis to triclosan. Antimicrob Agents Chemother 2008; 52:991-4.

Suller MT, Russel AD. Triclosan and antibiotic resistance in Staphylococcus aureus. J Hosp Infect 2000; 41:107-9.

Sundheim G, Langsrud S, Heir E, Holck AL. Bacterial resistance to disinfectants containing quaternary ammonium compounds. Int Biodeterior Biodegrad 1998; 41:235-9.

Tabak M, Scher K, Hartog E, Romling U, Matthews KR, Chikindas ML, et al. Effect of triclosan on Salmonella typhimurium at different growth stages and in biofilms FEMS Microbiol Lett 2007; 267:200-6.

Takigawa K, Fujita J, Negayama K, Terada S, Yamaji S, Kawanishi K, et al. Eradication of contaminating Mycobacterium chelonae from bronchofibrescopes and an automated bronchoscope disinfection machine. Respir Med 1995; 89:423-7.

Talon D. The role of the hospital environment in the epidemiology of multi-resistant bacteria. J Hosp Infect 1999; 43:13-7.

Tart AH, Wozniak DJ. Shifting paradigms in Pseudomonas aeruginosa biofilm research. Curr Top Microbiol Immunol 2008; 322:193-206.

Tattawasart U, Maillard J-Y, Furr JR, Russell AD. Development of resistance to chlorhexidine diacetate and cetylpyridinium chloride in Pseudomonas stutzeri and changes in antibiotic susceptibility. J Hosp Infect 1999; 42:219-29.

Tattawasart U, Hann AC, Maillard J-Y, Furr JR, Russell AD. Cytological changes in chlorhexidineresistant isolates of Pseudomonas stutzeri. J Antimicrob Chemother 2000a; 45:145-52.

Tattawasart U, Hann AC, Maillard J-Y, Furr JR, Russell AD. Outer membrane changes in Pseudomonas stutzeri strains resistant to chlorhexidine diacetate and cetylpyridinium chloride. Int J Antimicrob Agents 2000b; 16:233-8.

Taylor JH, Rogers SJ, Holah JT. A comparison of the bactericidal efficacy of 18 disinfectants used in the food industry against Escherichia coli $\mathrm{O} 157: \mathrm{H} 7$ and Pseudomonas aeruginosa at 10 and $20^{\circ} \mathrm{C}$. J Appl Microbiol 1999; 87:718-25.

Tennent JM, Lyon BR, Midgley M, Jones IG, Purewal AS, Skurray RA. Physical and biochemical characterization of the qacA gene encoding antiseptic and disinfectant resistance in Staphylococcus aureus. J Gen Microbiol 1989; 135:1-10.

Thomas L. Maillard J-Y, Lambert RJ, Russell AD. Development of resistance to chlorhexidine diacetate in Pseudomonas aeruginosa and the effect of 'residual' concentration. J Hosp Infect 2000; 46:297-303.

Thomas L, Russell AD, Maillard J-Y. Antimicrobial activity of chlorhexidine diacetate and benzalkonium chloride against Pseudomonas aeruginosa and its response to biocide residues. J Appl Microbiol 2005; 98:533-43.

Thorrold CA, Letsoalo ME, Dusé AG, Marais E. Efflux pump activity in fluoroquinolone and tetracycline resistant Salmonella and $\mathrm{E}$ coli implicated in reduced susceptibility to household antimicrobial cleaning agents. Int J Food Microbiol 2007; 113:315-20.

Tilt N, Hamilton MA. Repeatability and reproducibility of germicide tests: A literature review. J AOAC Int 1999; 82:384-9.

Tkachenko O, Shepard J, Aris VM, Joy A, Bello A, Londono I, et al. A triclosan-ciprofloxacin crossresistant mutant strain of Staphylococcus aureus displays an alteration in the expression of several cell membrane structural and functional genes. Res Microbiol 2007; 158:651-8. 
Ubeda C, Maiques E, Knecht E, Lasa I, Novick RP, Penades JR. Antibiotic-induced SOS response promotes horizontal dissemination of pathogenicity island-encoded virulence factors in staphylococci. Mol Microbiol 2005; 56:836-44.

Valkova N, Lepine F, Valeanu L, Dupont M, Labrie L, Bisaillon JG. Hydrolysis of 4-hydroxybenzoic acid esters (parabens) and their aerobic transformation into phenol by the resistant Enterobacter cloacae strain EM. Appl Environ Microbiol 2001; 67:2404-9.

Van Klingeren B, Pullen W. Glutaraldehyde resistant mycobacteria from endoscope washers. J Hosp Infect 1993; 25:147-9.

Ventullo RM, Larson RJ. Adaptation of aquatic microbial communities to quaternary ammonium compounds. Appl Environ Microbiol 1986; 51:356-61.

Walsh SE, Maillard J-Y, Russell AD, Hann AC. Possible mechanisms for the relative efficacies of ortho-phthalaldehyde and glutaraldehyde against glutaraldehyde-resistant Mycobacterium chelonae. J Appl Microbiol 2001; 91:80-92.

Walsh SE, Maillard J-Y, Russell AD, Charbonneau DL, Bartolo RG, Catrenich C. Development of bacterial resistance to several biocides and effects on antibiotic susceptibility. J Hosp Infect 2003; 55:98-107.

Wang $H$, Dzink-Fox JL, Chen M, Levy SB. Genetic characterization of high-level fluoroquinolone resistant clinical Escherichia coli strains from China: role of acrR mutations. Antimicrob Agents Chemother 2001; 45:1515-21.

Wang C, Cai P, Guo Y, Mi Z. Distribution of the antiseptic-resistance genes qacEDelta1 in 331 clinical isolates of Pseudomonas aeruginosa in China. J Hosp Infect 2007; 66:93-5.

Wang JT, Sheng WH, Wang JL, Chen D, Chen ML, Chen YC, et al. Longitudinal analysis of chlorhexidine susceptibilities of nosocomial methicillin-resistant Staphylococcus aureus isolates at a teaching hospital in Taiwan. J Antimicrob Chemother 2008; 62:514-7.

Weaver L, Michels HT, Keevil CW. Survival of Clostridium difficile on copper and steel: futuristic options for hospital hygiene. J Hosp Infect 2008; 68:145-51.

Webber MA, Randall LP, Cooles S, Woodward MJ, Piddock LJ. Triclosan resistance in Salmonella enterica serovar Typhimurium. J Antimicrob Chemother 2008; 62:83-91.

Weber DJ, Rutala WA. Use of germicides in the home and the health care setting: is there a relationship between germicide use and antibiotic resistance? Infect Control Hosp Epidemiol 2006; 27:1107-19.

Wenzel RP, Hunting KJ, Osterman CA, Sande MA. Providencia stuartii, a hospital pathogen: potential factors for its emergence and transmission. Am J Epidemiol 1976; 104:170-80.

White DG, McDermott PF. Biocides, drug resistance and microbial evolution. Curr Opin Microbiol $2001 ; 4: 313-7$

WHO, the world health report 2007 - A safer future: global public health security in the 21st century; available at URL: http://www.who.int/whr/2007/en/index.html (accessed 25 February 2009)

Williams GJ, Denyer SP, Hosein IK, Hill DW, Maillard J-Y. The development of a new three-step protocol to determine the efficacy of disinfectant wipes on surfaces contaminated with Staphylococcus aureus. J Hosp Infect 2008; 67:329-35.

Williams GJ, Stickler DJ. Effect of triclosan on the formation of crystalline biofilms by mixed communities of urinary tract pathogens on urinary catheters. J Med Microbiol 2008; 57(Pt 9):1135-40.

Winder CL, Al-Adham IS, Abdel Malek SM, Buultjens TE, Horrocks AJ, Collier PJ. Outer membrane protein shifts in biocide-resistant Pseudomonas aeruginosa PAO1. J Appl Microbiol 2000; 89:28995.

Wright NE, Gilbert P. Influence of specific growth rate and nutrient limitation upon the sensitivity of Escherichia coli towards chlorhexidine diacetate. J Appl Bacteriol 1987; 62:309-14.

Zgurskaya HI, Nikaido $\mathrm{H}$. Multidrug resistance mechanisms: drug efflux across two membranes. Mol Microbiol 2000; 37:219-25. 


\section{GLOSSARY}

The terms in the glossary were generally used as previously defined by EU legislation, with some adaptations as presented below.

\section{Antimicrobial}

Antiseptic

Antisepsis

Bioavailability

Biofilm

Chemical disinfection

Disinfectant

Handrub

Health care

Household

Microcosm

Molecule (active)

Resistance

Selective pressure

Surface disinfection

Therapeutic use a chemical substance which, at low concentrations, exerts an action against microbial and exhibits selective toxicity towards them.

product -excluding antibiotics -that is used to bring about antisepsis (CEN/TC 216)

application of an antiseptic on living tissues causing an action on the structure or metabolism of micro-orrganisms to a level judged to be appropriate to prevent and/or limit and/or treat an infection of those tissues (CEN/TC 216)

the concentration of biocides or antibiotics in contact with the target organism

biofilms are communal structures of microorganisms encased in an exopolymeric coat that form on both natural and abiotic surfaces

the reduction of the number of micro-organisms in or on an inanimate matrix or intact skin, achieved by the irreversible action of a product on their structure or metabolism, to a level judged to be appropriate for a defined purpose (CEN/TC 216)

product capable of chemical disinfection

product used for post-contamination treatment that involves rubbing hands, without the addition of water, which is directed against transiently contaminating micro-organisms to prevent their transmission regardless of the resident skin flora (CEN/TC 216)

environment encompassing hospital, retirement-medicated home, general practitioner practices

home environment

a community of micro-organisms

the active principle

the capacity of an organism or a tissue to withstand the effects of a harmful environmental agent.

chemical, physical, or biological factors or constraints which select well-adapted bacteria or induce the expression of specific biological mechanisms involved in the bacterial response to external stresses

chemical disinfection of a solid surface, excluding those of a certain medical and veterinary instruments by the application of a product (CEN/TC 216)

use of antimicrobials to treat individual humans or animals (or groups of animals) suffering from a bacterial infection. 